\title{
A PERFECTIONIST DEFENSE OF FREE SPEECH
}

\author{
Jonathan K. Miles
}

\section{A Dissertation}

Submitted to the Graduate College of Bowling Green

State University in partial fulfillment of the requirements for the degree of

Doctor of Philosophy

December 2009

Committee:

Daniel Jacobson, Advisor

David Jackson,

Graduate Faculty Representative

Fred D. Miller Jr.

Steven P. Wall

Ellen F. Paul 
(C) 2009

Jonathan Miles All Rights Reserved 


\begin{abstract}
Daniel Jacobson, Advisor

This dissertation presents a perfectionist argument for viewpoint neutral free speech. It is argued that developed states ought to maintain or adopt the Viewpoint Neutral Principle:

As a matter of public morality, any public institution is disqualified from intentionally aiming to binder the expression of any viewpoint by suppression except for purposes of temporary censorship to prevent clear, present, and imminent danger.
\end{abstract}

This principle allows for regulation but does not allow for censorship due to objectionable viewpoints. After demonstrating how the standard justifications for free speech are not sufficient for the viewpoint neutral principle, I construct a Millian self-development argument drawing from the oft neglected justification of freedom of speech in On Liberty.

Mill argues that a person is not deserving of confidence in his opinion unless he has engaged in certain practices of justification for his own opinions. These practices are the only way to acquire the intellectual virtue of justified belief-forming, and censorship undermines these practices. Furthermore, the intellectual virtue of justified belief forming informs moral virtues which include dispositions to express praise or blame.

Censorship can undermine and, in some cases, make impossible the practices of justification. If the state engages in viewpoint specific censorship of public speech, it undermines the individual pursuit of justified opinion to the extent that it hinders critical reflections, adjustment, and exposition of opinions.

After explicating the argument itself, I apply the justified opinion argument to one contemporary example. The International Covenant on Civil and Political Rights under the auspices of the Universal Declaration of Human Rights of the United Nations has passed articles 7/19 and $7 / 20$. These resolutions violate the viewpoint neutral principle. It is argued that developed nations should reject these resolutions in order to preserve (among other things) intellectual virtue. 
If there is any fixed star in our constitutional constellation, it is that no official, high or petty, can prescribe what shall be orthodox in politics, nationalism, religion, or other matters of opinion, or force citizens to confess by word or act their faith therein.

Justice Robert H. Jackson, West Virginia Board of Education v. Barnette 


\section{DEDICATION}

This dissertation is dedicated to the countless Chinese Christians who have been imprisoned or killed for the crime of sharing ideas. It is also dedicated to the thousands driven from their homes in the Orissa region of India for defying the national religion.

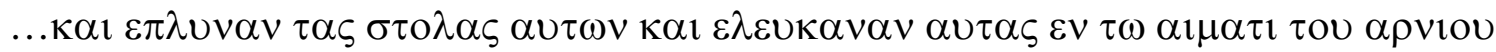




\section{ACKNOWLEDGEMENTS}

I wish to thank the members of my committee for their instruction and wisdom. I especially want to thank Dan Jacobson for directing this new argument by instilling in me a love for the classical arguments of Mill. My thanks also go to Fred D. Miller for deepening my respect for Aristotle and for teaching me how to imitate good writers. Steve Wall nurtured my peculiar perfectionist bent. Ellen Paul deserves thanks for hours of discussion about the law and first amendment jurisprudence. I have benefitted from countless conversations and critiques by Fred Miller's dissertation group. Virtually everyone in the Bowling Green Philosophy Department has suffered through some fragment or another of my argument. Special thanks go to Leanne Kent, Corwin Carr, Ben Dyer, Noah Levin, Kari Dyer, Terrence Watson, and Peter Jaworski. They not only listened to but challenged every premise. The argument is better for their generosity. The mistakes are all mine. Special thanks also goes to Jan Narveson for patiently arguing the general rights strategy with me. I must also thank two organizations for funding my graduate education. Without the Humane Studies Fellowship from the Institute for Humane Studies and the Earhart Fellowship from the Earhart Foundation, this project would never have been completed in a timely manner. Special thanks go to Ben Dyer for formatting wizardry and Microsoft alchemy. Finally I could not have done any of this without my wife, Stacie Botsay Miles. It was once said that Ginger Rogers could do everything Fred Astaire could do, only backwards and in high heels. Stacie has struggled through the ups and downs of this project as much as I have only she did it while giving birth and then raising a toddler. She is more precious than jewels, the heart of her husband trusts her, and her children will call her blessed. 


\section{TABLE OF CONTENTS}

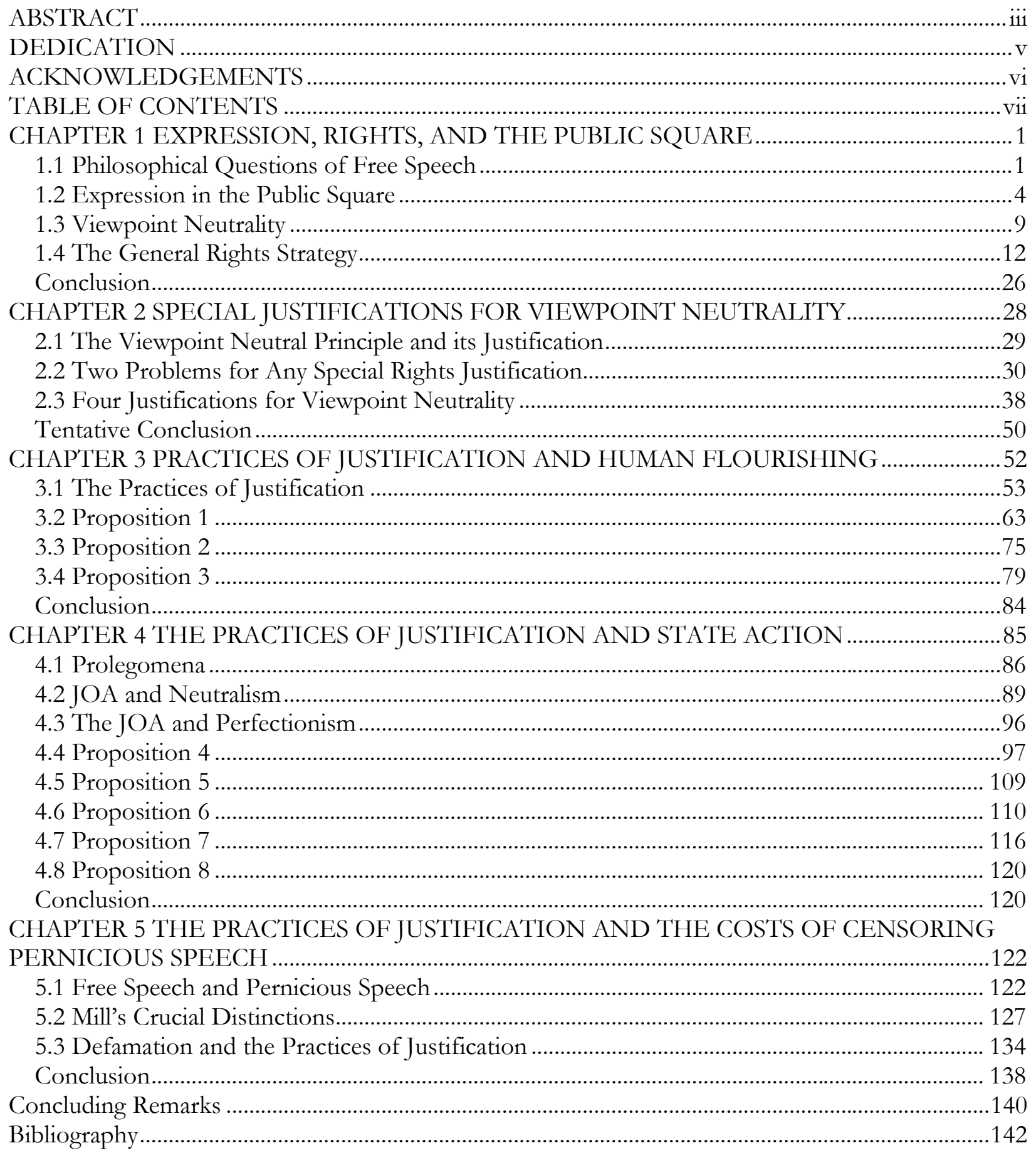




\section{CHAPTER 1 EXPRESSION, RIGHTS, AND THE PUBLIC SQUARE}

Freedom of speech is a problem. It is no embellishment to say that enforcing, interpreting, and applying just what is meant by freedom of speech is one of the most controversial areas of politics and jurisprudence. However, freedom of speech is not just a problem of enforcement and application. It is also a philosophical problem. There are two major philosophical difficulties with freedom of speech. They can be divided into the conceptual question and the justification question.

\subsection{Philosophical Questions of Free Speech}

The conceptual question asks: "What is the scope of free speech? What things are we free to express? What is the difference, if any, between speech that leads to action (e.g. persuasion or incitement), expressive acts (e.g. flag burning), and acts that might also be expressive (e.g. chaining one's self to a tree in protest)?

J.S. Mill had the conceptual question in mind when he said that freedom of speech is concerned with sentiment and opinion and is to be qualitatively differentiated from the other things we do with words such as promise, threaten, lie, bestow titles etc. In the famous essay on freedom of thought and discussion in On Liberty, Mill says, "For no one pretends that actions are to be as free as speech for even speech loses its immunity when it becomes action" (III, 1). ${ }^{1}$ Therefore to alleviate confusion between freedom to express sentiments and opinions from expressive acts that use words and to work within Mill's distinction, we can talk about "freedom of sentiment and opinion" or sometimes simply "free speech."2 While there will be borderline cases, "free speech" should not be

\footnotetext{
${ }^{1}$ Unless otherwise noted, all quotations from On Liberty are from J.S. Mill ON LIBERTY in Focus, ed. John Gray and G.W. Smith, (London: Routledge, 1991). Specific references within On Liberty will be given simply as (Chapter, paragraph).

2 Throughout this dissertation, "freedom of speech" or "free speech" is used interchangeably with "freedom of expression."
} 
taken to include the other things we do with words such as promise, decree, or reveal secrets or threaten.

If the conceptual question can be said to properly concern sentiments and opinions, a theory of freedom of sentiment and opinion can still be quite problematic. Mill says that any concept of freedom of thought and discussion must include opinions whose content is pernicious, useless, hateful, or offensive.

The justification question in effect asks, "How do we justify including the hateful, offensive, and useless speech in that class of expression that is immune to censorship?" Few sane people deny that freedom of expression can cause a great deal of emotional distress, social discord, and political unrest. That some action causes harms like these is normally good reason to restrict the action. But as T.M. Scanlon notes, part of the philosophical puzzle of freedom of expression is justifying why expressive speech-acts are prima facie immune to restriction. ${ }^{3}$

While the philosophical questions about freedom of expression are a subset of the general philosophical problems of rights and political morality, Scanlon notes that one of the particular difficulties with discussing rights to expression is locating those classes of speech acts that are immune from the normal restrictions of actions on the basis that they harm. Article 19 of the Universal Declaration of Human Rights states: "Everyone has the right to freedom of opinion and expression; this right includes freedom to hold opinions without interference and to seek, receive and impart information and ideas through any media and regardless of frontiers."4

This chapter attempts to achieve three goals. First, it frames the problems of freedom of expression as problems for applied ethics and political philosophy centering on the justification and conceptual questions.

\footnotetext{
3 Thomas Scanlon, The Difficulty of Tolerance : Essays in Political Philosophy (Cambridge ; New York: Cambridge University Press, 2003), 6.

4 The UN Universal Declaration of Human Rights, http://www.un.org/en/documents/udhr/index.shtml\#a19 [available August 29, 2009]
} 
Second, this chapter focuses on arguably the most pernicious and tendentious aspect of the free speech debate: viewpoint neutrality. Viewpoint neutrality is a policy that no government should restrict speech on the basis of its viewpoints. Viewpoint neutrality invokes both the conceptual and justificatory difficulties just mentioned. The challenge of viewpoint neutrality in the public square is whether or not to conceive of freedom of expression in such a way that it remains content neutral when clearly this would require allowing pernicious, repugnant, and hateful content that harms others and, but for being speech, could legitimately be sanctioned.

If pernicious viewpoints, those that are harmful, dangerous, or corrupting, represent an exception to the neutral stance, how neutral is the state policy? The conceptual question applies to viewpoint neutral policy. So does the justification question. If no exceptions are made for harmful content, what of Scanlon's problem of justifying the clear harms of allowing hateful and pernicious speech as immune from restriction when other harms clearly are not?

Third, this chapter rejects a traditional way of solving these applied problems. The standard philosophical modus operandi for defending freedom of expression is to locate a right that constrains government regulation. If freedom of speech is conceived and justified as some sort of moral right, then this constrains the government from regulating its practice. There are two ways to argue for the right to expression: 1) subsume freedom of expression under another right like property or general freedom of movement or 2) make freedom of expression a right on its own.

We can call the first strategy "the general rights strategy." The second can be labeled "the special rights strategy." Both of these strategies leave the conceptual and justification questions without adequate resolution. This chapter reveals the unattractiveness of the general rights strategy as a solution. Chapter 2 tackles the special rights strategy.

Still, the rights invoking strategies are not the only way to protect viewpoint neutrality. Whether or not there is a fundamental right to freedom of expression, there can be reason for 
governments to adopt a kind of neutrality whether or not there is a right to freedom of expression. An argument for this strategy will be offered in chapters three and four. First, it will be helpful to define the parameters of free speech and the concept of viewpoint neutrality.

\subsection{Expression in the Public Square}

Freedom of expression is about public expression. Expression in the privacy of one's own home is not normally within the scope of freedom of expression discussions. It is only when that private expression becomes public and others have to hear it that expression becomes an ethical issue.

It will be helpful to clarify what is meant by Public Square. Etymologically, the public square metaphor starts with a physical space not privately owned to which all citizens have equal right to access and use. Traditionally this has been a park or square in the middle of town. Thus, every citizen enjoys a liberty to occupy the space with no one having the right to sole possession of the space itself.

This space was and is often a place where one can express one's opinion about political, religious, and other matters of human interest. It is not assumed that there is a privilege for this kind of expression however. Because everyone enjoys liberty to use the public square, expression must not exceed certain limits that interfere with others' use of the space. These limits are usually content neutral. There are restrictions on time, place, and manner of one's use of the public square that could interfere with others' use of the square. Time restrictions could include no speaking or expressing during hours when others are sleeping. Place restrictions would include the rule that one cannot express one's opinion in the middle of someone's volleyball game. Manner restrictions might include no speaking above a certain noise level.

This forum does not necessarily have to be a physical place like a public park. For the purposes of this dissertation, the public square is any forum where every individual enjoys a prima 
facie liberty to use the space and where any individual cannot exclude others without just cause and due process.

The public square would include the World Wide Web, community bulletin boards in public buildings, and sidewalks. What all these forums have in common is a condition of reasonable access and non-excludability. Indeed browsing the internet is a public forum. One can filter out unwanted preferences to some extent but one will inevitably come upon opinions and sentiments that one would rather not have seen at all. Furthermore, being subject to these preferences means that no one can be excluded without due process and cause. Private space does not have this feature. ${ }^{5}$ If I want to exclude someone from my private property, the presumption is that I don't have to give either cause or engage in any due process. But in public forums there is a presumption that everyone has the liberty to occupy this space.

Given this definition of Public Square, why is freedom of expression particularly problematic?

Consider a very common scenario in the public square:

\section{Standard Persuasive Offer}

Anne is one of many people walking through a park and Bob thinks $x$ is something Anne ought to believe or do. ${ }^{6}$ If both Anne and Bob subscribe to the injunction against coercion, Bob cannot make Anne do $x$ and cannot force Anne to live her life according to $x^{7}$ However, there is nothing inconsistent with Bob's negative duties to Anne that prevents Bob from persuading Anne to see it his way. Anne may or may not be open to changing her mind. Anne may hold that she does not believe or should do $x$ but is unsure about whether she is right. However, whether she is unsure about $x$ or convinced about her position on $x$, when Bob tries to persuade Anne to see it his way, if Anne does not want to hear arguments for $x$ at this time, then Bob's persuasive offer is unwelcome. If Bob is standing in the public

\footnotetext{
${ }^{5}$ This is slightly different from common space which could be owned in common by a group of people. Examples include co-ops, community spaces in apartment complexes, etc. Here excludability could require a process. Each member is subject to a contractual agreement and presumably could exclude only according to the agreement. Furthermore, common space does not have the accessibility of public space. Note however, that while common space differs from public space, the same sorts of conflicts of preferences that give rise to the problem of the public square will affect any large common space. The reason is that conflicts of preferences occur with any large group whether it is a community co-op garden or a public city park.

${ }^{6}$ Another version of the standard persuasive offer is that Anne believes that some way of life or activity $\mathrm{x}$ is wrong and bad for society and individuals. The persuasive offer that Anne makes is that Bob ought to believe that $x$ is bad as well and join her in convincing others that $x$ is bad.

${ }^{7}$ I say "live her life according to $x$ " because the idea of forcing Anne to believe $x$ seems to me problematic if not unintelligible setting aside concerns over brain washing or seduction.
} 
square spouting the virtues of $x$, and Anne does not want to hear it for whatever reason, then Bob is infringing on Anne's stroll.

As indicated, we can call this scenario the standard persuasive offer in the public square. Bob as a speaker in the public square clearly has interests in reaching as wide an audience as possible. How do these interests clash with Anne's interests? We can represent the interests of Bob, Anne, and bystanders as the following: ${ }^{8}$

Speaker Interest: (Bob) Reach the widest audience possible with the message.

Audience Interest: (Anne) Pick and choose which messages to be exposed to and consider.

Bystander Interest: Travel through the space without having to attend to any messages.

Because this is the public square and everyone is subject to everyone else's preferences for the use of the space, no one's interests are considered privileged. That is, Bob has as much claim to this space as Anne (who may or may not want to hear Bob's message) or any bystander that would rather not hear any message. Bob's interests are not per se harmful even if they are unsolicited. Bob does not have the right to be heard by Anne; however, he does plausibly enjoy the liberty to persuade Anne. Anne does not have the right to never be confronted by Bob's message, but she plausibly has the liberty to not be harassed by Bob.

Now extend the public square metaphor to cyberspace. Anne is not strolling; she's surfing the net. Through some search engine, she comes upon Bob's blog. Bob is blogging about how meat eating is murder and human carnivores are immoral, stupid, and possibly evil. Because the internet itself is a public square, Anne cannot lobby to have Bob's blog taken off the web. Bob enjoys the same access Anne does to the cyber-audience. Bob's interests in convincing others of the horrors of eating meat are not per se harmful to Anne. However, Bob does not have the right (or thanks to filtering software, the means) to make Anne listen to his message if she clicks elsewhere. Bob does have the liberty to persuade Anne if she decides to linger and read his blog-posts. Also, just as in the

${ }^{8}$ This schema of interests is taken largely from ibid., $85 \mathrm{ff}$ 
public square, Anne does not have the right never to be confronted by an angry vegan. However, she does have the right avoid Bob's vegan ranting by hitting the back button.

To illustrate the complexities of speech regulation, let us borrow a well-tried theme from science-fiction. Suppose we were capable of making available an impenetrable personal force field to every person. ${ }^{9}$ If there was some message one did not want to hear, all that would be necessary is to mute the offending message from penetrating the force field. If there was some offensive image one didn't want to see, one could cause appropriate sized blurring for that image. Everyone would be able to select the messages they wanted to attend to without seriously affecting the preferences to others. In this science-fiction world, Bob could speak whatever he wished. Everyone else could mute Bob and Anne could listen and decide if she wanted to hear what Bob had to say.

This would not insulate any offensive message. This is because of some peculiar things about expression. First, expression can be offensive without ever being heard. Joel Feinberg argues that one can be profoundly offended by the bare knowledge that something is being done elsewhere. ${ }^{10}$ The force field would not insulate against this kind of offense. Second, a peculiarity about expression is that speech and visual symbols are such that one can be offended merely by experiencing them and in a sense one cannot unsee them. If Anne is confronted only a few seconds before she mutes Bob, the offense could be hurtful regardless of her force field. ${ }^{11}$

The real-world regulation of public square endeavors is to approximate the force-field. The goal is to accommodate the liberties of speakers, audiences, and uninterested bystanders in such a way that the liberties of each are respected as much as is consistent with the liberties of everyone else.

\footnotetext{
${ }^{9}$ For the inspiration for the example see Anderson Poul, Shield, (Berkley, 1982).

${ }^{10}$ Joel Feinberg, The Moral Limits of the Criminal Law, Vol. vol. 2 Offense to Others (New York: Oxford University Press, 1984), $51 \mathrm{ff}$.

11 I've benefited a great deal from conversations with Leanne Kent regarding this scenario.
} 
Bob can speak but there are restrictions on how much of the public square he can co-opt. This means there are time, place, and manner restrictions that have nothing to do with the message itself. Anne can attend to Bob but she also must have reasonable liberty to avoid Bob's message (i.e. Bob cannot hound Anne if she requests him to back off.). As for Carl, and every other bystander, it must be the case that reasonable avoidance would include certain volume levels for Bob's message.

However, these reasonable regulations do not solve the important ethical problems. Even the force field is not an ideal of free speech. How much offense/hurt provides a cause to limit Bob's liberty of expression? In other words, what is the justification that can be offered for making an exception for Bob's expression that would not be ordinarily made? This is the justification problem. Another serious problem is which of these interests has pride of place when we talk about individual liberty - those of the speaker, the audience, or bystanders? There is one more worry. Perhaps the force-field could be bad for the audience if they could simply mute Bob. It will be a major argument of this dissertation that screening off unwanted or offensive speech has a cost for both the speaker and the audience. If we block out speech that offends and yes, even harms our sensibilities too much, we undermine the justification for our moral condemnation of those opinions and more importantly the character of the people who make them.

It seems that time, place, and manner restrictions do not get at the problem. Some points of view are harmful even if they are only heard for a moment. Some opinions are profoundly offensive even if not heard. Just knowing some opinions are free to disseminate is offensive. Restricting the mode of dissemination does not solve the justification or conceptual problems. The conceptual and justification problems center on the value or disvalue of the viewpoints being expressed and the people who are expressing them. Are some viewpoints worthy of complete censorship because of their harm or offense? When no is the answer, justifying a bands off approach is a problem. 


\subsection{Viewpoint Neutrality}

If one thinks that a liberal government should remain neutral about different conceptions of the good life, it follows that there would be good reason to adopt viewpoint neutrality. However, one of the major developments in political philosophy is recent criticism of the liberal neutrality thesis. ${ }^{12}$ If there is no reason for liberal neutrality, it seems plausible there is in principle no reason for strict viewpoint neutrality. Or is there? There is in fact a non-neutral reason to stick with viewpoint neutrality. We can call this the Viewpoint Neutral Principle:

In order to foster and maintain individual rational justification, as a matter of public morality, any public institution is disqualified from intentionally aiming to hinder the expression of any viewpoint by suppression except for purposes of temporary censorship to prevent clear, present, and imminent danger.

One major tenet of the classical liberal veneration of freedom of speech is that any regulation of speech must be content neutral. Mill argued that to censor speech on the basis of its content was to claim infallibility in deciding the certainty of the worthlessness of some idea for others. It also would deprive society of many partial truths that come in the package of false ideas. Further, to decide the worthlessness of some idea for others through censorship robbed them of a valuable human practice-deliberation about the good life. Therefore, no regulation can be on the basis of the subject matter or viewpoint. Any state regulation must allow expression of any sentiment or opinion.

That sentiment has been carried forward into modern liberal states, none more so than in America. Content neutrality defined as neutrality with regard to subject matter or viewpoint, has been called the core of any concept of freedom of expression. ${ }^{13}$ Justice Robert Jackson said, "If there is any fixed star in our constitutional constellation, it is that no official, high or petty, can

\footnotetext{
12 See Steven Wall, Liberalism, Perfectionism and Restraint (Cambridge, England ; New York: Cambridge University Press, 1998), 244, and Thomas Hurka, Perfectionism, 1st Oxford University Press pbk. ed. (New York ; Oxford: Oxford University Press, 1996, c1993), 222.

${ }^{13}$ Larry Alexander, Is there a Right of Freedom of Expression? (New York: Cambridge University Press, 2005$), 11$.
} 
prescribe what shall be orthodox ... in matters of opinion." "14 Justice Scalia writes in the unanimous opinion of R.A.V. v. St. Paul, “Content based regulations are presumptively invalid.”" ${ }^{15}$ For clarification, this dissertation will use viewpoint neutrality rather than content neutrality to capture this core idea. This is because content-based regulation can be confusing. Regulation based on content could be invoked without being viewpoint specific. For instance an injunction against "paid political ads by corporations or paid by unincorporated entities with corporate money" would be contentbased but not viewpoint specific. ${ }^{16}$

To counter this confusion we can think of the "one fixed star" as viewpoint and subject matter neutrality. As a matter of policy, no government official should decide which viewpoints or subject matter is orthodox in the public square. In other words, no speech should be censored on the basis of the content of its subject matter or viewpoint.

Historically, speech that was offensive, disparaging, or even pernicious was seen as a necessary evil given that to silence such speech would violate the content neutral standard. When a Nazi rabble-rouser wanted to march through a neighborhood full of holocaust survivors, the ACLU argued that to prevent the march would violate the First Amendment. This was the case no matter how much anyone despised the content of the speech in question. ${ }^{17}$

Many find reason to qualify their veneration of speech rights in order to counter-balance freedom of speech with other values like equality. They see the need to de-sanctify the one fixed star, righting the scales of justice in favor of the powerless and marginalized. As one proponent of this ideology put it, "The first amendment and the fourteenth amendment have never had a fair fight

\footnotetext{
14 West Virginia State Board of Education v. Barnette 319 U.S. 624 (1943). Because of the conceptual and justificatory problems with enforcing this principle, Jackson's statement has been called "Barnette's Big Blunder", See Steven D. Smith, "Barnette's Big Blunder," 78 Chicago-Kent L. Review 625 (2003)

${ }_{15}$ R.A.V.v. St. Paul, 505 U.S. 377, (1992).

${ }^{16}$ Bipartisan Campaign Reform Act of 2002 (BCRA, McCain-Feingold Act, Pub.L. 107-155)

${ }_{17}$ Phillipa Strum, When the Nazis Came to Skokie, (Lawrence, Kansas: University of Kansas Press, 1999). Strum says, "For more than fifty years the ACLU's position had been that it was more dangerous to allow the government to pick and choose the speech it could forbid than to allow unpopular or even obnoxious speech to be spoken in public" (25).
} 
in this country." ${ }^{\prime 18}$ According to these advocates, speech rights with their protection of hate speech, has trumped the principle of equal protection. ${ }^{19}$

At the heart of these sentiments is a questioning of the value of viewpoint neutral regulation and the liberal institutions that support that value-most notably speech rights and the complicated jurisprudence that protect them. Those who think free speech should not include hate speech systematically criticize the classic defense of free speech most famously articulated by J.S. Mill in On Liberty. The verdict is that the classic defense of free speech fails to provide a justification for content neutral regulation of freedom of thought and discussion that has historically been the underpinning of First Amendment jurisprudence.

One critic of liberalism's historic position on free speech has called the veneration of speech rights above equality and social justice, "free speech fundamentalism", and those who continue to hold on to the archaic idea that Congress shall make no law abridging any freedom of speech, "Free Speech Fundamentalists." 20

This is part of the philosophical problem to which Scanlon alluded. Normally if something harms, we think it legitimate to weigh that harm against other interests. However freedom of speech is treated differently in free societies. Even though only the naïve argue that sentiment is harmless, historically the harms have been downplayed in favor of the right to express any opinion or sentiment. Why should the state be neutral about the content of all speech? Some demeaning speech is of such slight social value that it can rightly fall into the class of speech that is prohibited like libel,

\footnotetext{
${ }^{18}$ Catharine A. MacKinnon, Only Words (Cambridge, Mass.: Harvard University Press, 1993), 73.

${ }^{19}$ In a strange reversal of fortune, we find the defenders of liberal speech rights to be conservatives associated with the Right in America who have in the past tended to favor curtailing speech rights. The religious right now spends more legal energy defending the First Amendment than it ever did calling for censorship.

20 See Frederick Schauer, Free Speech: A Philosophical Inquiry, (Cambridge: Cambridge University Press, 1982) and Owen Fiss, The Irony of Free Speech, (Cambridge Massachusetts: Harvard University Press, 1996).
} 
obscenity, and fighting words. Indeed Charles Lawrence III has opined that racist hate speech harms in such a way that it ought rightly to be considered a kind of tort for which victims can sue. ${ }^{21}$

There are literally volumes written on the various conflicting arguments within this debate.

We are left with an intuition that speech should be protected to some degree, but not to any degree.

It is somehow special but how special and what efforts should be made to protect it is as controversial a debate as any.

\subsection{The General Rights Strategy}

Traditionally philosophical treatments of the conceptual and justification problem have looked to a rights based strategy to solve the philosophical problem highlighted by a clash of interests in the public square. One strategy is to ground the value of free speech in a general right to liberty or as a subset of a more general right like property. For the sake of brevity, we can refer to this as the general rights strategy. The other strategy is to carve out a special right to free speech based on its value to individuals and/or society as a whole. We can refer to this as the special rights strategy. In what follows I will show why the general rights strategy is problematic for viewpoint neutrality. Chapter 2 does the same for the special rights strategy.

On the general rights strategy, freedom of speech is not special-though it is valuable. It is valuable as an instance of a more general right to liberty that stems from self-ownership. If we own our bodies, we surely own our speech organs. Thus, our ability to speak should be protected as one function of a free being.

Freedom of speech can also be conceived as more accurately deriving from a more fundamental civil liberty like the right to property. A person can speak his mind provided he is on his own property or has permission to speak on another's property. He even has the right to hire a hall to speak his peace. In any of these cases, the right to speak one's mind is parasitic on the right to

21 "If He Hollers Let Him Go: Regulating Racist Speech on Campus," Words that Wound: Critical Race Theory, Assaultive Speech, and the First Amendment, ed. Mari Matsuda, et. al., (Boulder, Colorado: Westview Press, 1993). 
do whatever one wants on one's own property or on property one has retained as part of a contract. We can say that free speech is only special as an instance of the exercise of one's general right to non-interference in one's life.

The general rights strategy presents a free speech dilemma. Either speech rights are valuable (and by extension, justified) as part of a more general right to liberty or they are only valuable because of some special interest they provide for individuals or society. There is good reason to shy away from the latter. If we accept that speech rights are special and valuable in themselves, we owe a reason why speech is so important as to be immune from legal sanction even though it harms just like other acts.

If we accept the first horn of this dilemma, speech rights exist but they are not special in themselves. Speech rights are derivative from a more general right to liberty of person (selfownership) or property. They are not sacrosanct. This strategy explains why free speech is protected as a right when other interests are ostensibly not. If we own anything it is our speech organs. This seems very close to the thought that we own our bodies. While our ownership of our speech is not really separate from our ownership of our bodies, it seems a natural extension of the latter and can explain why a free society would want to protect free speech as special even though its not.

It also explains the move to curtail speech only in ways that are viewpoint neutral. We cannot discriminate on the basis of viewpoint because what is important to protect is the freedom to speak. To censor on the basis of viewpoint is not to value the interest to speak and thus to not value the right to be free.

However, the general rights strategy denies the value of speech as a positive good in itself. Its value is only as an exercise of the general right to liberty. If speech is just an instance of selfownership, then the value of speech is subsidiary to self-ownership. Thus, any speech that would 
impinge on self-ownership must give way to the greater value of a general right, whether it be liberty or property.

While this solution to the free speech puzzle answers all the questions, ultimately this solution is one to be rejected if we are to give a philosophical justification that supports viewpoint neutrality. The price of adopting this solution is an inclusion/exclusion principle that, while being technically viewpoint neutral, would ultimately discourage far too much speech.

To illustrate this, let me engage a concrete philosophical argument for this horn of the free speech dilemma. While this view has been held in one form or another by many libertarians ${ }^{22}$, the only extended discussion of the value of free speech for libertarianism is found in an article by Jan Narveson.

In "Freedom of Speech and Expression: A Libertarian View," Jan Narveson begins his argument for justifying a conception of free speech by denying that speech is special. He embraces the first horn of the free speech dilemma. ${ }^{23}$ He says, "I will argue (1) that there is indeed a general principle of free speech, but (2) deny that it is 'special' or at least it is very special ...” (59). For Narveson, freedom of speech is not a special right at all. It is rather derivative from the general principle of liberty — a principle which Narveson identifies with Mill (64). We can call this a derivative justification for free speech rights. Freedom of speech is derived from our general selfownership rights. It requires no independent justification and indeed it is a mistake to look for one.

This general principle of liberty is expressly the liberty to control one's own self. Narveson explicitly says, "Liberty is self-ownership" (63). It is necessarily a negative right. For Narveson, all rights constrain what others can do to us. They only impose duties that are satisfied by noninterference with our liberty. Self-ownership means that we have a right to do with ourselves what

\footnotetext{
${ }^{22}$ For examples of these kinds of arguments see Ayn Rand, "The Rights of Man" Capitalism the Unknown Ideal, (New York: Signet Publishing, 1966) and Murray Rothbard, The Ethics of Liberty, (New York: NYU Press, 2003).

${ }^{23}$ Jan Narveson, "Freedom of Speech and Expression: A Libertarian View," Free Expression: Essays in Law and Philosophy, ed. W.J. Waluchow, (Oxford: Clarendon Press, 1994), 59-90.
} 
we want provided it does not interfere with someone else's self-ownership rights. A right to free speech and the right to private property are "both cases of the same thing" (67). Just as we own our houses and can do with them as we will, we also own our organs and our abilities to express and $\operatorname{speak}(67) .^{24}$

According to this reasoning, once we realize that free speech and property rights are derived from the same general principle of self-ownership, much of the conflict over free speech will dissipate. On private property the owner sets the rules of who can speak and who cannot. ${ }^{25}$ However, Narveson also admits that inevitably there will be places that are not owned in private. ${ }^{26}$ There will be public spaces, and here things are more complicated. Here we have people who want to speak and others who may not want to hear this speech (or are at least indifferent to it.)

This is in fact the environment we all live in when we engage with the outside world. We leave the relative isolation of our private property where we control what we encounter and enter a world where others do not think as we do and often want to express those thoughts. Indeed, people want not just to express their ideas for the sake of expressing thought, but rather to convince us to change our minds. It is important in conceptualizing the dilemma of free speech in a free society to notice that a lot of free speech is intended to persuade others.

In civic life outside our private spheres, there are people who want to speak and indeed to persuade others to think as they do. There are people who may or may not want to be persuaded of whatever is on offer in the public square. Inevitably the liberties of these people are going to collide

${ }^{24}$ Ibid. Narveson is not the only libertarian to take this tack when it comes to dealing with the problem of free speech. Murray Rothbard also grounds free speech in property rights. He says, "In short, a person does not have a 'right to freedom of speech'; what he does have is the right to hire a hall and address people who enter the premises ... There is no extra 'right of free speech' or free press beyond the property rights that a person may have in any given case," Murray Rothbard, The Ethics of Liberty, (Atlantic Highlands, New Jersey: Humanities Press, 1982), 113-14.

${ }^{25}$ Narveson, 66. Narveson says, "If I own the space in which you propose to speak, my right of ownership permits me to make it a condition of your further occupancy that you speak only as I wish you to: for instance, not at all, or only on certain subjects and in certain manners."

${ }^{26}$ Rothbard more radically claims that in a libertarian society there would be no public property per se, Ethics of Liberty, 115-16. 
in what Jeremy Waldron calls "ethical confrontation." ${ }^{27}$ When this happens, is the right to speak privileged or the right to silence? For Narveson this is clear, "Silence, I believe is the indicated baseline, just as having the air in one's lungs in its normal, unpolluted condition is the baseline for smokers in the vicinity" (67).

All unwanted speech is analogous to pollution. This is because any attempt to persuade us causes us to have to attend to such persuasion. This requires us to have our perceptive faculties in some state or another. We must lend our ears to the speech in question even if just to ignore it. Selfownership of our faculties entails that there exists a negative right for others not to put our perceptive faculties in any particular state without our permission. We have a right to not be bombarded by noise from others.

The implications of this are vast, for if noise pollution is defined as any unwanted imposition on our perceptive faculties, any unwanted viewpoint is prima facie a violation of our liberty. If I want to convince people of the virtues of vegetarianism by standing in JFK airport and passing out veggie tracts, then I will ostensibly offend many people on their way to Burger King. More importantly, on Narveson's conception I will be violating their liberty by forcing them to at least attend my speech long enough to give me the brush off or engage me in some other manner.

Narveson does say that this pollution need not be stopped as a matter of course or law. He advocates regulating this speech according to its avoidability and level of annoyance. It is important that we recognize that for Narveson any unwanted speech is prima facie verbal pollution and, like all pollution, can be tolerated or restricted according to a cost/benefit calculation. ${ }^{28}$ The kind of speech that Mill thought valuable, the expression of thought and conscience about life and democracy that

\footnotetext{
${ }^{27}$ Jeremy Waldron, "Mill and the Value of Moral Distress," Political Studies, vol. 35, (1987): 410-423, 414.

28 Alternately, if we adopt Rothbard's "hire a hall method of free speech" it does not eliminate the problem of public persuasion for ostensibly one would have to convince others to attend his speech on vegetarianism at the hall he has rented and that would entail public confrontation (even if with television ads). The point is that at some point in the chain that leads to the hall for the speech, there is the confrontation with those who may or may not want to hear the speech, and property rights do not eliminate this confrontation.
} 
is necessary for forming individuality and insuring that dogmatism does not reign, is often public and unwelcome. ${ }^{29}$ If we agree that silence--not speech--is the baseline in society, ethical confrontation would then fall under the category of noise pollution.

Narveson's position is viewpoint neutral in the sense that any speech can be suppressed if it is unwanted enough. Since freedom of speech is valuable only as an instance of the general right to liberty, when any speech is unwanted, its value is subsidiary to the general right to liberty and therefore can be suppressed. Contrast this to the view that freedom of speech is special as a positive good for individuals that underpins many of the liberal institutions regarding free speech. If freedom of speech is a positive good for individuals to decide what they believe, we are compelled to restrict as little as possible. Because we want more debate not less, we have to restrict in a viewpoint neutral way consciously and as carefully as possible.

Perhaps more troubling is worry about the libertarian concession to persuasion, in lieu of paternalism and moralism. Narveson has said that forcing people to act on certain moral grounds is a violation of self-ownership. No one can force you to give up your money to charity or to pay for the welfare of another. However, the libertarian principle does not explicitly rule out that one can be persuaded to act in a certain way for the good of others. ${ }^{30}$ In other words, coercion is out, but persuasion is in.

It is a good thing too. Much of the civic speech to which I referred, falls under the standard persuasive offer I mentioned earlier. Anne is one of many people walking through the airport and Bob thinks $x$ is something Anne ought to believe or do. If both Anne and Bob subscribe to the injunction against coercion, Bob cannot make Anne do $x$. However, there is nothing inconsistent

${ }^{29}$ In conversation with the author, Narveson stated that the right to dissent against the government ought to have special place because of what is at stake if government has too much power.

${ }^{30}$ Narveson speaks to the acceptability of persuasive dialogue as alternative to coercion in "Contracting for Liberty," Liberty in the 21 $1^{\text {st }}$ Century, ed. Tibor R. Machan and Douglas B. Rasmussen, (Lanham Maryland: Rowan and Littlefield, 1995), 23. 
with Bob's duties to Anne that prevents him from trying to persuade her about $x$. If Bob stands in the public square and preaches about $x$, and Anne does not want to hear it for whatever reason, then by Narveson's lights, Bob is infringing on Anne's perceptual faculties. He is polluting the public square, albeit perhaps pollution that can be ignored or avoided. Narveson suggests that the method for deciding the wrong of some speech making is to weigh its level of annoyance against its level of avoidability:

Roughly speaking, then, we may hypothesize that given a relevant threshold of noisesomeness [sic], the more unavoidable the exposure to the items in question, the more control over the content should be put in the hands of involuntary observers. Conversely, the more easily avoided, the less control those parties have (73).

Narveson says that those who advocate a strong presumption against regulating speech tend to assume that the annoyance level is zero. He does not think this is usually the case. In fact he advocates a maximin principle for weighing the interests of multiple observers in which "those who are the most unfavorably affected should have the most control over the content, in respect to those properties unavoidably encountered by those persons" (74).

Even if we bracket concerns about this approach creating an offense-taker's veto, it does not take long to see that Narveson's maximin principle runs counter to Mill's culture of free speech where rival ideologies fight under hostile banners (II, 39). Mill did not think that public persuasion and public opinion would register as a zero on the annoyance scale. In fact, he was sure that if the kind of free speech he advocated were allowed to go unregulated, there would be much annoyance.

Yet Mill did not subscribe to a maximin principle when it came to civil discourse. Consider Mill's statement that, "If all mankind minus one, were of one opinion, and only one person were of the contrary opinion, mankind would be no more justified in silencing that one person, than he, if he had the power, would be justified in silencing mankind (II, 1). This mankind minus one kind of speech is indicative of most public persuasion. It is often one of a minority seeking to gather support through converting the skeptical, the indifferent, and occasionally the hostile. Their ideas 
will be unpopular and perhaps unwelcome. This is the state of much religious persuasion, political campaigning, and moral protest.

For Narveson, self-ownership sets the bounds for speech. Self-ownership means that we can use our speech organs as we choose, but the self-ownership of others requires that no one has to listen to the speech. Just like street musicians, as long as the music does not annoy too many, then the music can play, however there is not right to an audience.

Mill would have this unpopular speech protected from weighting principles and calculations about avoidance and annoyance. Furthermore, it is clear that Mill's concept of free speech is not grounded in self-ownership such that freedom of speech is the freedom to exercise our self-owned speech organs. In fact, Mill dismisses the value of speech as merely the exercising of our speech organs for our own benefit. He says, "Were an opinion a personal possession of no value except to the owner, if it be obstructed in the enjoyment of it were simply a private injury it would make some difference whether the injury was inflicted only on a few persons or on the many" (II, 1). Free speech is of interest not just to protecting individual rights of autonomous expression. Unsolicited and perhaps unwelcome public speech is of interest to the very workings of life.

He says that the kind of silencing that comes from weighting the unwanted property of speech results in a "peculiar evil" that ends up "robbing the human race" of chances to sift ideas and separate truth from error (ibid). He says, "If the opinion is right, they are deprived of the opportunity of exchanging error for truth; if wrong they lose, what is almost as great a benefit, the clearer perception and livelier impression of truth produced by its collision with error"' (ibid). Free speech is necessary to allow us to be confronted with the strongest arguments for the good life and to choose between them. This is something that must be done in public. Narveson admits that he parts ways with Mill on the value of speech. He says:

J.S. Mill to the contrary notwithstanding, society is not an academy. The right to express oneself to those willing to hear provided it is not done in such a way as to pose a threat to 
others beyond one's immediate audience, does not rest on society's valuing the truth. It rests on something more general and more fundamental: the rights to be who you are and do what you want, whatever others may think (78).

It seems then that Narveson and Mill disagree about the value of the freedom of speech. Narveson privileges individual pursuit of choices and thus unwelcome persuasion has no special status because what is important to promote is individual freedom of choice whatever those choices (provided they do not harm others.) This individual freedom can be accomplished best when we are not unduly confronted by speech we don't necessarily like.

Mill on the other hand, believes that there is something at stake above the interest to go through life unimpeded by noisome speech. To use Narveson's own sentiments, Mill seems to claim the following: being who we are and doing what we want is inexorably bound up in how we react to other ways of life being offered to us in the public square, and that value is being able to listen, adjust and criticize opinions, judgments, and sentiments. Self-ownership does not insulate us from having to attend and respond to ideas that we may not necessarily want to hear.

Narveson makes much of the fact that while a person enjoys ownership of his speech, he does not have a right to be heard. I agree, but there is a substantive distinction between a right to avoid unwanted speech and the right to retreat from or engage it. Consider the standard persuasive offer again. This time Abby is a vegetarian and thinks Burger King perpetuates the torture of animals in factory farms. Betty loves a Whopper everyday around noon. What Betty does is, from Abby's point of view, perpetuating a climate of torture for creatures with some moral status. ${ }^{31}$ Again, Abby subscribes to Narveson's injunction against coercion. Abby does not think that there should be a law against Betty eating burgers. However, Abby also accepts Narveson's concession that when it comes to self-regarding vices, she is perfectly at liberty to try to get Betty to see it her

\footnotetext{
31 I say "some moral status" because I leave room here for Abby to believe that it is wrong to torture animals in factory farms while also not believing that those same animals have rights on the same level as human beings. Obviously if Abby thought the animals had self-ownership rights to life, then coercion could be justified even from Abby's libertarian point of view on the basis of harm.
} 
way. So Abby stands outside of Burger King on the public sidewalk and attempts to persuade Betty not to buy a Whopper. Betty is confronted with some weirdo hippie who thinks eating beef is sin. This is an imposition on her lunch. By Narveson's lights, it is the kind of pollution that must be weighed against how avoidable and annoying it is.

The question is, "Does Betty have a right against ever being confronted with Abby's passionate plea for vegetarianism or rather does Betty have a right to retreat from or engage Abby's persuasive offer?" Keep in mind that in Narveson's libertarian conception of the state it might be fairly easy to avoid confrontation altogether. On Betty's private property she can bar any solicitation for any cause. If the mail service is private then she can subscribe to mail services that don't allow direct mail from vegan groups. In the public sphere, according to Narveson, the baseline is silence. The mere imposition of Abby's unwanted diatribe is subject to calculation of avoidability and annoyance. Abby would have to curtail her speech, or be forced to do so, when it is deemed unwanted by too many. If self-ownership entails that we have a right against our perceptive faculties being confronted with unwanted propositions, then Abby has a lot of avenues closed to her and Betty can craft most of her relationships in such a way that she rarely--if ever--must confront thoughts counter to her own.

The right to retreat from someone's unsolicited speech is a different matter. Abby is presenting a persuasive offer. Narveson acknowledges that under the libertarian conception, persuasion is acceptable. Abby wants to win the opportunity to convince Betty. Betty can decline Abby's persuasive offer in several different ways. Betty can ignore Abby, which is a way of retreating from the debate. Betty can also express her displeasure with Abby ruining her lunch. But Betty can also engage Abby in a debate about the moral status of cows, for Abby has the right to speak, but this does not guarantee her right to unimpeded speech. 
If we deny that silence is the baseline as Narveson says, then there could exist in the public square an expectation that one will be confronted with people who want to persuade us of things. This expectation means that we do not have a right to avoid as much as a right to retreat either to our private sphere or some other public sphere (but the expectation of confrontation will still be assumed). We also have the right to engage such sentiments either by expressing disapproval or by attempting counter persuasion in the form of public debate. ${ }^{32}$

Now consider Narveson's aforementioned liberal value of persuasion. Suppose that Abby and Betty are both good Libertarians. Abby and Betty acknowledge the injunction against coercion for someone's own good. But Abby does not just think vegetarianism is good for Abby (and the animals) but for Betty as well. Abby has a perfectionist intention. She wants to convince Betty for Betty's own sake that doing wrong to animals is bad for her. How genuine is Betty's concession to persuasion if silence is the baseline in public?

What is important to remember is that we have two people who value self-ownership, and neither values self-ownership more than the other. Abby, out of respect for Betty's self-ownership, will not force Betty to stop eating meat. However, if Abby's right to persuade is strongly curtailed by how annoying or unavoidable it is, then how much does Betty really value Abby's right to persuade? Is it merely placatory to make Abby feel better about the plight of animals that she can try to persuade Betty to stop supporting the beef industry?

But suppose one is a skeptic about all this discussion getting anywhere? One of the biggest objections to Mill's value of liberty of thought and discussion is that it necessarily assumes that there is something to be gained by engaging in unrestricted civil discourse. Eric Barendt in his legal

\footnotetext{
32 In looking at Pareto optimality, the optimal would be for either Abby or Betty to convince the other (assuming their beliefs are mutually exclusive). If Abby can convince Betty then her goal will be accomplished and Betty will agree. If Betty can convince Abby to lighten up, then both Abby and Betty can coexist with less "noise". The best way for either of these options to occur is some sort of debate or compromise. Avoidance really does not solve the underlying moral convictions of Abby. Actual conversion (either Abby or Betty) is the optimal solution since it leaves both with the same sort of commitments. It is interesting that engagement not avoidance is the optimal solution.
} 
exposition of free speech argues that this Millian assumption is flawed. ${ }^{33}$ Narveson agrees, "There is scarcely any reason to think that the good life can be 'agreed upon through unlimited discussion and peaceful persuasion." 34

If all we are worried about is protecting self-ownership then setting up a society in which there is no expectation for confrontation and persuasion is perfectly fine. If we are skeptical about objective criteria of the good life or that a culture of free speech will inform us about it, the kind of speech that vegetarians or Jehovah's Witnesses wish to persuade us with is really not all that valuable and we really have not lost much if we curtail their persuasive offers. However, if we think there is some greater interest, as this chapter has argued Mill did, the right to avoid all unwanted speech presents a problem for the expectation of silence in the public square.

If discussion about vegetarianism, the kingdom of God, parenting, and the fate of the local city park are part and parcel of being who we are and doing what we do even if it is only in forming and justifying our beliefs and opinions in reaction to the opinions of others, then it seems that the expectation that others will persuade us and allow us to respond or retreat from such persuasive offers is of vital importance to the process of being who we are and doing what we do. What Narveson's libertarian conception of free speech does is bring in to stark contrast a distinction in classical liberal perspectives. There are classical liberals who would hold that individual liberty is all that matters. This liberalism says live and let live, period. As long as someone's life does not harm anyone else, then what she does with that life is her own business.

However, there is another liberal tradition that has equal claim to the classical liberal pedigree. ${ }^{35}$ This tradition agrees that individual liberty is sacrosanct. There is no coercion allowed to

\footnotetext{
${ }^{33}$ Eric Barendt, Freedom of Speech, (Oxford: Oxford University Press, 2005), 8

${ }^{34}$ Narveson, 80. Also Narveson implies elsewhere that as long as the underlying assumptions are "accurate" dialogue is a good idea. However, "the prospect of an interminable stretch of discourse" gets us nowhere and impedes us from getting on with our lives. "Contracting for Liberty," 23.
} 
make someone live a certain kind of life. However, this liberalism does not say liberty of choice is all that matters, nor does it remain skeptical that there are some life plans that are better than others. It is perfectionist. There are ways to flourish and ways to flounder in one's life. And it is precisely this flourishing that is at stake when people debate about the morality of eating meat, protest a war, or rail for or against a particular religion.

It is important here to make another distinction between fallibilism about the good life and skepticism about the good life. Mill's fallibilism should not be confused with skepticism. Mill doubts that we can ever have certainty about the good life. We can never know as a society which lives are definitely the ones to pursue. But this does not mean there aren't good lives and bad lives and that there is a truth of the matter about what counts as a good life and a bad one. The antithesis of fallibilism is dogmatism (asserting that we know exactly which life is good for which persons) not objectivism about truth and the good life. However the knowledge we can have about good lives is an individual conviction. Indeed, precisely because good lives are objectively good, we need examples and arguments for good lives available in the public square so that we can come to our own informed judgments about good lives.

Both of these liberalisms are consistent with the principle of liberty and self-ownership. The perfectionist can be just as committed to anti-paternalism and anti-moralism as the non-perfectionist liberal. However, for the perfectionist classical liberal, persuasion is not just a concession. It is the principal means by which she can affect flourishing for those she cares about and her society at large. A robust, vigorous, expectation of debate about the good life is the means by which the perfectionist can throw her ideas into the fray and test them, sift them, and honestly try to convince her fellows.

\footnotetext{
35 See especially John Milton's classic essay, “Areopagitica” as an example of a religious perfectionist who argued for freedom of civil speech in order for perfectionists (especially religious perfectionists) to persuade without violating liberty of thought. Areopagitica and other Tracts, (London: Dent Publishing, 1900).
} 
Even if we don't share the convictions of the perfectionist liberal, this does not mean we can dismiss the plea for a venue for confrontational speech to occur. For one of the convictions of liberalism is that people ought to pursue their lives in the way they see fit provided it does not harm others. It seems uncontroversial that there are a lot of people who would agree with the liberal perfectionist tradition who believe that some kinds of lives are better than others even if they are not willing to violate individual liberty in order to promote those lives. Indeed, it is because of respect for self-ownership that persuasion is seen as the only way to promote these good lives.

The worry with the general rights strategy is that if we construct our society in such a way that these people cannot have the venue to persuade others of their perfectionist convictions, then the liberal state may end up marginalizing these perfectionists in ways inconsistent with the goals of liberalism—different ways of life co-existing.

What Narveson's libertarian view suggests is that there is a tension between an interest in free speech for our deliberation about the good life_-what I have called the value of ethical confrontation — and the grounding of speech rights in a general right to liberty based on ownership of our perceptive faculties. Specifically if the state is only charged with protecting rights grounded in this self-ownership, there exists a presumption against confronting one with unwanted speech.

This brings up a bigger tension between self-ownership rights and the concession that others can persuade us but not coerce us. If we say that in lieu of paternalism, those who hold perfectionist convictions still have the right to persuade us, this seems to intuitively commit us to place a high priority on giving them opportunity to persuade us; otherwise, our nods to persuasion are merely placatory.

The general rights strategy is too costly. It is important to note that rejecting Narveson's kind of argument does not imply 1) that there is no general right to liberty 2) that freedom of speech is not an interest that has a close relationship to self-ownership. Indeed to deny the general rights 
strategy does not necessarily commit one to denying the force of self-ownership as a basis for a general right to liberty or specific rights to the fruits of labor, or property acquisition. ${ }^{36}$

If we wish to justify a coherent and plausible justification for liberal speech rights that captures our intuitions about the value of free speech, we cannot rely on its being epiphenomenal on a general right to liberty. Viewpoint neutrality has to have a separate value and separate justification. It is special in some way that can justify the institution that protects it.

If we abandon the general rights strategy, speech is special but we must provide some justification for why it is special given all the harm it admittedly does. What makes freedom of speech special? The special rights strategy has traditionally appealed to four goods that freedom of speech provides or protects. I mentioned four that are the most prevalent. 1) Speech has been thought special in protecting the interest of political debate and the democratic process. 2) It has also been thought special for promoting more truth in society. 3) The special nature of speech has been thought to reside in a kind of respect for individual autonomy. 4) Speech is thought to be special in that it produces self-development. The next chapter will examine each of these strategies. However, none of them will turn out to provide good justification for viewpoint neutrality.

\section{Conclusion}

There are two important philosophical questions that bear on speech rights and regulation. Answering the conceptual and the justification question is a major task of any applied philosophy defense of free speech. Any sufficient philosophical defense of free speech must answer both the conceptual question "What is the scope of free speech?" and the justification question "How do we justify including hateful offensive and useless speech in the class of expressions that is immune from censorship?"

\footnotetext{
${ }^{36}$ Also to deny that the general right to liberty can justify free speech is not imply that there is no independent value to freedom or self-ownership.
} 
This chapter also identified the central issue of free speech. The most troubling aspect of free speech centers on allowing the expression of sentiments and opinions no matter how pernicious_-which was dubbed "viewpoint neutrality" — and justifying this neutrality as a policy for the state. Thus, the problem becomes how to justify neutrality among sentiments and opinions even though such a stance will allow speech that will harm. The challenge is how to justify protecting speech that harms when normally the condition of harm is seen as a reason to sanction harmful acts.

This challenge presented a dilemma. Either speech is derivative of some more important value like self-ownership which is valuable enough to warrant special protection (the General Rights Strategy) or speech is special in itself (the Special Rights Strategy). The first horn of this dilemma dubbed the "General Rights Strategy" was examined and rejected. Chapter 2 examines the claim that speech is special in itself. 


\section{CHAPTER 2 SPECIAL JUSTIFICATIONS FOR VIEWPOINT NEUTRALITY}

The last chapter laid out the two major questions confronting any philosophical treatment of the viewpoint neutral principle. The conceptual question asks: "What is the scope of the freedom to express? What things are we free to express? What is the difference, if any, between expressions that lead to action, expressive acts, and acts that might also be expression?" The justification question asks "How do we justify including the hateful, offensive, and useless speech in that class of expression that is immune to censorship?"

Chapter 1 also argued that the general rights strategy answered the conceptual question by sublimating speech rights under more general rights like liberty or property. While answering the conceptual question, however the general rights strategy did so at the expense of the justification problem. Some speech that is hateful, offensive and useless can be said to infringe on liberty and, because of the special nature of speech, property rights do not insulate bystanders from pernicious speech.

This chapter turns to the special rights strategy. Based on this strategy, free speech should be a special right based on principle. Kent Greenawalt calls it a political principle and differentiates a principle of freedom of speech from a general principle of liberty, "To be significant, a principle of freedom of speech must go beyond [a general principle of liberty] positing constraints on the regulation of speech that are more robust than constraints on other matters." ${ }^{37}$ The special rights strategy attempts to locate something unique about freedom of speech that can justify allowing false, pernicious, and even potentially dangerous viewpoints when actions that produce the same results are prohibited. Therefore the special rights strategy answers the justification question by giving a principled reason for including speech that harms in the protected class of speech. ${ }^{38}$

\footnotetext{
${ }^{37}$ Kent Greenawalt, “Free Speech Justifications,” Columbia Law Review, Vol. 89, No. 1, (January, 1989):119-155,122.

${ }^{38}$ Cf. T.M. Scanlon, The Difficulty of Tolerance, 6 ff.
} 
Traditionally there are four such justifications offered for designating free speech as a special right. This chapter examines each of these justifications to see if any offer good reason to adopt viewpoint neutrality. The conclusion will be that none of these will do as a justification for the viewpoint neutral principle. These justifications run into two problems that make them insufficient as grounding for viewpoint neutral speech policy: 1) the priority problem and 2) the instrumentalism worry. This does not mean, however, that we should give up on viewpoint neutrality. Chapter 3 will argue for another justification for viewpoint neutrality that does not incur these weaknesses. This chapter proceeds by expanding on the nature of the viewpoint neutral principle. After this, the chapter explains the two weaknesses and why they are particularly troubling for viewpoint neutrality. Finally, it examines each of these justifications and argues they suffer from one or both of these weaknesses.

\subsection{The Viewpoint Neutral Principle and its Justification}

It might be helpful at this point to restate the principle of viewpoint neutrality for which we need a justification:

As a matter of public morality, any public institution is disqualified from intentionally aiming to hinder the expression of any viewpoint by suppression except for purposes of temporary censorship to prevent clear, present, and imminent danger.

As chapter one argued, the viewpoint neutral principle represents a plausible version of the traditional legislative and judicial injunction against viewpoint specific restrictions on expression. It is what Kent Greenawalt calls a "disqualifying principle," disqualifying legislatures from passing laws that outright censor rather than regulate. ${ }^{39}$ While the viewpoint neutral principle is consistent with U.S. First Amendment jurisprudence, it does not depend on U.S. jurisprudence. All free societies

\footnotetext{
${ }^{39}$ Greenawalt,122. This principle is also the rationale behind the Two-Tier system of American speech regulation. Second Tier regulation includes time, place and manner restrictions. These restrictions are not thought to infringe on viewpoint neutrality. Viewpoint specific regulation however would be considered a first tier restriction and as such would require "compelling interest"—usually "clear and present danger"— to override the viewpoint neutral principle.
} 
have some form of this principle, and any society that does not fully support this principle should not be considered free.

This traditional principle against suppressing speech on the basis of its viewpoint is being challenged notably with regard to hate speech provisions that would make it a crime to utter degrading sentiments and opinions about groups or individuals on the basis of their race, sex, nationality, or sexual orientation. ${ }^{40}$

One way to justify this viewpoint specific legislation is to assert there is no good justification for adhering to this viewpoint neutral policy, but there are good reasons to abandon it. The other is to argue that while there is good justification for the policy it can be overridden by greater concerns or weightier values.

This chapter is concerned with the first strategy—-the claim that viewpoint neutrality has no special pride of place when considering speech regulation. Since I want to discuss the putative justifications for sticking with viewpoint neutrality, this chapter will just stipulate that in the absence of a good justification to the contrary, the costs associated with a culture of viewpoint neutrality would outweigh the benefits of viewpoint neutrality. If there were no reason to be viewpoint neutral, regulation that hindered or punished certain pernicious viewpoints, in theory, would be morally acceptable.

\subsection{Two Problems for Any Special Rights Justification}

There are two problems for any special right to free speech. Since the U.S. has the strongest viewpoint neutral tradition let me confine my argument to examples from the current defense of the traditional U.S. commitment to viewpoint neutrality and its opposition. Within the U.S. debate, four traditional justifications have been offered as to why the viewpoint neutral principle should have pride of place in a free society:

\footnotetext{
40 Matsuda et. al., 89ff.
} 
1) The Democracy Justification: Freedom of expression is a function of democratic legitimacy. The democratic system will break down if public institutions regulate political discussion on the basis of viewpoint.

2) The Truth Justification: Freedom of expression is a means to finding the truth about what is best for society. The best way to produce more aggregate truth in modern society is to refrain from regulating viewpoints.

3) The Autonomy/Respect Justification: Viewpoint neutral regulation is a way of respecting individuals as free, autonomous agents who would not cede their judgments about the messages they would hear to any governmental body.

4) The Self-Development Justification: Public institutions must be viewpoint neutral in order to foster and maintain individual self development. ${ }^{41}$ Censorship robs individuals of their considered judgment.

All of these suffer from either of two difficulties: a) they appeal to collective interests

primarily and only individual interests secondarily (the priority problem) or b) they fall prey to a

particular worry about their instrumental value that leaves them vulnerable to wide exceptions to viewpoint neutral principle that undermine the justification for the principle itself (the

instrumentalism worry). Before I get to each of these putative justifications, let me first explain what I mean by the two difficulties for the special rights strategy.

\subsubsection{The Priority Problem}

The Priority problem makes the claim that any justification that grounds viewpoint neutrality should make it clear which has priority — individuals or society. Furthermore if the priority is first and foremost on society and not individuals, this will cause problems in justifying its prohibition to members when the collective interests and the individual interests in expression of viewpoints conflict. Collective interest does not provide a strong enough reason for viewpoint neutrality.

There is a relationship between the individual interest in free speech and the collective interest in regulating public fora that further explains why viewpoint neutrality does have value for

\footnotetext{
41 The reader might think there is a justification that is missing, namely one that Mill relies on in his defense of the freedom of thought and discussion in On Liberty. In essay II, Mill defends unregulated thought and discussion on the grounds that a man would have no confidence in his opinions if he were not subject to counter-argument from passionate opponents. Mill then says without unregulated freedom of opinion and sentiment this activity would not occur. This very argument is the subject of chapter three.
} 
society but only secondary to the value for individuals. Is there a reason to think freedom of expression is fundamentally an individual interest and only derivatively a societal interest? Consider a quote from T.M. Scanlon:

The most general participant interest is, then, an interest in being able to call something to the attention of a wide audience ... A speaker may be interested in increasing his reputation or in decreasing someone else's, in increasing the sales of his product, in promoting a way of life, in urging a change in government, or simply in amusing or shocking people. ${ }^{42}$

The content of all of these kinds of speech is controversial. Hardly any society is going to agree on what are the best life or the best policy let alone the value of abject shock or amusement. Scanlon says, however, that not all of these expressions are of equal importance for society as they frequently are in the mind of the speaker. So which has priority: societal interests or individuals? Scanlon seems to say that prima facie it is the individual.

He uses religious speech as an example: "It would be clearly antithetical to freedom of expression, for example, to accord greater protection to exponents of true religious doctrines than to exponents of false ones...This is so because the 'further interest' at stake ... is the interest we all have in being able to follow and promote our religious beliefs whatever they may be” (87).

Scanlon seems to be saying that certain kinds of speech are valuable for individuals to be able to speak. Because of this, we cannot make presumptions about the value of the content of their speech without some overriding interest. Overriding interests may be as simple as the interests of audiences to avoid the speech in question or to allow more than one person to exercise their expression.

However, notice that these interests are viewpoint neutral. We can simply say any speech that cannot be avoided is unethical. Likewise, any speech regardless of its viewpoint can be regulated so

42 T.M. Scanlon, the Difficulty of Tolerance, (Cambridge: Cambridge University Press, 2003), 86. 
that all speakers have a chance to express their opinion in an orderly manner. ${ }^{43}$ But what is so wrong with viewpoint specific regulation for individuals? What does it do to a speaker to have her speech censored on the basis of its viewpoint? This is actually a good question to ask in deciding whether collective or individual interests should have pride of place. Exploration of that question serves to make a case for viewpoint neutrality as a prima facie interest of individuals that is not easily overcome by the interests of society and highlights the priority problem.

Scanlon concisely pinpoints the fundamental conflict between the interest to express a message and the interest not to hear it. "They [the speakers] want to gain the attention of people who would not otherwise consider their message. What audiences generally want, on the other hand, is to have expression available to them should they want to hear it ...” (ibid). Audiences have an interest to be able to pick and choose based on viewpoint they want to hear. However, speakers often want to confront those who otherwise will not listen.

Scanlon thinks satisfying the preferences of speakers, audiences, and bystanders would be almost impossible. It does not seem to be a problem that can be solved by mapping out some value. Which is more untenable: gathering as large a public audience as possible or excluding from public space viewpoints that cause others harm? Even coming up with some way to maximize preferences with regard to these values would be extremely problematic.

The question above suggests at least three solutions to this conflict. The first is to deny the value of the individual claim to as wide an audience as possible (though not to any particular audience) and thus make all expression a private matter. As Narveson suggests, on one's own property one can decide if one wants to listen or not (67). Another solution would be to deny the value of the audience to avoid unwanted viewpoints. This would mean that the value of unwanted

\footnotetext{
43 While so-called second tier regulations (time, place and manner restrictions that don't censor viewpoints entirely) can be more pernicious than putative viewpoint specific regulation, I am not in principle concerned with such time, place, and manner restrictions. I will simply assert that these time, place, and manner restrictions as a collective interest do not in principle undermine the priority of individual interests in viewpoint neutrality.
} 
viewpoints is minimal. The most efficient option is to weigh the two, but on what principle would we rely to adjudicate this balancing?

Perhaps some speech is important for audiences whether they like it or not. Political speech is important because of the importance of an informed electorate. But why would we think that confronting someone with a criticism of their most cherished political beliefs is any less objectionable than confronting them with criticism of their most cherished beliefs about any and all aspects of a good life (i.e. the philosophical, religious, artistic, etc.)?

In the absence of any good reason that any one kind of speech is more important simplicter, it seems reasonable to simply assume that all of these categories of opinions are important and there is no principled reason to think one is more important than the other.

It is plausible that what makes all of these categories important and what intuitively separates the importance of advocacy from merely shocking speech is that beliefs (and the actions that flow from these beliefs) are the constituents of our character. Forming judgments about the political, philosophical, religious, and ethical is a distinctively human sort of activity. This is just an extension of Scanlon's comment about "being able to follow and promote our religious beliefs whatever they may be." The same can be said for ethical, philosophical, artistic, and political beliefs.

With this assumption about these opinions comes another assumption. Because every person has the responsibility to form these beliefs, there is an element of choice. Every person is assumed to have some control. Picking and choosing on the basis of viewpoint does not require that we are screened off from speech we do not like. It merely means that audiences can pick and choose which viewpoint they will accept or reject. This is precisely what makes us intuitively think that the harms that come from offense, disgust, etc. are acceptable harms. 
As Scanlon rightly notes, if we simply absorbed as justified belief every opinion we encountered, our intuitions about the costs of unwanted opinion would be quite different. ${ }^{44}$ That there is a choice when it comes to unwanted opinions is at the heart of our tolerance, and most individuals are both capable and responsible to form opinions about the opinions of others when they are expressed. Freedom of speech generally and viewpoint neutral free speech in particular is special because of its connection to specific and fundamental human activities of communication such as persuasion, advocacy, and expression.

The interest in freedom of expression and viewpoint neutral regulation is not, however, merely an individual interest. This is because of the peculiar nature of speech. The very exercise of freedom of expression requires interaction with an audience albeit not any specific person or group. Thus a prima facie claim to be able to reach as wide an audience as possible does not necessarily entail that a speaker has a claim to an audience of any particular person or group. Though a case can be made that protesters or advocates may be able to claim that it is important that they have their say with persons who hold some particular belief or set of beliefs, someone protesting second-hand smoke might claim that the audience she wants to reach is not just any audience but tobacco executives or smokers.

Individual interest cannot easily be separated from the value of speech for society. J.S. Mill made the bold claim that freedom of speech is not only a vital interest for individuals but for the health of any free society. Mill says of the spheres of liberty, certain freedoms such as freedom of thought, opinion, and assembly are vital to any free society, and, "No society in which these liberties are not, on the whole, respected, is free whatever may be its form of government; and none is completely free in which they do not exist absolute and unqualified" (I, 12-13).

${ }^{44}$ Ibid. 
This seems to make a statement about freedom of thought as constitutive of individual life (which is Mill's primary justification) but the sine qua non of a free society. A society without freedom of thought and discussion is not a free society. Any society where thought and discussion are not absolutely and without qualification permitted, cannot be said to be completely free.

Many have objected that the "absolute and unqualified" must be a bit of a rhetorical flourish because arguably Mill himself qualifies his definition of the first sphere of liberty, making allowances for legal sanction of certain contexts such as delivering a diatribe about how corn-dealers are starvers of the poor before a mob outside of a corn-dealer's house. However, this same viewpoint written in the op-ed section of the local paper should not be censored. Mill's "absolute and unqualified" can then be seen as viewpoint neutral but context specific (III, 2). "Absolute and unqualified" refers to the viewpoint or subject matter. However, time, place, and manner restrictions (e.g. not to a mob outside of someone's house) are subject to regulation and practical consideration. This means that society is not free if any subject matter or point of view expressed in sentiment or opinion cannot be uttered in some context or other. ${ }^{45}$

Given all of this, what is the majority saying when it presumptively discriminates on the basis of the message the speaker wants to deliver? The majority concludes that the overriding reason to stifle this individual speech is that the majority has determined that the harms of the viewpoint for the audience and the bystanders override the individual activity of choice regarding which expression individuals choose to listen to.

This is a strong claim to justify to the individual. It is the responsibility of individuals to make up their own minds about which opinions they adopt, to express their opinions, and to test them. To abandon viewpoint neutrality without a very strong reason is essentially to co-opt the choices of the audience and the speakers.

\footnotetext{
45 See Daniel Jacobson, "Mill on Liberty, Speech, and the Free Society," Philosophy and Public Affairs 29, no. 3 (Summer, 2000), 276.
} 


\subsubsection{The Instrumentalism Worry}

Any justification that says the value of viewpoint neutrality is merely a means to some other valuable end runs the risk of allowing viewpoint specific exemptions that undermine the valuable end. But what is wrong with speech being merely instrumentally valuable as a means to some other valuable good? This is a worthy question and not one that can be argued merely on the merits that such a view would provide.

Call an instrumental justification one that says freedom of speech is special only because it has the effect of producing some other good and that is the only reason speech ought to be protected. The worry is: If we adopt any instrumental justification, it is vulnerable to exceptions to the class of protected messages that would be viewpoint specific, thus undermining the strength of a viewpoint neutral disqualifying principle.

We can summarize the instrumentalism worry regarding freedom of expression as the following:

If freedom of expression derives its value from some result it produces then the expression is valuable only as a means to an end. If the costs of protecting expression are high and it is reasonable to believe that public institutions can achieve the desired end even if, or actually by, suppressing the right, it would be rational to suppress the particular expression.

As was stated earlier, this dissertation does not dispute the claim that the costs of protecting expression are high. We need not rehearse the costs that many have endured in order to tolerate hate speech, vulgar speech, and offensive expression. In the absence of some competing reason, it is perhaps reasonable to censor pernicious, false, or misleading speech if we can achieve the desired result without the incredibly high costs. The instrumentalism worry has a certain structure that leads to a rejection of the viewpoint neutral principle:

1) Viewpoint neutrality is only a means to some valuable end.

2) The valuable end can be promoted or protected by suppressing some viewpoint(s)

3) It is reasonable to suppress such viewpoints to preserve the valuable end. 
4) This provides good reason to make an exception to viewpoint neutrality.

However, once the exception is made, a new problem emerges as to what differentiates this offending viewpoint from other offending viewpoints that undermine the reason for viewpoint neutrality. If there are exceptions, then why hang on to viewpoint neutrality given its high costs? It would seem better to abandon talk of neutrality and carve out principles for viewpoint censorship.

\subsection{Four Justifications for Viewpoint Neutrality}

With these two problems in mind, we can now examine the four traditional justifications for viewpoint neutrality mentioned earlier. What will become obvious is that this section spends considerably more time on the autonomy argument than the others. There is a good reason for this. T.M. Scanlon's autonomy argument has much in common with the self-development argument since autonomy can be viewed as an important (if not the most important) form of selfdevelopment. It will be important then to carefully differentiate Scanlon's autonomy from the selfdevelopment justification.

\subsubsection{The Democratic Justification}

An important justification for the special protection of freedom of speech is that protecting speech is instrumentally valuable to the end of producing legitimate political participation as citizens. If political participation is the important content; what of non-political speech? This has always been the difficulty with the democratic justification. The idea that free speech is special because it provides a check on government and fulfills the democratic mandate fell on hard times shortly after Alexander Miekeljohn first offered it. ${ }^{46}$ Legal scholar, Martin Redish points out that "Meiklejohn in later years appeared to soften the rigidity of his lines of demarcation [between political and non-

\footnotetext{
46 Alexander Miekeljohn, Political Freedom, (New York: Random House, 1960).
} 
political speech] by effectively extending his doctrine-in a somewhat less than persuasive manner-to many forms of apparently nonpolitical speech." ${ }^{47}$

However, Redish argues these extensions are not logically necessary and later proponents of this view, namely Robert Bork, have successfully argued that such extensions are ad hoc. ${ }^{48}$ Instead, Bork bites the bullet and accepts that as Redish puts it, "the sole purpose served by the constitutional guarantee is to aid the political process, and that absolutely no other form of expression can logically be considered to fall within it" (592).

If this is true then the value of so-called "non-political" speech is minimal. However, most people would think that speech about the good life apart from the political process—namely the religious, the ethical, and the philosophical — are part and parcel of freedom of speech. Based on the political justification, much of the debate about religion, morals, lifestyles, etc., will be less important especially given the cost of protecting this non-political speech. At the very least, expressive speech and persuasion about the good life could be censored in a way that is not viewpoint neutral.

Also, the political justification does not make clear why we ought to value freedom to engage in political speech over freedom of speech about the good life in general. George Kateb has remarked that we may just as plausibly assert that the democratic debate inherent in our political process exists to protect the activity of free speech as to say that free speech exists to protect democratic debate. ${ }^{49}$ At least it is not irrational to think one is just as valuable as the other.

Beyond these considerable worries, the democratic justification as articulated by Miekeljohn and Bork suffers from both of the problems I explained earlier, though not to equal degree. The democratic justification runs afoul of the priority problem. If we adopt the democratic justification, it is clear that the justification of freedom of speech is grounded in the collective interest of a well-

\footnotetext{
${ }^{47}$ Martin H. Redish, "The Value of Free Speech," University of Pennsylvania Law Review 130, no. 3 (Jan., 1982 ), 591.

48 Bork Robert, "Neutral Principles and some First Amendment Problems," Indiana Law Journal 47, no. 1 (1971), 591.

${ }^{49}$ George Kateb in Judith N. Shklar and Bernard Yack, Liberalism without Illusions : Essays on Liberal Theory and the Political Vision of Judith N. Shklar (Chicago: University of Chicago Press, 1996), 226.
} 
functioning democracy. This means that speech is valuable to the extent that it provides a forum for political discussion. Government protects political viewpoints in the interest of promoting diversity. Any other viewpoints do not contribute to the political discussion and have no principled standing to be protected. True there may be practical problems with separating political viewpoints from other viewpoints, and there may be specific worries about government making the distinction. However, the point is that viewpoints are not protected because they serve some individual interest in expression. Rather, the individual interest is subsumed under the concern over democratic procedure and legitimacy.

Second, the democratic justification seems to manifest the instrumentalism worry. In fact, the democratic justification seems to fit the structure of the instrumentalism worry fairly well. 1) A well-functioning democracy is the end 2) Neutrality regarding political viewpoints is merely the means to that end. 3) It is reasonable to think that we can achieve the end by censoring certain viewpoints at odds with democracy 4) Therefore, it is reasonable to make exceptions for these viewpoints.

While governments distinguishing political viewpoints practically is a deep concern, if we buy the democratic justification, there is no in principle reason to adopt viewpoint neutrality about all political viewpoints. For instance, by the lights of the democratic justification, government could legitimately restrict viewpoints at odds with democracy. But this would include several political viewpoints such as anarchy and several religious viewpoints that would call for religious rule. Even if the latter did not expressly call for the overthrow of democracy but did require the institution of religious laws, the instrumentalism worry is of concern.

\subsubsection{The Truth Justification}

The second candidate for the justification of viewpoint neutrality is that viewpoint neutrality will result in more truth. This is also an instrumental account. However, we cannot dismiss it solely 
on that basis. The question is: Does it suffer from the instrumentalist worry, the priority problem, or both?

This kind of argument is often attributed to Mill but is most often associated with Oliver Wendell Holmes. Here is Holmes' famous dissent in Abrams v. United States.

The best test of truth is the power of the thought to get itself accepted in the competition of the market ... we should be eternally vigilant against attempts to check the expression of opinions we loathe and believe to be fraught with death, unless they so imminently threaten immediate interference with the lawful and pressing purposes of the law that an immediate check is required to save the country. ${ }^{50}$

According to Holmes we must remain neutral about ideas because through freedom of expression, we find truth. It is important to mention that Holmes was a pragmatist about truth. Truth was tantamount to the majoritarian position that could "lick all others.",

There are many problems with the marketplace metaphor. The least of the problems is that people do not often pick opinions out of the marketplace of ideas as consumers pick out the best fruit the way Holmes' metaphor implies. The marketplace metaphor also assumes that each opinion or sentiment is discrete and can be compared to others. This implies that everyone has access to the same marketplace of ideas and that everyone is on an equal footing when it comes to selling their ideas. It could be argued that public fora are not so ideal.

Holmes' marketplace metaphor is dependent on his pragmatism. If we rely on the metaphor of buying and selling ideas, we run into a different debate about markets and their neutrality. Does everyone really have equal access? After all, when it comes to media, some have more chances than others to get their message to consumers. Relying on the marketplace of ideas metaphor invites objections like the following: "When the wealthy have more access to the most potent media of

\footnotetext{
50250 U.S. 616 (1919) (Holmes, J., dissenting).

51 William B. Lockhart, The American Constitution : Cases, Comments, Questions, 8th ed. (St. Paul, Minn.: West Pub. Co., 1996), 626.
} 
communication than the poor, how sure can we be that 'free trade in ideas' is likely to generate truth?" 52

Holmes' metaphor is a good example of the first weakness I mentioned. Holmes' truthfrom-the-marketplace-of-ideas approach locates the interest of neutrality in society not individuals. Society as a collective is better off if its members more or less adopt true beliefs, but what is true is only what the majority of society judges it to be.

Chapter 3 will argue that the truth justification as it is normally construed cannot easily be attributed to Mill. Whether it is accurate to attribute this idea to Mill or not, it certainly is not Mill's sole justification. There are significant difficulties with using truth as a justification for viewpoint neutrality. Eric Barendt summarizes the "Millian" argument from truth (9ff.) The truth argument involves two different formulations that are "dependent on whether the expression which might be suppressed is possibly true or (almost) definitely false." The former should be immune from regulation because regulation would assume infallibility about some idea and the latter should not be regulated because if false beliefs are censored, "people holding true beliefs will no longer be challenged and forced to defend their views," resulting in true beliefs becoming what Mill deemed dead dogma.

Barendt says the problem is that this argument assumes that in all circumstances (with the exception of an emergency) the publication of truth is the highest good for society, but this seems arbitrary because there are other competing values. It is especially problematic for viewpoint neutral regulation because a society may plausibly protect other values like racial harmony that could entail prohibiting racist speech in order to protect that harmony.

It is not irrational to value racial harmony over truth. It is rational to value order over inflammatory speech. Barendt argues that if free speech is valuable only as a means to truth, "the

\footnotetext{
52 Lockhart et. al, 786.
} 
risk of immediate damage which may occur from the acceptance of falsehood should be balanced against the long-term benefits of constant, uninhibited debate" (10). Thus, it seems that the truth justification suffers from the priority problem. Individual interests are subordinate to societal interests. However, societal interests could justify viewpoint specific regulation. Individuals could in principle be barred from viewpoints that the majority believe contribute to false beliefs.

Barendt also explicitly mentions the instrumentalism worry. He argues that if truth is the goal, then it seems proponents of this justification must concede that some viewpoints aren't valuable for truth at all. The "argument from truth" values propositions whether they are true or mistaken (9). Some speech would not seem to fit easily into the category of true or false propositions. Nazi demonstrations, emotive political speech, and personal abuse all "fall outside the categories of expression which Mill had in mind when he formulated the argument from truth" (11).

Once again a worry about justifying merely instrumental reasons leaves the justification in danger of dying the death of a thousand exceptions. If truth is the end and viewpoint neutrality merely the means, it is reasonable to think that prohibiting pernicious speech that is either false (e.g. “The earth is flat") or non-veridical (e.g. “Government sucks!”), could actually contribute more to the goal of truth than adopting a policy of viewpoint neutrality.

\subsubsection{The Autonomy Justification}

A third candidate for a philosophical justification of viewpoint neutrality is the justification that finds the value of viewpoint neutrality in respect for rational, autonomous agency. The strongest articulation of this view comes from T.M. Scanlon's article "A Theory of Freedom of Expression" and its sequels, "Freedom of Expression and Categories of Expression" and "Content Regulation Reconsidered." ${ }^{33}$ Scanlon's argument is the "strongest" because the argument of "Theory" is that

\footnotetext{
${ }^{53}$ All published Thomas Scanlon, The Difficulty of Tolerance : Essays in Political Philosophy (Cambridge: Cambridge University Press, 2003), 273. "A Theory of Freedom of Expression" will hereafter be referred to as "Theory." "Freedom of
} 
false, destructive and even dangerous speech should be protected even if its consequences are worse than they would be if we censored the pernicious speech.

In "Theory" Scanlon argues that speech rights are necessary for political legitimacy. Any government that censors sentiments or opinions on the basis that such speech will produce dire consequences fails to treat its citizens as "equal, autonomous, rational agents" (14).

The autonomy in question is cashed out in terms of reasons for action. For agents to be autonomous requires that they form independent reasons for their beliefs and actions. Autonomous agents may rely on the judgment of others (even the government) but to be autonomous, they must act on this opinion on the basis of independent evidence for that reliance. As Scanlon puts it, "He must be prepared to advance independent reasons for thinking their [the judgment of others] judgment likely to be correct, and to weigh the evidential value of their opinion against contrary evidence" (16). Scanlon calls this the "Millian Principle" (ibid.)

Scanlon rightly contends that the Millian principle will preclude government restriction of speech on the basis that the speech in question might produce dire consequences. Scanlon does leave open the possibility that circumstances are so dire that they could warrant censorship, but since the above principle is a principle of political legitimacy, any such censorship due to a dire emergency would constitute a shift in political authority. Such a state of emergency would have a different basis for political legitimacy (24).

It seems of the three candidates for a philosophical justification of viewpoint neutrality mentioned thus far, Scanlon's argument for treating people as autonomous, rational agents is the most likely to provide something like the viewpoint neutral principle. There is strong justification for viewpoint neutral regulation in order to preserve respect for rational agency in any government regulation of speech.

Expression and Categories of Expression" will be referred to as "Categories." "Content Regulation Reconsidered" will be referred to as "Regulation." 
Unlike the previous two candidates, it does not seem that Scanlon's rational agent justification suffers from the priority problem. The rational agent argument clearly grounds viewpoint neutrality in the individual interest in being treated with respect as primary, and the collective interest in social order only secondarily. However, there are some problems with relying on Scanlon's argument as a justification for viewpoint neutrality.

First, it seems that Scanlon's argument falls prey to the instrumentalism worry. At first blush, Scanlon's argument would provide a strong reason for any regulation to be viewpoint neutral. If we prohibit some speech on the basis of its viewpoint we fail to treat people as autonomous agents. Instead we make them accept the judgment of another (societal or governmental) without giving them independent reasons for accepting this judgment.

However, as Susan Brison points out, this would protect almost all opinions and sentiments. ${ }^{54}$ It would seem that if treating people as autonomous agents is what is of paramount value, and then Scanlon's Millian principle does not provide reasons for prohibiting speech that specifically undermines autonomy - most notably hate speech. In other words, if it can be shown that 1) the perniciousness of hate speech is that it undermines autonomy and 2) governments can reasonably identify such autonomy undermining opinions and sentiments, there is not a reason why governments cannot issue viewpoint-based restrictions on hate speech for the purpose of treating each citizen as equal, autonomous and rational agents.

Setting aside whether or not government can identify undermining opinions, Brison's argument reveals that Scanlon's argument from respect is vulnerable to the instrumentalism worry. If free speech rights are valuable merely as a means to respecting autonomous agents, and we can pick out viewpoints that undermine autonomy, an independent reason is needed why the

\footnotetext{
54 Susan J. Brison, "The Autonomy Defense of Free Speech," Ethics 108, no. 2 (Jan., 1998), 312.
} 
government cannot be viewpoint specific in restricting that speech, especially if individuals can be more autonomous as a result of screening off certain hateful viewpoints.

Second, while Scanlon's argument ostensibly grounds viewpoint neutrality in an individual's interest, it turns out that the interest is very thin. In Scanlon's argument, an autonomous agent is one who believes and acts based on specific kinds of reasons but Scanlon's "Millian principle" does not explain how such behavior becomes part of a person's life. People don't simply find themselves with the habits of independent justification and rational deliberation. What is missing from Scanlon's Millian principle is the character that makes decisions in an autonomous way. This is something Mill himself touched on. A policy of viewpoint neutrality is valuable not just as a way to treat people in a way they are due, but it is also necessary to produce the kind of deliberating character that makes up an autonomous agent.

Third, and perhaps most important, Scanlon's concept of autonomy simplicter does not withstand his own modifications. In "Categories," Scanlon significantly weakens the Millian principle. He concludes that different categories of expression can conflict. Political speech as a participant interest can clash with the audience interests in having access to a fair debate. Thus, it may be necessary to restrict campaign spending in much the same way that we limit the length of campaign speeches (103). However limiting campaign-finance reform might be, it would still be viewpoint neutral because no particular viewpoint or subject matter is intentionally singled out even if it turns out that one viewpoint is partially suppressed and another gains an advantage it did not previously have.

Furthermore, the relative value of categories of expression could lead to content and viewpoint specific restriction. Recall the distinction from Chapter 1. Content specific censorship is a broader category than viewpoint specific censorship but narrower than general regulation of time, place, and manner. An example of content specific censorship would be a ban on a certain kind of 
advertisement or a ban on all parades with political content. Banning leaflets that call for the overthrow of the government would be an example of censorship that is viewpoint specific. It is possible to censor a viewpoint without censoring a specific content. However, if government censors an entire content, it is inevitable that viewpoints will be censored. In "Categories" Scanlon says that the category of advertising can be legitimately censored (104 ff). Later in "Content Regulation Reconsidered," he expands this to say that restriction of cigarette advertising is consistent with freedom of expression as well (161).

Scanlon abandons viewpoint neutrality in the process of abandoning content neutrality with little concern for their close connection. With regard to categories, any discussion of viewpoint neutral regulation still requires non-neutral judgments about the relative value of different kinds of speech (e.g. commercial speech, political speech) (ibid). Scanlon says, "I claimed that the Millian principle was a constraint on the justification of restrictions on expression that arose from the idea of autonomy itself and did not depend on judgments about the relative value of different forms of expression" (162). Since it is impossible to be neutral in making judgments about the value of categories of expression, and it is necessary for government to make these judgments, a vital piece is missing from the Millian principle. This leads Scanlon to abandon his strong content neutral Millian principle by saying:

While the impermissibility of (some forms of) content regulation has a special place on the 'surface' of freedom of expression (i.e. in the constraints that make up the practical content of that right), this does not reflect any special objection to such regulation that is apparent at a more fundamental level (162).

In other words there is no good reason to stick with the strong Millian principle that prevents the government from weighing the relative importance of different categories as long as the government respects the right of autonomous agents to make up their own minds ("Theory", 14). But he also downplays the value of viewpoint neutrality when he says: 
Regulation that discriminates among speakers on the basis of their points of view can reflect the judgment that some of these points of view are mistaken, but it can also have other aims ... More benignly viewpoint-based regulation may be aimed at securing a higher degree of fairness in public discussion by constraining those who already have a great deal of exposure in order to give others a chance to be heard. Our resistance to viewpoint discrimination differs from our resistance to judgmental regulation ... [the fear of viewpoint discrimination] arises from partiality rather than paternalism (ibid, 65-6).

Scanlon seems to say that our intuitive fear of government censorship of viewpoints is really about our fear that the government will censor for our own moral good (paternalistic judgmental regulation). However, viewpoint discrimination--the silencing of some viewpoints in order for others to be heard well--is shied away from because of concerns about partiality to one viewpoint or another. He dismisses this latter worry by saying, "Unlike the aims that lie behind some judgmental restrictions, motives of partisanship lack even prima facie justificatory weight... They thus present no theoretical problem in our thinking about freedom of expression but only pose a threat to be guarded against" (ibid.)

It is reasonable to think Scanlon is wrong about the theoretical problem. Denying the proponents of equal access to the public square is arguably just as paternalistic as punishing viewpoints by censorship. Both interfere with the autonomy of agents. Scanlon's thought seems to be that viewpoint specific censorship is acceptable as long as it is not judgmental viewpoint specific censorship. It seems spurious to say that government can silence viewpoints without discriminating between the relative value of some opinion or sentiment and that this silencing will not undermine autonomy.

Scanlon's Millian principle sought to protect a strong content neutral free speech principle even in the face of otherwise unacceptable consequences so that autonomous agents can exercise their own judgment. However, Scanlon abandons content and viewpoint neutrality because he says that autonomy is at the heart of the Millian principle for free speech. By Scanlon's own lights that autonomy justification is not strong enough to protect viewpoint neutrality. 
If there is any hope for a viewpoint neutral principle, two things are needed. 1) a non-neutral justification since Scanlon is right about the impossibility of complete neutrality when it comes to government regulation but also 2) a justification that does not suffer from the weaknesses of the autonomy justification.

\subsubsection{The Self-development Justification.}

The self-development justification argues that free speech is necessary as a means to individual self-development. Some advocates argue that free speech allows individuals to develop virtues useful for free societies such as tolerance. Others contend that viewpoint censorship robs individuals of character-building deliberation.

If the argument is of the former type, then ostensibly the value of viewpoint neutrality is in society's interest in helping its citizens develop tolerance toward other citizens. This could be expected to clash with individual character building. For example, if virtue is the goal, then the character-building practices of recognizing and expressing disdain at vicious behavior would conflict with a societal interest in not just mere restraint from condemnation but tolerance toward divergent life choices. The priority problem does not seem to be solved by grounding freedom of expression in character development.

If the argument is of the latter type, then a policy of viewpoint neutrality is instrumental to individual character development. This is precisely where the instrumentalism worry rears its head. 1) If certain character traits are the end and 2) viewpoint neutrality is only valuable as a means to that end, and 3) it is reasonable to think allowing some viewpoints would undermine or discourage self-development then 4) it is reasonable to make exceptions for opinions that undermine selfdevelopment.

The self-development justification loses much of its intuitive appeal when presented with the case of hate speech, for if there is any speech that is likely to harm an individual's own character 
building, it would be viewpoints that seek to degrade individuals on the basis of their race, nationality, sexual orientation, etc.

Furthermore, if we widen the instrumental value of viewpoint neutrality to any component of individual self-development, there is a related worry that the self-development justification will prove too much, not too little. Larry Alexander says, "Virtue Theories fail as general theories of freedom of expression ... they are radically overinclusive." ${ }^{55}$ After all, if self-development is the value to be promoted, this could justify sweeping positive duties for the state to provide free travel, compulsory liberal arts education, and possibly one's own private library. ${ }^{56}$

If this is correct, the primary objection to the self-development justification is that either it is under-inclusive (for it picks out some societal virtue like tolerance without really explaining why non-tolerant viewpoints are allowed) or over-inclusive in that the justification has as its scope all of individual development and this would require much more than viewpoint neutrality. Either way, the self-development justification as sketched here does not hold much hope for a compelling reason to adopt viewpoint neutrality.

\section{Tentative Conclusion}

It seems that none of the traditional justifications for viewpoint neutrality are sufficient to justify a viewpoint neutral premise. Does this mean viewpoint neutrality founders against the objection that given the harms of allowing certain viewpoints there is no good justification for holding on to viewpoint neutrality? Not necessarily.

There is nothing that says a modified version of these justifications could not overcome the priority problem and the instrumentalism worry. The next two chapters present a modified version of the self-development argument based on the virtue of justified belief forming that Mill alludes to in Chapter 2 of On Liberty. In that essay, Mill presents what could be called the "rational justification

${ }^{55}$ Larry Alexander, Is there a Right of Freedom of Expression? (New York: Cambridge University Press, 2005), 132.

${ }^{56}$ Cf. Barendt, 10-12. 
justification." For clarity I will refer to this kind of justification as the Justified Opinion Argument for viewpoint neutrality (JOA). 


\section{CHAPTER 3 \\ PRACTICES OF JUSTIFICATION AND HUMAN FLOURISHING}

The standard justifications for freedom of expression do not hold much promise for establishing the viewpoint neutral principle. Chapters 3-4 offer an intellectual development argument called the "Justified Opinion Argument" for viewpoint neutrality (JOA). Unlike the other selfdevelopment arguments, the JOA relies on a specific kind of intellectual development — the ability to engage in the practices of justifying one's opinions and sentiments - that is part of broader human flourishing. The conditions for acquiring and practicing intellectual virtue require that one not be protected from or denied access to opinions and sentiments. My argument can be summed up in the following set of propositions:

\section{The Justified Opinion Argument for Viewpoint Neutrality}

1) The ability to justify one's opinions and sentiments is partly constitutive of human flourishing because it is constitutive of intellectual virtue.

2) If some opinions or sentiments are systematically censored by law a) the practice of justifying one's opinions and sentiments is compromised and b) the justification of specific opinions is undermined.

3) If some opinions or sentiments are systematically censored by law, a constituent of flourishing will be compromised.

4) The state should not hinder people from the pursuit of their own flourishing provided it is compatible with the flourishing of others.

5) The state should prevent legislation that systematically censors any opinions or sentiments.

6) Developed states have the institutions to prevent systematic censorship of opinions (underdeveloped states or governments in a temporary state of emergency may not have the means to prevent censorship of opinions).

7) Adopting the viewpoint neutral principle is the best way for developed states to prevent legislation that would systematically censor some opinions or sentiments by law.

8) All other things being equal, developed states should adopt (or maintain) the viewpoint neutral principle.

Since questions about the necessary conditions of justification and conditions of human flourishing are sometimes more controversial than questions about policy, this chapter is dedicated to 
explaining and defending Propositions1-3). Propositions 4-8 are handled in Chapter 4. Together they make up the Justified Opinion Argument (JOA) for viewpoint neutrality. Before examining each of these propositions, it will be necessary to take up an argument from On Liberty concerning confidence in one's opinion.

\subsection{The Practices of Justification}

The JOA as an intellectual development argument draws from a neglected argument in Mill's On Liberty in which he says that having to justify one's opinions is a valuable form of intellectual development regardless of the harms that come from allowing pernicious viewpoints into the public square. Mill claims that a man is not deserving of his confidence in his opinion unless:

He has kept his mind open to criticism of his opinions and conduct. Because it has been his practice to listen to all that could be said against him; to profit by as much of it as was just, and expound to himself, and upon occasion to others, the fallacy of what is fallacious (II, 32).

Recall that one of the philosophical questions in Chapter 1 was the "the justification question" which asks, why is speech protected given that protecting speech will result in harms that otherwise would justify restricting this activity? One of Mill's arguments is that viewpoint specific censorship undermines the condition of having justified opinions because such censorship would prevent individuals from three practices that make one deserving of confidence in one's opinion. These are critical attention ("listen to all that could be said against him"), critical adjustment ("profit by as much of it as was just"), and critical exposition ("expound to himself, and upon occasion to others, the fallacy of what is fallacious").

Critical attention refers to the practice of listening to all that is said against one's position. This practice can be divided into a strong and weak version. On the strong version, one is not justified unless one seeks out objections to one's opinion on some subject. Astrologers are remiss because they don't consider seriously the objections to their occupation. On the weaker version of critical attention one is justified provided one remains open to objections or criticism but one is not 
required to seek them out. A vegetarian would be justified in her opinion "eating meat is immoral" provided this opinion was the result of some good reasons and she is open to counter-evidence that her opinion is ill-founded. She does not go out of her way to avoid counter-argument or evidence to the contrary.

Critical attention is an open-ended condition. Being open to hear counter-arguments to one's own opinion never really ends. In fact, to engage in critical attention could mean that when a belief is so settled into one's mind as to be nearly certain, one should always be open to new criticisms of that opinion and perhaps seek out those criticisms.

Critical adjustment refers to the practice of modifying one's opinions given counter-evidence and profiting from what is just in them. Mill cannot mean by "just" the same thing as "justified" lest he be guilty of a circular argument. Instead, Mill is more likely referring to a sort of sifting process. No opinion is rejected out of hand. Rather, opinions are sifted to find that which is just, much like the flour is sifted to remove impurities. One's opinions are never impervious to the best elements of even the worst arguments if these elements are valid and relevant.

A quick example: Suppose I am of the opinion that Social Security is a legitimate form of social insurance. In order to preserve my confidence in my opinion, I listen to someone who thinks social security is a Ponzi scheme. If I deem this argument has some legitimate points, my confidence will only be preserved if I can glean what is good from this argument and adjust my own position. This does not mean that I have to give up my position wholesale. Instead I may have to moderate my opinion to accommodate what is just or right given the reasons and arguments of someone else.

Critical exposition is perhaps the most problematic of Mill's practices. Mill describes this practice in a curious manner. He says, that in order to be worthy of confidence, a man must also "expound to himself, and upon occasion to others, the fallacy of what is fallacious." 
What does Mill mean by “expound to one's self?” This could be a metaphor for deliberation and critical thinking. However, why describe critical thinking in terms of exposition to one's self? It may be that Mill equates exposition with others as a kind of thinking aloud. Indeed Daniel Jacobson makes a convincing argument that this is exactly what Mill intends. ${ }^{57}$ This is not as strange as it sounds. Most people who are critically examining an issue will do as Mill says and put themselves in the mental position of those who disagree with them. Critical examination could mean creating an inner dialectic between various positions if no interlocutors are available.

Most likely Mill does not mean by "fallacious" the technical term in logic. Instead by "fallacious" we can infer all kinds of criticism from sentiments (e.g. "This is evil") to factual claims like "This is false." It is reasonable to think of freedom of thought and freedom of expression as being so closely related as to be the same activity. When we expound to others why some opinion is fallacious or wrong, we are indeed using the dialectic as a way of thinking about the subject not merely communicating it to someone else. It is also easier to work out one's own opinion when it is possible to present that opinion to others in dialectic.

Finally, there may be another side to critical exposition. Critical exposition includes judgments based on an examination of the best and worst sides of an argument. Critical exposition could also refer to judgments of individuals not just their arguments. One of the most important kinds of individual judgments is praise and criticism of the character of others. Later a case will be made that these kinds of judgments rely on access to information as much or more than judgments of arguments. In other words, an assessment of character can only be accurate when one is allowed access to false, even pernicious opinions and those that purvey them.

The kind of "confidence in one's opinion" to which Mill refers begins to look like a kind of second-order intellectual virtue acquired and sustained by the practices of justification just as other

${ }^{57}$ Daniel Jacobson, "Mill on Liberty, Speech, and the Free Society," Philosophy and Public Affairs 29, no. 3 (Summer, 2000), 284. 
virtues like honesty are acquired and sustained by practicing honesty. In this case, the virtue of justification requires us to find the right reaction to the sentiments and opinions of others and avoid the excesses of overreaction on the one hand and indifference on the other. Justified judgment of one's opinions and that of others is a mean between extremes. Indeed Aristotelian language is appropriate, because the practices of justification seem to yield an intellectual virtue of justified judgment in the same way that practices of courage yield the moral virtue of courage.

This would mean, however, that justification must be seen as more than merely a property of truth claims. It may also be an activity that yields a virtue for which people are praised for acquiring and blamed for lacking. People can be more or less justified in their opinions and their opinions can be justified as well. These two notions can come apart, however. It seems very plausible that one could believe something that is justified without also being personally justified in believing $p$ (e.g. believing that vaccinations are important to prevent the spread of disease but only because the village shaman spoke of evil spirits in the blood.)

This turns out to be a crucial distinction for Mill's case about the man who deserves to say he has confidence in his opinion. Mill's conditions for justification are quite strong. One is not deserving of confidence if one has not engaged in the practice of critical attention, adjustment, and exposition. This seems at odds with the traditional interpretation of Mill as someone whose only interest is more truth in the world or even that people end up with true beliefs. To allow these practices to go forth unregulated, as Mill argued society should, is likely to produce many false beliefs. It is also likely that unregulated opinions will result in many people believing false, dangerous, and vicious things.

A major criticism of freedom of expression is that in allowing a thousand flowers to bloom, it is naïve to think none of them will be useless and some will not be vile and poisonous. Is Mill naïve about the consequences of unregulated opinions? A case can be made that Mill does not have 
the stark optimism that a free marketplace of ideas will produce more "true belief" as is often attributed to him. ${ }^{58}$ Rather beliefs that are tested and held as a result of critical attention, adjustment, and exposition, as opposed to blind faith or complacency, are what are indicative of human excellence (II, 19).

Mill goes so far as to say that those who do not engage in the practices of justification cannot "know" that their opinion is true. He says, "Their conclusion may be true but it might be false for all they know" (II, 23). It seems here that to "know" in this sense requires the practices of justification, because he says, "they have never thrown themselves into the mental position of those who think differently from them, and considered what such persons may have to say ... do not, in any proper sense of the word, know the doctrine which they themselves profess"(II, 23). The process necessary for a justified opinion is one in which individuals have "thrown themselves in the mental position of those who think differently." This is consistent with the three activities of critical attention, critical adjustment, and critical exposition.

If what Mill has in mind by "deserving of confidence" is S being justified in believing $p$ rather than S's belief in $p$ being justified, then it explains why Mill, who has no illusions about people choosing true beliefs over false, (e.g. II, 17), continues to argue that individual justification is furthered by free speech and stifled by censorship. ${ }^{59}$ The condition of being justified-that one is in a good position to think one's opinion is true and responsibly held— is, according to Mill,

\footnotetext{
${ }^{58}$ For examples of this misreading of Mill as being optimistic about truth in the marketplace of ideas see Eric Barendt, Free Speech, 8-14 and Alan Haworth 44-46. Also see Jacobson's discussion of L.W. Sumner and Owen Fiss in, "Why Free Speech Includes Hate Speech," New Waves in Applied Ethics, eds. Jesper Ryberg, Thomas Petersen, and Clark Wolf (Palgrave Macmillan, 2007)

${ }^{59}$ Daniel Jacobson points out, "While belief in P might be promoted by various means, including brainwashing, knowledge of P cannot be promoted by any method that undermines our justification for believing P." Jacobson, "Why Free Speech Includes Hate Speech", 30. I settle for justified opinion rather than knowledge as Mill does because the value of knowledge hinges on a great deal of epistemology. Since my overall goal is an argument for viewpoint neutrality, not solving the justification problem in epistemology, justified opinions and their value will suffice for the argument for viewpoint neutrality.
} 
praiseworthy and virtuous for individuals even if that virtue comes with the cost of more false, pernicious, and unjustified beliefs in the word.

Whether or not this is Mill's position is best left to Mill scholars. However, if one is constructing a Millian argument, it is not necessary to embrace naivete about the effects of free speech to defend viewpoint neutrality. But it may be necessary to decide that " $\mathrm{S}$ is justified in her belief" is intrinsically valuable to human beings in a way that "S's belief is justified" is not.

Because this is such a crucial distinction let me clearly lay out this distinction and then argue that a Millian argument for viewpoint neutrality like the JOA relies on the intrinsic value of human beings being personally justified in their own beliefs in order to develop intellectual virtue.

Mylan Engel calls this crucial distinction the difference between personal and doxastic justification. ${ }^{60}$ Alvin Plantinga has made the distinction between justification-which is an evaluation of epistemic duties-and warrant-which is that property that makes true belief become knowledge. The debate about warrant and justification is a contentious one. One does not need to settle the definition of warrant to accept the JOA. Whatever the property that turns true belief into knowledge, Plantinga and his critics agree that there is a difference between evaluating a person's reasons for believing and evaluating a belief as one worthy of anyone believing it. To avoid the justification/warrant debate, we will retain the classic term "justification” and use Engel's terminology that differentiates between evaluating $\mathrm{S}$ as being justified in her belief (personal justification) and evaluating S's belief as being justified (doxastic justification). ${ }^{61}$

\footnotetext{
${ }^{60}$ Mylan Engel, "Personal and Doxastic Justification in Epistemology," Pbilosophical Studies 67, no. 2 (1992), 132.

${ }^{61}$ Engel gives an example where Sally's belief is evaluated as justified while Sally is judged personally unjustified in her belief. "Sally is told by her incompetent logic instructor that modus ponens is an invalid argument form. Not realizing her instructor's incompetence, she comes to regard modus ponens as an invalid form. One day, in a moment of wanton logical abandon, she comes to hold a belief on the basis of a modus ponens argument with obviously true propositions. Here we have a situation where Sally's belief is perfectly reasonable (since it follows from true propositions) but Sally is unjustified in believing it (because given her situation, she is being epistemically irresponsible in using modus ponens)" (ibid).
} 
An example will be helpful. Friedrich Kekulé had a day-dream/vision that was inspiration for his theory of the structure of the benzene molecule. Kekule said in a speech in 1890 that he had solved the problem of how hydrogen and carbon atoms can bond after a vision of a snake eating its own tail. There was no countervailing evidence at the time to dispute Kekulé's theory. However, if someone believed his theory solely on the basis of the dream, most would say they were not justified in forming this belief. ${ }^{62}$ However, the belief that benzene molecules mimic the shape in Kekulé's dream was and is justified. Kathleen Lonsdale verified Kekulé's theory in 1929.

The distinction between personal justification and the doxastic justification can be seen if we note that the belief "benzene is structured like a snake biting its own tail" would be doxastically justified even if no one ever had believed it. The x-ray defraction completed by Lonsdale is proof that benzene molecules are in that shape. However, if someone cited as his reason for believing Kekulé's theory that it had come to Kekule in a dream, then they would not be justified (or in Mill's terms "deserving of confidence") in their opinion.

This indicates that what Engel means by "personal justification" can be identified with epistemic virtue. The practices that are part of anyone's epistemic duties in a given situation render her belief personally justified. If personal justification is shorthand for having the epistemic virtue to engage in the practices that produce epistemically praiseworthy beliefs, then we have a much narrower self-development argument than those presented in Chapter 2. Furthermore, this narrow intellectual development argument does not fall prey to the instrumentalism worry. Recall that the instrumentalism worry can be stated in this way:

If $x$ derives its value solely from some result it produces, $x$ is valuable only as a means to an end. If the costs of protecting $x$ are high and it is reasonable to believe that public institutions can achieve the desired end even if, or actually by, suppressing $x$, it would be rational to censor $x$.

\footnotetext{
${ }^{62}$ Kekule's own testimony indicates the dream functioned as a catalyst for looking at problem of benzene structure a different way. See A.J. Rocke, "Hypothesis and Experiment in the Early Development of Kekulés Benzene Theory" Annals of Science, vol. 42, no. 4, (1985):355-381, 381.
} 
For instance, if freedom of speech is valuable only as a means to self-development and public institutions can help achieve self-development more by suppressing some speech that hinders the self-development of its targets, then this is a reason for public institutions to censor that speech. This is an argument that has been leveled at both hate speech and pornography. ${ }^{63}$

This chapter will argue that the JOA does not suffer from this worry for two reasons 1) the development of intellectual virtue is not merely a means to the end of flourishing as a developed person. Being intellectually virtuous just is partly constitutive of flourishing. 2) While it is possible that suppressing certain viewpoints may help some aspects of self-development, any censorship will undermine the practices of justification and thus will put intellectual self-development in jeopardy. This means that the practices of personal justification are the only way to acquire the virtue of justified believing.

If personal justification is constitutively valuable, then it explains why Mill, who has no illusions about people choosing true beliefs over false, (II, 17), continues to argue that individual justification is furthered by letting a thousand opinions bloom yet stifled by censorship. The condition of being justified-being in a good position to think one's opinion is true and responsibly held — is, according to Mill, praiseworthy and virtuous. And without the conditions of critical attention, reflection adjustment, and exposition, one cannot be said to be justified in one's opinion.

This constitutive move serves to rebut a particular kind of objection. If justification is only a good indicator of true beliefs, then justification is only instrumentally valuable as a means to adopting true beliefs. On this view, justification is important to ensure truth and the freedom to express opinions is important as a means to access evidence for justification.

\footnotetext{
${ }^{63}$ On hate speech, see Susan J. Brison, "The Autonomy Defense of Free Speech," Ethics 108, no. 2 (Jan., 1998), 312. On pornography see Robert P. George, Making Men Moral (Oxford: Clarendon Press, 1993).

For an argument for why pornography should not be considered part of the protected opinions of free speech see my "Bumper Stickers and Boobs (or Why Pornography is not like Free Speech)" (forthcoming in Pornography and Philosophy from Blackwell publishers.)
} 
Any Millian argument that makes this assertion faces a serious objection. If truth is what we are after, it is plausible that society could suppress some bad opinions and still end up with justified believers without allowing access to every and all opinions. We can call this the philosopher-kings objection (PK). PK can be summed up in the following challenge:

If it is possible, in principle, to brainwash people to believe true beliefs and to imitate the practices of justification by including the best counter-arguments as part of the programming, philosopher kings could create justified believers without the risks of open and free deliberation.

The PK objection is the flip-side of the fallibility argument attributed to Mill. Mill says that one reason for allowing unregulated viewpoints is that no one is capable of being infallible when screening off viewpoints (II, 3). But his critics can easily reply that it is only a practical epistemic deficiency, not a moral imperative, which blocks us from assuming infallibility. It is not wrong in theory to assume infallibility; it is only practically impossible.

While philosopher-kings who are certain about every justified opinion or sentiment, is arguably a fantasy, it is plausible that there are some opinions for which we can say there is near certainty. Judgments such as "Slavery is fit for some races" and "It is okay to have sex with eightyear olds" could arguably fit into this category. People who adopt such views are irresponsible, wicked, or both. It might be reasonable to think censoring those few opinions would do more good than harm because there is almost no hope that such opinions stated in public contribute anything to justified belief-forming and actually could cause some people to adopt very bad beliefs. No one should hold these beliefs because they have little or no justification in the doxastic sense.

But if a Millian says that what needs to be preserved is personal justification, this cannot be accomplished with infallible philosopher kings. To see why, consider Barb. Barb has been brainwashed to believe $x$ and as part of the brainwashing, her programmers have included common objections and responses that would replicate the outcomes of the practices of justification. 
Doxastic justification is determined by reliable evidence. Since Barb’s programmers are philosopher-kings (and good programmers), Barb's opinions are doxastically justified. Barb holds beliefs that anyone who rationally looked at the evidence would be justified in holding. Personal justification however, is a normative evaluation of belief-forming. Since Barb's opinions are programmed rather than inferred, she lacks personal justification. We might praise Barb's programmers but would not praise Barb’s intellectual virtue.

Given Mill's description of the man "deserving of confidence in his opinion" if and only if he has engaged in the practices of justification, I think what Mill has in mind is personal justification. This seems borne out by a description of those who passively believe and do all the right things without any justification and asking the rhetorical question, "What will be his comparative worth as a human being?" (III,4). Barb does not have the virtues of justified believing because she has not acquired them by exercising the practices of justification.

Personal justification is evaluated in terms of epistemic praise or blame. As Engel puts it, "When we evaluate person S as being personally justified in believing $p$, we are evaluating S positively, and when we evaluate $\mathrm{S}$ as being personally unjustified in believing $p$, we are evaluating $\mathrm{S}$ negatively from the same point of view" (Engel, 139). This positive and negative evaluation is equated with praise and blame based practices of justification: "If a person comes to believe $p$ in an epistemically responsible manner (e.g. reasoning carefully, checking her work, considering defeaters, weighing evidence), she is worthy of epistemic praise and is, therefore personally justified in believing $p$ " (Ibid.)

Barb, however, does not come to believe her opinions in an epistemically responsible way. She is programmed. This is true even if the beliefs themselves are justified for Barb to believe. We can still evaluate her negatively in terms of personal justification while admitting that her opinions are doxastically justified. As such, the answer to the PK objection is that justification is a normative 
and personal activity. Justification cannot be manufactured by even infallible philosopher-kingsany more than any virtue can be acquired in the same way.

To sum up: Mill says that no one is deserving of confidence in his opinion unless he has subjected that opinion to the practices of justification — critical attention, critical adjustment, and critical exposition. The confidence in which Mill speaks is best understood as personal justification for one's opinions. This personal justification is constitutive of intellectual virtue which in turn is constitutive of human flourishing.

The justified opinion argument uses this conception of justification as the goal of the intellectual self-development argument. Because personal justification is constitutive of-rather than instrumental to-intellectual virtue, it cannot be suppressed in order to promote intellectual virtue. Furthermore, because the practices of justification are constitutive of personal justification, anything that would hinder the exercising of these practices undermines the acquiring of intellectual virtueand by extension human flourishing. We are now ready to consider the JOA in its entirety.

\subsection{Proposition 1}

The claim of Proposition 1 is the following: The ability to justify one's opinions and sentiments is partly constitutive of human flourishing because it is partly constitutive of intellectual virtue. Even though I have attempted to clarify what I mean by justification, this proposition practically bristles with other controversial questions, such as: 1) what does "opinions" mean in this context? 2) What does “intellectual virtue mean?”(And perhaps most controversial of all) 3) what does "flourishing" mean? In what follows, I respond to these objections by expounding on the meaning of these phrases and how they relate to each other.

\subsection{1 "Opinions"}

Having and forming justified opinions is important. These opinions include the ethical, the religious, and the political. But they also include what Mill refers to as the "business of life," which 
presumably includes the social, the scientific and the aesthetic (II, 28). In order to pick out the class of opinions relevant to public speech regulation in, we can carve out a nuanced distinction between “belief” and “opinion”. The Oxford English Dictionary lists "belief” as a synonym for "opinion." However, it is plausible to think of an "opinion" as a species of the genus "belief." On this definition, all opinions are beliefs but not all beliefs are opinions because opinions are the result of a process of weighing evidence under the burdens of judgment. ${ }^{64}$

Taking our cue from the OED, we can give a rough distinction between beliefs and opinions as follows: An opinion is a particular kind of belief which exhibits both of the following conditions: 1) The opinion is formed as a result of weighing some evidence and can be properly said to "be reached" rather than to simply be believed. 2) The judgment reached is only settled by inference from reasoning.

The belief that my son is crawling on the floor in front of me is not an opinion but it is a belief. Such a belief is not properly called an opinion because I do not "reach the conclusion" that my son is crawling, but I do believe he is crawling. Whereas the belief "Social security is vital for our country" is a belief but more properly an opinion because such beliefs are "concluded" or inferred from evidence. Examples of the type of beliefs referred to would include the following:

1) "Eating meat is immoral"

2) "There is good evidence God exists"

3) "Universal healthcare is a basic right."

These opinions satisfy both criteria. The belief is plausibly reached through deliberation, and disagreement about the belief can only be answered by inference from some evidence.

${ }^{64}[\mathrm{http}: / /$ dictionary.oed.com/cgi/entry/00332720?query_type=word\&queryword=Opinion\&first=1\&max_to_show=1 0\&sort_type $=$ alpha\&result_place $=1 \&$ search_id $=$ Xtn0-hALSOa-13011\&hilite $=00332720]$ (Accessed July 2009). The OED seems to recognize the differentiation in its definition between beliefs simplicter and a special kind of judgment or conclusion reached. The OED gives as its primary definition "a view held about a particular issue; a judgment formed or a conclusion reached; a belief; a religious or political conviction." 
One other distinction is important. Some beliefs are settled more on theory than observation. That my son is crawling in front of me is a belief. What the temperature on the surface of the sun is, is not a belief like the belief that my son is crawling in front of me. However, the temperature on the surface of the sun is in principle settled in the same way. If we could measure the temperature on the surface of the sun with accuracy, it would not be a theoretical opinion. However whether $9 / 11$ was a hoax cooked up by the government is a belief that can only be verified by inference and interpretation of evidence.

The beliefs I mentioned above in 1-3 are theoretical opinions that must be settled by inference and are subject to what Rawls called the burdens of judgment. ${ }^{65}$ They are also, I think, the judgments that Mill thought were subject to the practices of justification. With these clarifications in place, it is important to consider just what is meant by flourishing in Proposition 1.

\subsection{2 "Flourish"}

It is with the word "flourish" that the JOA gets its self-development pedigree. I take "flourishing" to be a life of human excellence developed through practices of virtue. The JOA is an intellectual development argument that takes the virtue of justified believing to be partly constitutive of human excellence. This Neo-Aristotelian understanding of self-development which I will call “Aristotelian Individual Perfectionism Model” (hereafter AIP) comes with some necessary assumptions about what makes a life good. ${ }^{66}$ Succinctly the AIP has five components. Human

\footnotetext{
65 John Rawls and Erin Kelly, Justice as Fairness : A Restatement (Cambridge, Mass.: Harvard University Press, 2001), 35-7. Rawls uses the term, "burdens of judgment" to account for how reasonable disagreement could occur given the same facts that are in need of interpretation. He offers three burdens that are relevant to justification of opinions and sentiments that will likely not be solved by appeal to some specific information. 1) The evidence may be conflicting and complex 2) Even if the evidence is agreed upon, people may still disagree about the weight such evidence has on the conclusion. 3) Any moral or political concept is subject to hard cases with a range of indeterminacy.

${ }^{66}$ Much of what follows is adapted from Douglas B. Rasmussen and Douglas J. Den Uyl, Norms of Liberty : A Perfectionist Basis for Non-Perfectionist Politics (University Park, Pa.: Pennsylvania State University Press, 2005), 127-42.
} 
flourishing is objective, differs between agents, is constitutive in nature, is self-directed, and is social. $^{67}$

1) Objective: Flourishing is to be desired because it is choice-worthy not only because it is desired or chosen.

Proposition 1 of the JOA argument assumes that there are objective standards of human flourishing. This means there are objectively good ways of life that are valuable for their own sakes. In this regard, Proposition 1 is a perfectionist proposition. Objective components of a good life are not valuable because of the pleasures they produce or the desires they satisfy. They are valuable because they are part of an objectively good life.

2) Flourishing differs between agents. Even though flourishing and its components are objective (in that they are necessary for any flourishing), the manner in which these components are instantiated will be different for different people.

To claim that flourishing differs between agents is to claim three things about the nature of flourishing. First, no two cases of flourishing are the same. The flourishing of Abby is not only different than the flourishing of Bob, but they are most definitely not interchangeable. ${ }^{68}$ Flourishing is individualized. As Rasmussen and Den Uyl put it, "It is only when the individual's particular talents, potentialities, and circumstances are jointly engaged that these goods and virtues become real or achieve determinacy"(133).

Second, that some virtue or practice results in the furthering of agents' flourishing is a moral reason to pursue regardless if pursuing it results in the flourishing of others or in better consequences for the world. ${ }^{69}$ There is no best life for all people that can be prescribed. Rather for each person there is a combination and working out of constituent goods that is only realized in a

\footnotetext{
${ }^{67}$ Rasmussen and Den Uyl do not use all of these terms. I have combined their term "individualized" with "agentrelative."

68 It may not be possible to aggregate flourishing because of this. For an argument that flourishing can be aggregated, see Thomas Hurka, Perfectionism, (Oxford: OUP, 1993), 69-82.

${ }^{69}$ Rasmussen and Den Uyl give a formal definition of agent-relativity as the following:

"Human flourishing $\mathrm{F}$ for a person $\mathrm{P}$ is agent-relative if and only if its distinctive presence in a world $\mathrm{W}_{1}$ is a basis for $\mathrm{P}$ ranking $\mathrm{W}_{1}$ over world $\mathrm{W}_{2}$ even though $\mathrm{F}$ may not be the basis for any other persons ranking $\mathrm{W}_{1}$ over $\mathrm{W}_{2}$. (135).
} 
specific person's life. Just as the diets of wrestlers differ in the amounts of protein but all wrestlers need protein, so the intellectual development of each person will differ but intellectual development is still an objective component of all human flourishing.

Third, while it is true that flourishing is individual, there is nonetheless a fact of the matter about what will be required for a specific individual to flourish and this fact is not dependent on individual desires. Furthermore, a particular person can be wrong about what makes him flourish and as a result he can fail to flourish.

3) Flourishing is constitutive in nature. Flourishing includes several constituent goods that are necessary but not sufficient without the others.

These goods are pursued for their own sake but also for the sake of flourishing. However, flourishing is not pursued for any further reason. The constitutive goods are those that are not merely a means to achieving the good of flourishing as if once we achieve flourishing, they are no longer needed. Rather they are properly expressions of flourishing in the way that first downs are expressions of playing a good football game. ${ }^{70}$

There is a great deal of ambiguity about the term "constitutive" in philosophy. In its simplest connotation, "constitutive" refers to the parts that consist of a whole. These constitutive parts can be necessary or unnecessary. A pirouette is constitutive of ballet but not necessary to some particular instantiation of ballet (i.e. one could have a ballet without a single pirouette.) However, a constitutive part could also be necessary for the whole. For instance, performing pirouettes is necessary for a performance of Swan Lake. Often this is the sense used for "constitutive" to distinguish some sine qua non of the whole from an unnecessary part. However, there is another connotation of "constitutive." The term can refer to the value of some part to a whole. This use of the term

\footnotetext{
70 There is some ambiguity in philosophy in defining "constitutive value" For some constitutive value can be described in negative terms. On this view, something is constitutive if it is neither sufficient nor merely instrumental. My claim is a bit stronger. In the JOA, if the practices of justification or constitutive of intellectual virtue and intellectual virtue is constitutive of flourishing, then the practices of justification are neither merely instrumental nor sufficient for intellectual virtue but the practices of justification are also intrinsically valuable in themselves and valuable as a part of intellectual virtue. See Ian Carter, "The Independent Value of Freedom," Ethics 105, no. 4 (07, 1995), 819.
} 
"constitutive" serves to distinguish constitutive from merely instrumental value. For instance, virtue can be properly said to be constitutive of flourishing for Aristotle. Virtue is not merely instrumental to flourishing; it is part of the activity of flourishing in much the same way as first downs are constitutive of a football game. One cannot be said to play football without first downs and one cannot be said to flourish, according to Aristotle without being virtuous.

In so far as the term is ambiguous, it will be necessary to pick out exactly what is meant by “constitutive of intellectual virtue." This will require some degree of stipulation not simply a clarification of its usage. In order to capture the various uses of the term, we can stipulate that x can be said to be constitutive of $y$ if and only if:

1) $x$ is insufficient for $y$

2) $x$ is a necessary part of $y$

3) $x$ is not merely instrumental to $y$

4) $y$ itself is not merely instrumental to anything else.

A mundane example may help here. A timing gun is merely instrumental to good engine timing on an automobile. It is neither necessary nor sufficient, and it is merely instrumental to the activity. Once the timing is set using the gun, it is no longer necessary for a well running car. However, timing itself is not only instrumental to a well running car but constitutive of proper engine performance. It just is part of a properly running engine. Without the element of proper timing the engine does not run well.

The components of flourishing are "constitutive of flourishing." Each one is necessary, insufficient by itself, not merely instrumental to flourishing, and flourishing itself is not merely instrumental to anything else. Thus virtue and reason are not means to flourishing but rather constitutive of flourishing. The goods of flourishing can be both internal and external. This is a 
contentious debate among accounts of flourishing. What all flourishing accounts agree on, however, is that the only way to flourish is by rational pursuit of virtue.

4) Flourishing is self-directed.

Each individual is responsible for her own flourishing. In the De Anima, Aristotle says that while perception is non-voluntary, a human being can exercise his knowledge when he wishes [417b18-26]. ${ }^{71}$ This seems to indicate that human flourishing because it requires the actualizing of rational desire over appetite is "a self-directed activity" 72 The acquisition of virtue is essentially an individual activity that requires a person to take responsibility for her own flourishing. As Rasmussen and Den Uyl put it, "Human flourishing consists in a person maintaining those virtues for which he alone is responsible and that in most cases allow him to attain the goods his life requires"(ibid.)

There is no substitute for this process. In fact, as Linda Zagzebski argues, bypassing the process of acquiring virtue through virtuous action is to destroy the notion of virtue. ${ }^{73}$ As an example, Zagzebski asks us to consider the transformation machine. The transformation machine is the lesser known thought-experiment by Robert Nozick. Like the experience machine, Nozick asks us to imagine a machine that can alter our very nature. Since the experience machine, according to Nozick, is undesirable because human beings want to do not just experience, he posits a transformation machine that "transforms us into whatever sort of person we'd like to be (compatible with our staying us)., ${ }^{, 74}$ Zagzebski rejects the idea of the transformation machine not because it is unacceptable but because it is conceptually impossible given the nature of virtue (118-

\footnotetext{
71 This translation is from (Rasmussen and Den Uyl, 138). Rasmussen and Den Uyl note that "wishes" refers to Aristotle's boulesis or rational desire not mere whim. The argument I make here about self-directedness and speech is heavily indebted to Rasmussen and Den Uyl's argument for self-directed human flourishing in Norms of Liberty.

72 ibid, 139

${ }^{73}$ Linda Trinkaus Zagzebski, Virtues of the Mind: An Inquiry into the Nature of Virtue and the Ethical Foundations of Knowledge (Cambridge ; New York, NY, USA: Cambridge University Press, 1996), $116 \mathrm{ff}$.

${ }^{74}$ Robert Nozick, Anarchy, State, and Utopia (New York: Basic Books, 1974), 44.
} 
9). ${ }^{75}$ The intuition is that moral character as part of our individual identity is intrinsically connected to interaction with the world. Character acquired "at the flip of a switch" is insufficient.

The choice to acquire virtue in this way is a single act and a single act is insufficient to warrant praise in the way that we normally praise a virtue acquired through habit. Even if the person that came out of the machine were a saint, as Robert Roberts notes we would hardly canonize him. Rather we might praise the machine's designer since it seems proper praise might be due the designer but in no sense is the recipient of the treatment due the praise worthy of virtue (Roberts, 235).

5) Flourishing is Social.

We have already hinted that the practices of justification and the ability to justify one's opinions and beliefs are socially situated. But this claim is stronger. Not only is it the case that the practices of justification are dependent on social interaction, so is flourishing. Contrary to the gloss on Aristotelian egoism, human flourishing cannot be accomplished apart from others. To paraphrase Aristotle, the one who can flourish outside of a community is either a god or an animal. ${ }^{76}$

The AIP is by no means unproblematic. If one rejects Neo-Aristotelian moral perfectionism outright in favor of a desire-satisfaction account of the human good, The JOA will not be compelling. Accepting Proposition 1, however does not commit one to a full-fledged moral perfectionism. It seems plausible that a person who lives her life without engaging in the practices of justification or only rarely is simply not flourishing as well as someone who does live a life marked by personal justification. To accept that the ability to justify is necessary for a person to live up to her potential as a human being is quite enough to accept Proposition 1.

${ }^{75}$ Robert Roberts in Robert B. Kruschwitz and Robert Campbell Roberts, The Virtues : Contemporary Essays on Moral Character (Belmont, Calif.: Wadsworth Pub. Co., 1987), 263., makes the same claim. "We can guess that it will never be possible to give a person a moral 'identity'--a tough abiding passion for justice or stable and focused desire to relieve suffering--by injecting him with a drug or giving him a brain operation or fiddling with his genes." (235).

76 Politics, 1253 a27-29. 
To those who would say that self-development is not objective or only depends on pleasures or desires, we can but point to the fact that any self-development argument would have to admit at least three of the AIP presuppositions since any self-development argument agrees that 1) selfdevelopment is good for all people (objective) 2) self-development is an individual enterprise (agent-relative) 3) self-development is an activity for which one is both morally responsible and choice-worthy (self-directed).

To reject any self-development argument for viewpoint neutrality by rejecting its major proposition is not to reject the argument but to reject a conception of self-development. It goes without saying then that this dissertation cannot defend the concept of self-development or the AIP itself — for that would be another dissertation in itself. ${ }^{77}$

In the literature of free speech and its criticism, the objections to the self-development argument for free speech are internal to the self-development process itself. Critics charge that selfdevelopment arguments are unsatisfactory because they are either over-inclusive, justifying all sorts of provisions and entitlements, or they are under-inclusive by privileging certain bourgeois virtues over other competing virtues like justice and equality. ${ }^{78}$ They also suffer from the instrumentalism worry. If self-development is the goal then it seems plausible that suppressing some opinions could result in more self-development for some people. The JOA argument is designed to answer these kinds of objections not objections to the value of self-development itself.

Granting that self-development and the AIP are not rejected out of hand, it will be important to clarify the Neo-Aristotelian concept of "flourishing" to address specific concerns about

\footnotetext{
${ }^{77}$ Many ordinary non-philosophers do live their lives as if something like Proposition 1 is true. We tend to think that people who live lives based on unjustified opinions are doing something blameworthy. There is a defect in their character. They simply don't do belief forming well. Either they must keep themselves sequestered from the outside world to avoid non-believers, or they must disengage from the debates in the public square that are important to any human being. Furthermore, those who do not disengage but express their opinions all the while refusing to listen to or adjust their opinions at all are blameworthy in their reasoning and their interaction with others. To the extent that their ability is within their control, we consider them blameworthy.

${ }^{78}$ See Chapter 2 for more of this argument.
} 
intellectual development and human flourishing. Any philosophical claim about human flourishing is subject to a particular kind of skeptical objection embodied in the following question: "Is it not quite plausible that people can live good enough lives for themselves without at the same time meeting the conditions of flourishing including intellectual virtue?" The implied answer is "Yes, there are all kinds of good lives in which people either do not possess the ability or don't use the ability to justify their opinions or sentiments."

This objection is not an objection to a self-development argument but rather an objection to the value of intellectual development to overall flourishing. For the interlocutor, saying that intellectual virtue is a necessary condition of human flourishing is extremely intellectualist. It would perhaps imply that the average person who lives his life without concern for rigorous intellectual pursuits does not flourish.

Proposition 1 is intellectualist in one sense. Proposition 1 assumes, in the Neo-Aristotelian tradition, that a good life is one of activity and that such activity consists partly of intellectual pursuits. Virtue includes intellectual virtue for which the capacity to justify one's beliefs is an epistemic virtue. And without it, one does not live a virtuous life according to reason.

This would mean that a person who lives her life without any development of her intellectual faculties would not be flourishing. However, like all virtues, the intellectual virtues differ across agents. Exercise is a necessary component of physical development; however, the amount of exercise varies with the individual. If one is a professional athlete, exercise is far more important than if one is an accountant. This means that the demands of intellectual development are not so extreme as to recommend that everyone must live the life of a philosopher to flourish but rather that without some care to develop intellectual virtues, one does not flourish.

However, this may still seem too extreme. Making intellectual virtue partly constitutive of flourishing is counter to most of western philosophy which sees intellectual virtues as distinct from 
moral virtues. Michael Stocker calls this the "purified view of the intellect." ${ }^{\text {,9 }}$ Counter to the intellectualist account of flourishing in the above paragraph, the purified view sees the development of the intellect as essentially an amoral pursuit and the moral virtues as distinct from the intellectual virtues. They are distinct in two ways: i) while some sort of moral virtue is necessary for flourishing, the purified view may deny that intellectual virtue is necessary for flourishing. ii) Virtues are also distinct in that one can develop one's intellectual virtues in isolation from one's moral virtues and (more tentatively) vice versa.

It is not necessary to take a position on the relationship with intellectual virtue, moral virtue, and flourishing. For instance, one would not have to agree with Zagzebski that intellectual virtues are best viewed as forms of moral virtue (139). It is enough to say that without some intellectual development which includes the practices of justification, one is hampered in living a life of virtue according to reason and thus does not meet the conditions of human flourishing within the AIP model.

An illustration will be helpful to see how intellectual virtues cannot be cleanly severed from moral virtue. Consider a typical situation in the public square-in this case the internet. Suppose that Oliver, a member of the North-American Man-Boy Love Association (NAMBLA), is the purveyor of a blog that routinely calls for the abolishing of age of consent laws in the US so that those so inclined can enjoy sex with minors. Oliver never suggests breaking the law, only that such laws are draconian. He peppers his site with statistics from various sources indicating that sex between adults and minors is in no way harmful and quite enjoyable for both adults and eight-year olds.

Sue comes upon Oliver's blog. She is initially repulsed by Oliver and thinks he and his ilk are intellectually irresponsible, wicked, or both. However, Sue wants to be personally justified in her opinion about Oliver and his opinion so she scans his arguments and sources. To see how Sue's

\footnotetext{
${ }^{79}$ Quoted in Zagzebski 139.
} 
intellectual virtue goes hand in hand with her moral virtue, consider this question. If Sue does not have some sort of appropriate visceral response to Oliver's spurious and potentially dangerous opinion, would we consider her flourishing according to the AIP? If not, then what would we expect to be a virtuous response for her to have towards Oliver's blog? It seems we would expect an appropriate moral judgment of Oliver and we would expect that judgment to be personally justified to Sue especially if the proper response is to make her judgment known to Oliver. Virtuous response requires both intellectual and moral virtue.

For instance, a virtuous response from Sue should be neither apathetic nor violent. If Oliver were standing in front of her, we would expect that a virtuous Sue would express some sort of judgment (e.g. Shame on you!) even if she thought Oliver could care less about her response to his opinion, but we would also expect her to refrain from expressing her displeasure with violence.

Ideally a virtuous judgment of Oliver would be more specific. We would want Sue to be able to express why Oliver is blameworthy and do so in a personally justified manner. However, to be justified in expressing her own opinion that Oliver is morally and intellectually bankrupt would require her to engage in the practices of justification and intellectual inquiry. Without exercising these intellectual virtues, Sue would be hampered in forming a justified opinion about Oliver. She may not be able to accurately assess whether Oliver is just intellectually irresponsible and led astray or someone who is perverse in his affections and seeks to harm children. She may confuse the argument for abolishing age of consent with the argument for abolishing certain statutory rape laws. She may form the unjustified association of gay men with pedophilia. The point is that we want Sue to be willing and able to express a justified moral judgment of Oliver, and she cannot do that properly without exercising her intellectual virtues. If one buys into Proposition 1, practices of justification are integral to the development of intellectual virtue. Without the ability to engage in the practices of justification, intellectual development is seriously compromised. 


\subsection{Proposition 2}

The claim of Proposition 2 is the following: If some opinions or sentiments are systematically censored by law a) the practice of justifying one's opinions and sentiments is compromised and b) the justification of specific opinions is weakened. A great deal rides on the phrase "systematically censored by law." Systematic censorship refers to legislation that outlaws the publishing, speaking, or discussion of a particular opinion and backs up this legislation with punishment. Proposition 2 does not directly relate to the social stigma of society that may have the effect of rendering some opinions anathema. This is a break from Mill who was as concerned about "tyranny of the majority" and "social stigma" as governmental censorship (I, 5).

The claim of Proposition 2 is that if some sentiments are systematically censored by the state; intellectual development suffers. This may be major when the very practices of justification are undermined, compromised, or made inaccessible. In other cases the hindrance may be minor as when a single opinion cannot be doxastically justified because counter-examples and counterevidence are suppressed.

To illustrate how the censoring of a viewpoint can affect justification, return to Sue and her encounter with Oliver's vicious blog. Would Sue’s intellectual development be seriously compromised if her practices of justification are hindered by a law banning Oliver's particular opinion?

It is important to understand what Proposition 2 is not claiming. To accept Proposition 2, one does not have to be committed to the proposition that Sue's own opinion of age of consent laws is compromised as soon as a law banning Oliver's opinion takes effect. Banning a single opinion or viewpoint does not immediately impair the practices of justification. However, something important is lost, and it is not just Sue's confidence that age of consent laws are moral. That 
particular justification may remain fairly stable. What may be undermined more quickly is her justification of the belief that those who believe such nonsense are irresponsible and blameworthy. Judgments that NAMBLA members are epistemically irresponsible are dependent on being able to assess beliefs in context and from the mouths of the proponents. This is even more clear when we move from an opinion that is arguably observational (e.g. "sex with children is harmful") to one that is more theoretical. The opinion that the Holocaust was exaggerated is currently banned in Germany. As with the previous examples, one specific opinion is banned. However this opinion is less observational and more theoretical. To refute Holocaust deniers one must rely on judgment, interpretation of historical data, and knowledge of the claims of both holocaust deniers and their critics. Therefore, to critically assess these kinds of beliefs and those that believe them requires access to the views as expressed by the proponents.

Suppose that Oliver's opinion—sex with minors is healthy, enjoyable for all parties, and should be legal—is banned by law. The virtue of justified believing, as I have described it, depends on critical attention, critical adjustment, and critical exposition. The JOA argument says that legislation that bans certain opinions or sentiments comes with costs to intellectual virtue. What is significant is that unlike the standard self-development argument, these costs are not leveled just against a speaker like Oliver but those who would respond to Oliver like Sue.

Once Oliver's opinion has been banned publicly by threat of fine or imprisonment, Sue’s opinion of NAMBLA supporters like Oliver may be limited to the sentiments of the mass of society which may or may not form justified opinions about Oliver's viewpoint. She may consider all NAMBLA supporters criminals. Furthermore, because of the ban, it is highly likely that her critical attention will not encounter arguments to the contrary.

Critical adjustment requires Sue to practice learning from even bad arguments and adjusting her criticisms accordingly. It is not enough to simply say, "People like Oliver are vicious and evil." 
She must be able to differentiate the claims of people like Oliver to see whether the proponents are evil or merely irresponsible and lacking in virtue. Because of the ban, Sue may not be able to make the distinctions between pedophiles, age of consent abolitionists, and those who oppose mandatory jail time for statutory rape convictions for other reasons. A legal ban has a way of ending discussions, not facilitating them.

Critical exposition requires Sue to practice expounding to herself and others the fallacy of what is fallacious. Once again it is important to make clear what Proposition 2 is not saying. It is not saying that legal censorship would entail banning the subject all together in order to undermine intellectual virtue. The ban on NAMBLA advocacy need not entail a ban on NAMBLA criticism in order to undermine Sue's intellectual development. Censorship makes the practice of critical exposition less immediate and it also makes it seem a waste of one's intellectual resources. Why should Sue spend time critiquing an opinion if society as a whole has deemed it anathema? This is especially true if she cannot test her convictions without risking investigation or even indictment for possessing literature expressing a banned opinion.

The ban on Oliver's opinion does have costs for Oliver. Because of the ban, he will never be able to subject his opinion to scrutiny outside of his own private circle because of fear of punishment. It is likely that he will never be confronted by the public ridicule his irresponsible beliefs deserve. He will not suffer the ridicule of a polite society that eschews ill-formed and vicious viewpoints and those who advocate them. Instead he will likely expound his views in an echo chamber of private meetings and clandestine chat rooms, never confronted with a single counterexample or counter-evidence. As Mill says, "It [censorship] maintains all prevailing opinions outwardly undisturbed ... the price paid for this sort of intellectual pacification, is the sacrifice of the entire moral courage of the human mind" (II, 19). 
Now, all of these losses will not likely be felt overnight. A ban on NAMBLA advocacy on one day does not abolish justified opinions about the character and beliefs of advocates of the abolition of age of consent laws. However, the next generation of citizens may well believe that NAMBLA and its opinions are awful and dangerous but it is likely they will not be able to draw upon much evidence to support this vague judgment. Sue's grandchildren may well hold a doxastically justified opinion that Oliver is blameworthy, but according to the JOA it is likely they will not be personally justified in holding that opinion because they will not be able to assess Oliver's opinion for itself.

The costs to intellectual development cannot be neatly severed from the costs of moral development. If dispositions to act on rational sentiments are acquired through response to the actions of others, Sue's grandchildren may not have the disposition to respond to the unique repugnance that comes from Oliver's opinion. Feeling disgust at the shameful opinions of others expressing that moral judgment in the appropriate way and at the appropriate time is an important exercise of moral virtue and without it, something important is missing. When the content of a particular point of view is banned from public expression, the occasions to shame someone for its expression in public is seriously diminished.

Proper attribution of blame to someone's character requires being able to distinguish between several different shades of irresponsibility. Are the Holocaust deniers duped by bad history, or are they wicked and racist? The proper judgment entails being able to make these fine-grained distinctions. Without the honest debate about age of consent laws and sexual mores, Sue's grandchildren may not be able to distinguish those who are misguided or sympathizers who respond to deliberation about evidence if confronted, from those who are wicked and dangerous. In effect, the partially converted, who are open to testing their assumptions, would never be tested. Instead they would be lumped in with the wicked and the base. 
To sum up: Proposition 2 follows from the importance of the practices of justification. Personal justification, as I have described it, depends on critical attention, critical adjustment, and critical exposition. All three of these practices are undermined by censorship. This process is surely not immediate but, given the importance of the practices of justification for intellectual virtue, it is a foreseeable one.

\subsection{Proposition 3}

The claim of Proposition 3 is the following: If some opinions or sentiments are systematically censored by law, a constituent of flourishing will be compromised. Proposition 3 is the first inference of the JOA argument. If the best life possible includes the practices of justification for all but the most trivial opinions, then systematic suppression or censorship by law compromises one aspect of the pursuit of self-development.

If one accepts Propositions 1 and 2, then there is a strong reason to protect viewpoint neutrality. The value of allowing any viewpoint to be voiced, published, or expressed is the intellectual self development of individuals so that they can flourish. This is a special justification for the viewpoint neutral principle mentioned in Chapter 1. But does this new self-development argument escape the problems of the traditional self-development argument? Furthermore, does it avoid the general problems faced by the standard justifications for freedom of expression?

The answer is yes. It will be necessary to argue that the inference from Proposition 1-3 articulated here does not fall prey to the general problems with justifications for free speech or the specific problems of the self-development justification for free speech. First it will be shown that the inference is an improvement on the standard self-development argument. Second, we will consider the instrumentalism worry. 
Recall that the main criticism internal to the traditional self-development argument was that it either proved too much or too little. Larry Alexander gives a good summary of the dilemma facing self-development or virtue theories:

They are radically overinclusive. Tolerance can be cultivated by forcing people to endure, say insulting speech, or offensive speech; permitting speech that incites crime, ruins reputations, infringes on intellectual property rights, deceives ... These theories are also radically underinclusive ... for tolerance and other virtues can be cultivated equally well by forcing people to tolerate really loud noises, slaps to the face ... ${ }^{80}$

Since Alexander is attempting to deal with a whole class of virtue theories including ones involving tolerance, it will be important to specify what exactly is involved with the claim of "overinclusive" and "underinclusive" in Alexander's criticism in order to apply it to Propositions 1-3 of the JOA.

The charge of "overinclusive" indicates that the virtues freedom of expression is designed to foster, would allow for a great deal of speech that is traditionally not classed as protected speech. If freedom of expression is valuable as a means to developing tolerance or some other general liberal virtue, then why stop at opinions and sentiments? After all, we can learn to tolerate many things if necessary including criminal solicitation, the Anarchists Cookbook with its recipes for explosives, etc.

At the core of Alexander's critique is the idea that "evaluative neutrality" is at the heart of any putative right to freedom of expression. That is, a right to freedom of expression is the right to have one's opinions and sentiments regarded as just as good morally as anyone else's opinions and sentiments for the purposes of promotion or prohibition. If this is the case, then it is going to be very difficult to justify prohibiting incitement, criminal solicitation, etc., because they are opinions and sentiments. To prohibit them because they are dangerous is to make an evaluative judgment.

Notice however, that the JOA does not assume evaluative neutrality. In fact Proposition 1 assumes the value of human flourishing as objective. People can be wrong about their flourishing. However, because the JOA appeals to the value not of tolerance (which is vague to begin with) but

80 Alexander, Is there a Right of Freedom of Expression? 132-3. 
the conditions for the virtue of justified believing, it is not the case that all speech is protected including criminal solicitation and incitement. While both of these are speech acts, they are not purely opinion or sentiment. They fall into the category of "the other things we do with words" including threats, promises etc. These other speech acts are not necessary to form justified beliefs. Therefore, if we begin with the non-neutral value of intellectual development we can draw a relatively sharp line between opinion and incitement, solicitation, harassment etc. This is because what is being protected is not merely the right to express but the virtue of justified belief for audience, speaker, and bystanders.

The charge of "under inclusive" to which Alexander appeals, argues that if freedom of speech is supposed to provide a means to some virtue like liberal tolerance or intellectual development then this same value of development should require providing other means to development including travel, a personal library, or other intellectual enhancements. Alexander presents a reductio ad absurdum. If it can be shown that intellectual development is the reason for free speech then why stop at restraint? Why not provide other intellectual enhancements that would ultimately be unfeasible as a right?

This would be a compelling problem if "intellectual flourishing" or "virtue" was a vague notion. However, the point of the AIP was that flourishing is objective but very different for different individuals. This is never more the case than with the practices of justification. Justified believing, especially about the opinions of others, is not something that can be provided apart from some general instruction in the methods and values of justification which hopefully is part of general education. Furthermore, intellectual development is not guaranteed by providing travel, a library, etc. In fact, without experience in the practices of justification these provisions may simply be wasted as a means to intellectual virtue. Furthermore, because intellectual virtue, as constitutive of flourishing, differs radically with different agents, the immediate conditions and "goods" needed would make it 
very difficult to provide. The very nature of intellectual development, as the AIP conceives it, suggests that the most any collective measure could do to promote flourishing is to prohibit censorship.

The Justified Opinion Argument is not over-inclusive since it picks out a specific value for individual flourishing that requires access to opinions and sentiments rather than simply allowing all expression. Neither is it under-inclusive because the value promoted is one that is clearly identifiable. Furthermore, the flourishing JOA presupposes is so individualistic as to preclude the reduction to costly provision of other goods that may or may not contribute to intellectual virtue.

This leaves one further concern. Does the JOA argument escape the instrumentalism worry? Recall the structure of the instrumentalism worry from Chapter 2:

1) If viewpoint neutrality is only a means to some valuable end.

2) The valuable end can be promoted or protected by suppressing some viewpoint(s)

3) It is reasonable to suppress such viewpoints to preserve the valuable end.

4) This provides good reason to make an exception to viewpoint neutrality

More simply, if $x$ is instrumentally valuable to $y$ and $y$ can be promoted or protected better by censoring $x$, there is no good reason not to censor $x$.

Within the JOA argument there are several values that must be examined to see if they can escape the instrumentalism worry. There is the value of practices of justification for intellectual virtue. There is also the value of intellectual virtue to human flourishing. Finally there is the value of human flourishing itself. Since intellectual virtue and flourishing are standards of the selfdevelopment argument and the practices of justification are a new element to that argument, let me first deal with the value of intellectual virtue and human flourishing.

It should be clear by now that human flourishing is not a means to anything else. Flourishing is the sumum bonum of the AIP. The good life for human beings just is flourishing. Therefore I think 
it clear that human flourishing as a value does not suffer from the instrumentalism worry.

Intellectual virtue also escapes the instrumentalism worry because it does not fit the first condition. Intellectual virtue is not only a means to flourishing. It is constitutive of flourishing.

The JOA argues for a very specific activity that is necessary but not sufficient for intellectual development and virtue. Are the practices of justification and the state of having justified opinions merely instrumental to intellectual development? It would seem they are not. The practices of justification and justified believing are not a means to intellectual virtue. They are partly constitutive of intellectual development. They are a necessary but not sufficient activity that constitutes intellectual development. However, the practices of justification are not terminal. In order to maintain intellectual development one must continue to practice justified opinion formation. Thus, they are not merely instrumental.

However, even if someone were to accept that intellectual virtue is constitutive of human flourishing but think the practices of justification are only instrumentally valuable and have no value apart from intellectual development, the practices of justification will still avoid the instrumentalism worry. While it does seem that the practices of justification are valuable in themselves, it does not seem that the value of justified believing is important enough to override other values like truth, safety, etc. As a result, it is plausible to say that the value of justified opinions and the practices of justification are only valuable as means to intellectual virtue.

Even if the practices of justification were only valuable as a means to intellectual virtue, Propositions 1-3 would still escape the instrumentalism worry. Even if these practices and the beliefs that come from them are only valuable as a means to intellectual virtue, it is impossible to censor or suppress these practices in order to better promote intellectual virtue or human flourishing. Because of the peculiar nature of the practices of justification, one cannot suppress some opinions or sentiments in order to better promote justified believing. As the example of Oliver and Sue 
illustrates, the activity justifying one's opinions, especially of the opinions of others, suffers when even misleading, false, and pernicious opinions are censored. If this is correct, the practices of justification escape the instrumentalism worry because there is no way to promote intellectual virtue better by prohibiting the access to any opinion or sentiment without undermining the practices of justification.

\section{Conclusion}

In this chapter I have presented the first part of an argument for viewpoint neutrality. Since this argument appeals to the value of justified opinions as a reason to prohibit censorship of opinions and sentiments by law, I refer to it as the Justified Opinion Argument for Viewpoint Neutrality or the JOA. The practices of justification are a specific constituent of human flourishing. The JOA combines a Neo-Aristotelian account of flourishing with the Neo-Millian value of justified believing. Chapter 4 extends this argument to the realm of public policy where the value of the practices of justification and the damage wrought by censorship give good reason for the state to adopt a policy of viewpoint neutrality. 


\section{CHAPTER 4 \\ THE PRACTICES OF JUSTIFICATION AND STATE ACTION}

The last chapter made a case for the value of the practices of justification in regard to human flourishing. The practices of justification are constitutive of intellectual development and overall flourishing. Systematic censorship compromises the practices of justification and undermines the justification of specific opinions or sentiments and judgments about the character of those who hold such opinions. In short, if the practices of justification are undermined, human flourishing suffers.

This is a thesis about the nature of human flourishing. It says nothing about the relationship between the practices of justification and legitimate actions by the state.

Propositions 4-7 attempt to connect the above stated conclusion about human flourishing to political morality. The conclusion of Propositions 1-3 gives the state good reason to refrain from censorship and to adopt or maintain the viewpoint neutral principle discussed in Chapter 1. For convenience and clarity, let me reproduce the JOA as a point of reference.

\section{The Justified Opinion Argument for Viewpoint Neutrality (JOA)}

1) The ability to justify one's opinions and sentiments is partly constitutive of human flourishing because it is constitutive of intellectual virtue.

2) If some opinions or sentiments are systematically censored by law a) the ability to justify one's opinions and sentiments is compromised and b) the justification of specific opinions is undermined.

3) If some opinions or sentiments are systematically censored by law, a necessary constituent of flourishing will be compromised.

4) The state should not hinder people from the pursuit of their own flourishing provided it is compatible with the flourishing of others.

5) The state should prevent legislation that systematically censors any opinions or sentiments.

6) Developed states have the institutions to prevent systematic censorship of opinions. (Underdeveloped states or governments in a temporary state of emergency may not have the means to prevent censorship of opinions.) 
7) Adopting the viewpoint neutral principle is the best way for developed states to prevent legislation that would systematically censor some opinions or sentiments by law.

8) All other things being equal, developed states should adopt (or maintain) the viewpoint neutral principle.

In the last chapter I made my case for Propositions 1-3. Propositions 4-8 give a reason for the state to adopt a policy of viewpoint neutrality. This chapter will proceed along the same lines as Chapter 3. After some preliminary distinctions, a case will be made for (47) and for the policy implications contained in 8.

\subsection{Prolegomena}

Perhaps the best way to begin a case for Propositions 4-7 is to get clear on what is meant by "state action." Because the JOA argues for a disqualifying principle for legislation it will be important to define state action and more importantly the difference between state, government, and society.

It seems intuitive that states are not merely governments. Governments can change without a change of state. Public institutions such as public universities, public libraries, etc. are not properly thought of as government but they are part of the state. The state is also not the society. The state is a particular kind of political organization that includes a government but also public corporations, public universities, and central banks.

A major characteristic common to all states is the relationship between state, government, and law. Raz distinguished the terms "state" and "government." The state is a political organization; the government is the agent through which the state acts. The law is the vehicle through which the state exercises its power on individuals within its sphere. ${ }^{81}$ This distinction can be summed up into a working definition of the state.

\footnotetext{
${ }^{81}$ Joseph Raz, The Morality of Freedom (Oxford Oxfordshire; New York: Clarendon Press; Oxford University Press, 1986), 70.
} 
A state is a political organization that acts by way of an established government and implements its will via a set of formal rules and laws.

Therefore when speaking of a "state" and its reasons, this chapter refers to any political organization that uses a government to formally enact its will through the use of law. For the purposes of the JOA, "society" will serve as that which designates individuals, families, and voluntary civil associations apart from state and government. The JOA does not apply to these civil associations. This is a Millian sort of move. Mill speaks of the disapprobation of society apart from the censorship of the state, and while he is concerned about the tyranny of the majority, he does make a distinction between the evils of state censorship and the tyranny that comes from societies received opinions (II, 44). ${ }^{82}$

Granting this definition of the state, what should be the relationship between the state and human flourishing sketched in Chapter 3? The nature of the proper relationship between the state and the human good is a perennial source of controversy in political philosophy. Many contemporary political philosophers argue that state action should be neutral in some respect to the good for human beings. According to this neutralist thesis, the primary role of the state is not the good for human beings but rather what is right according to some conception of justice. This conception may vary from fairness in the case of Rawls to rights of self-ownership in the case of Nozick. ${ }^{83}$

A recent move in political philosophy, however, is to question the neutrality thesis. The neutrality thesis has been soundly criticized and some political philosophers find it untenable as a guide to public policy. ${ }^{84}$ Often anyone who advocates the impossibility of the neutrality thesis is labeled a perfectionist. George Sher defines the perfectionist thesis as

\footnotetext{
82 Examples of societal censorship would include shunning and excommunication by religious communities.

${ }^{83}$ For Rawls Rawls and Kelly, Justice as Fairness: A Restatement, 214 . For Nozick see Nozick, Anarchy, State, and Utopia, 367 This is not to be confused with the more general debate about the reasons for adopting state neutrality which could be either neutral or non-neutral.

${ }^{84}$ See Steven Wall and George and Klosko, eds., Perfectionism and Neutrality (Lanham: Rowan and Littlefield, 2003), 290.
} 
follows: "Governments may legitimately use their powers, including their formidable power to coerce, to promote activities and traits that are good ..."85 As Sher defines it, the perfectionist thesis is a claim about legitimate reasons for government action. This is true of the neutrality thesis as well. We can use the following as working definitions of the perfectionist and neutralist theses in order to show how the JOA argument fits into this debate.

Perfectionism: As a matter of political morality, states should take an active role in creating and maintaining social conditions that best enable each citizen to lead valuable and worthwhile lives of a specific sort.

Neutralism: As a matter of political morality, states should be neutral in their policies toward the human good.

With respect to Perfectionism and Neutralism what follows from the NeoAristotelian Individual Perfectionism implied in Propositions 1-3? This is an important question considering that the viewpoint neutral principle that is the ultimate goal of the Justified Opinion Argument is a kind of neutral principle for free speech. Yet, as we saw in Chapter 3, the value of personal justification inherent in Propositions 1-3 is decidedly nonneutral.

It would seem then that if a state were to act on the value of personal justification as a good for human beings, this would be at odds with some conceptions of Neutralism. The neo-Aristotelian perfectionist model I presented in 3.3 says that there are objective facts about the requirements of flourishing and that people can get these wrong. Neutralism, however says just because justified believing is partly constitutive of flourishing, is not a legitimate reason for the state to act.

${ }^{85}$ George Sher, "Freedom of Expression in the Non-Neutral State" in George Klosko and Steven Wall, Perfectionism and Neutrality: Essays in Liberal Theory (Lanham, Md.: Rowman \& Littlefield Publishers, 2003), 220. 
The eventual adoption of the viewpoint neutral principle, however, might be at odds with Perfectionism's pursuit of the good. After all, restricting certain viewpoints may be the best and most efficient way to ensure that good ideas prevail and bad ideas (i.e. ideas that undermine flourishing) do not gain a foothold in society. ${ }^{86}$ To put it another way, if Perfectionism argues that the state should promote human flourishing and the JOA clearly says there are objective facts about what flourishing requires, there is no reason in principle for the state to rule out censorship since many viewpoints will discourage virtue and selfdevelopment.

The JOA and the viewpoint neutral principle do not fit easily with either thesis. Let me take each of these challenges in turn in order to see how the JOA and the viewpoint neutral principle are neutralist in one way and perfectionist in another.

\subsection{JOA and Neutralism}

To understand how the propositions of the JOA argument relates to Neutralism crucial distinctions need to be made as to what is meant by "neutral" The important question to ask in considering the neutrality thesis is, "Neutral with regards to what?"

The first distinction to be made is between levels of neutrality and "neutral stances" the state can take. Neutrality when applied to state action can be implemented on several levels. Charles Larmore distinguishes between first-level and second-level neutrality. ${ }^{87}$ First level neutrality is a neutrality of procedure. State action must not give priority to any one conception of the good. It must instead treat all conceptions of the good the same. Second level neutrality is a comprehensive reason for first level neutrality that is itself based on neutral justification that does not rely on any controversial form of the good life.

\footnotetext{
86 See George, Making Men Moral, $192 \mathrm{ff}$.

87 Wall and and Klosko, Perfectionism and Neutrality, 290; ibid.
} 
It is quite possible to have first-level neutrality without second level neutrality. In fact, Larmore insists that Mill's neutral stance with regard to diversity and individuality is not based on second-level neutrality between conceptions of the good. ${ }^{88}$ It is rather because some lives are better than others but experience must decide what those are, that Mill adopts a first-level neutrality of procedure. Larmore, however, argues that first-level neutrality is not enough (ibid). To be liberal, a state must adopt a neutral justification for its political neutrality.

This can be accomplished in one of two ways. There could be a plurality of argumentative paths that would lead to political neutrality. Larmore opts for a free floating neutral justification based on a modus vivendi between rational agents. For the most part, this chapter will focus on first-level neutrality. It will become clear, however, why the JOA rejects second-level neutrality in the course of the argument. There are at least four "neutral stances" the state can take towards flourishing: neutrality of effect, neutrality of justification, moral neutrality, and legislative neutrality. ${ }^{89}$

\subsection{1 "Neutrality of effect"}

The state can be neutral with regard to controversial policies and institutions that would lead one religion, political ideology, or group of people to have an advantage over otherwise equal citizens. As Steven Wall puts it, "Policies and institutions which are subject to reasonable disagreement should not receive political support. Citizens should just take them off the agenda."

${ }^{88}$ Charles Larmore, The Morals of Modernity (Cambridge: Cambridge University Press, 1996)., 127-8.

${ }^{89}$ With the exception of "legislative neutrality,"these distinctions between neutral stances that Steve Wall calls "ideas of restraint" are largely taken from Wall, Liberalism, Perfectionism and Restraint, 31-2. 


\subsection{2 "Neutrality of Justification"}

The state could be neutral in regard to the justifications appealed to for state action. On this conception, the state should not appeal to controversial values as a justification for particular state actions. While the first neutrality is neutrality of political effect, the second form of neutrality says that the state should only appeal to neutral (reasonable, agreed upon, or non-controversial) justifications for its policies and laws.

Both neutrality of effect and neutrality of justification are controversial. However, it is reasonable to rule out neutrality of effect. Any legislation will end up favoring some ways of life over others. To think the state could refrain from any action that has the consequence of helping some ways of life fare better than others, seems overreaching. This is especially the case with policies toward expression. Viewpoint neutral policies will have the effect of making some opinions and proponents fare better than others. For instance, if the state passes a law that says "No pamphleteering in airports" a law that is neutral between viewpoints, the expression of certain religious groups for whom proselytizing is a religious practice or who rely on pamphlets to get out their message will cause these groups to fare worse than those who find no reason to pass out pamphlets in airports.

Neutrality of justification (or justificatory neutrality) involves justifications for state action. According to justificatory neutrality, the state cannot have as its reason for legislation a controversial value for which there is reasonable disagreement. For instance, justificatory neutrality would restrict the state from passing a law subsidizing crèches on courthouse lawns because the justification would be to promote controversial sectarian views about which there is reasonable disagreement. 


\subsection{3 "Evaluative/Moral Neutrality"}

The state should act as if it is agnostic about the values of its citizens. The state should abstain from taking any moral stance on the actions of its citizens. Any legislation regarding individual or group actions must be done in a way that is neutral between moral stances.

This neutrality was briefly mentioned in 3.3 and attributed to Larry Alexander. While Alexander calls this "evaluative neutrality", it seems clearer to call it moral neutrality since the values in question are almost certainly moral values. Alexander says that evaluative neutrality is at the heart of any state support of freedom of expression. He identifies this neutral stance with Liberalism. Alexander says that almost everyone agrees that any law that only protects expression that is unobjectionable is not really free speech. However, this produces a paradox. It is worth quoting Alexander at length to understand what he calls the paradox of liberalism and freedom of expression:

Any moral theory will deem certain states of affairs to be desirable and demanding of legal promotion, and certain interests to be demanding of legal protection from acts that threaten those interests. But both the media of expression and the messages conveyed may cause undesirable states of affairs and threaten protectable interests (per the moral theory in question); and conversely, suppression of expression by reference to its content or its media may cause desirable states of affairs and safeguard protectable interests (per that moral theory). Therefore government cannot permit the harmful expression without contravening the moral theory, which means, in turn, that the moral theory cannot demand protection of harmful expression without generating a paradox. ${ }^{90}$

An example of this paradox was mentioned in Chapter 2. States committed to a moral theory that places high value on individual autonomy must, on pain of inconsistency, censor expression that undermines autonomy. Alexander makes this case very strongly

...Evaluative neutrality cannot coexist with any normative theory. Any normative theory, liberal or not, will perforce take positions on what ought to be done ... To the extent that expression through its message ... threatens to produce states of

\footnotetext{
90 Alexander, Is there a Right of Freedom of Expression?, 177.
} 
affairs inconsistent with those the normative theory prescribes, to that extent the normative theory must... rule the expression to be pernicious and of negative value (177).

Alexander's moral neutrality paradox presents a tension between the spirit of freedom of expression and substantive moral theory. If freedom of expression is anything substantive, it must be freedom to express the worst ideas, but the state must be neutral with regard to the moral value of any idea or message. In essence the state must legislate as if "no idea is above the pale" morally. However, this moral neutrality will inevitably be at odds with any substantive moral theory a government must adopt. Any moral theory will have some message or medium that will threaten the outcomes deemed valuable by the moral theory in question. No moral theory can consistently support "no idea is above the pale."

There are two problems with Alexander's argument. First, the evaluative neutrality that he attributes to Rawls and Thomas Nagel is a substantive moral theory. Rawls and Nagel both have moral reasons for adopting justificatory neutrality. It is at best misleading to think that neutrality cannot issue from a substantive moral theory such as Rawls or Nagel's.

Second, the moral neutrality of "no idea is above the pale" does not necessarily cancel out every substantive moral theory. To say the state will act as if "no idea is above the pale" does not have to be at odds with any substantive moral theory such as the NeoAristotelian moral theory in 3.1. The fact that ideas, messages, and media can undermine those moral values the JOA proponent finds valuable (e.g. human flourishing) is a reason for censorship. However, the JOA proponent cannot advocate any legislation that will undermine flourishing in an effort to promote flourishing. Since there is not a way to censor that does not frustrate the practices of justification, censorship cannot be a means to promote flourishing. Contra Alexander, this restraint on the part of the state is not morally 
neutral. The state can be committed to a substantive moral theory for its justification of firstlevel neutrality.

The state does not have to refrain from making claims about the moral value of the messages in question as if it is "blind" to its own moral theory. Instead, because the dissemination of some hateful, dangerous, and useless messages undermines flourishing (if believed) the state has a duty to use means consistent with its own moral theory to discourage the belief in such messages.

If the state in question holds a Neo-Aristotelian individual perfectionism as in 3.1, there is good reason to persuade others to reject those messages. Mill refers to this when he claims that if the state and its citizens want to protect themselves from the dangers of Mormon polygamy, "Let them send missionaries, if they please, to preach against it; and let them, by any fair means (of which silencing the teachers [of Mormonism] is not one) oppose the progress of similar doctrines among their own people" (IV, 21)

It should be clear by now that the JOA rejects both justificatory and moral neutrality. However, it does so for different reasons. The JOA denies moral neutrality because the state has an obligation to promote a certain value. It is committed to a moral theory of individual perfectionism. The value of intellectual development and human flourishing is the reason the state should refrain from censorship. The fact that this conception of flourishing is controversial or would not be agreed upon is not a sufficient reason for the state to be neutral with regards to flourishing. Furthermore, because the practices of justification are constitutive of intellectual development, there is no way to promote the practices of justification by censoring bad opinions or even opinions at odds with the presupposed moral view of the state. 
As for justificatory neutrality, the JOA rejects this as well because it is inconsistent with the objective property of flourishing. If the parts of flourishing are objective, people can get them wrong. If the state has an obligation to promote flourishing, then it cannot accept justificatory neutrality. This political perfectionist inference means the state does not have to remain neutral in its justification. This does not mean it cannot have a very good reason to be neutral in its legislation—specifically the regulation of opinions and sentiments. All of this leads to a fourth kind of neutrality that describes the neutrality implied by the JOA.

\subsection{4 "Legislative Neutrality"}

The state can be non-neutral in its justification and still adopt a neutral policy in its actions. This neutral stance is not a neutrality of effect but rather neutrality in what qualifies as a legitimate regulation which may interfere with each individual's conception of the good. On this conception of neutrality, the state can remain neutral between viewpoints in its actions, eschewing censorship, without adopting justificatory neutrality.

There is one further distinction. This kind of state neutrality only refers to legislation not persuasion. The only requirement is that the state refrains from censorship. This means that it is consistent with legislative neutrality that the state promotes its own opinions in a non-neutral way provided it refrains from censorship. For instance it would be compatible with legislative neutrality (but not necessarily entailed by it) that the state sponsor public service announcements that promote certain opinions as being the right ones just as long as there was no punishment for those expressing contrary opinions. ${ }^{91}$

\footnotetext{
91 One further possibility: legislative neutrality, strictly speaking, only rules out censorship that silences opinions or significantly reduces their accessibility. If the state wanted to discourage with censoring, it could, in principle, tax pernicious opinions provided this did not lead to complete censorship. Practically, however, good public policy would almost certainly rule out the kind of censorship that merely taxes, but does not silence, opinions because of the strong incentive to tax views that are critical of the status quo.
} 
It goes without saying that there may be principled and prudential reasons why the state may not want to take a stand on non-political opinions or refrain from acting as a partisan speaker in the public square—not the least of which might be worries about intellectual virtue. After all, the bully pulpit of the state might induce some to simply adopt the state's values apart from their own practices of justification.

It should be clear from the above discussion that the JOA only allows legislative neutrality. Because of its perfectionist reasons at the second level of justification, the JOA cannot admit any of the other types of neutrality.

\subsection{The JOA and Perfectionism}

When we turn from Neutralism to Perfectionism, in some ways it is easier to reconcile the JOA to Perfectionism than it is to reconcile it with Neutralism. Perfectionism says: "As a matter of political morality, states should take an active role in creating and maintaining social conditions that best enable their citizens to lead valuable and worthwhile lives" (Wall, 8). This is a decidedly non-neutral principle. Perfectionism says that if we can know what is good for human flourishing, the state is not barred and may indeed be obligated to create and maintain conditions for flourishing. Just what this obligation entails will be discussed in detail in Proposition 4. However, there is nothing inconsistent about a neutral stance between viewpoints and the promotion of a non-neutral values like intellectual development.

The JOA argues for a meta-law, a law about laws that ex ante disqualifies any legislation that systematically censors opinions or sentiments on the basis of their viewpoint. The viewpoint neutral principle excludes only those state actions that punish, criminalize, or use prior restraint to censor some viewpoint. Any law that regulates expression must adhere to this meta-principle in order to satisfy the obligations of political morality. Furthermore, 
this does not require the state to treat all viewpoints as on a par morally. It only requires the state to be legislatively neutral. This means the state can attempt to persuade its citizens of the immorality of some viewpoint as a participant in the social discourse. With all of this in mind, we can now move on to the specific inferences that come with legislative neutrality.

\subsection{Proposition 4}

Proposition 4 says, "The state should not binder people from the pursuit of their own flourishing provided it is compatible with the flourishing of others." Propositions 1-3 argue that practices of justification are necessary for flourishing. The practices of justification require unhindered access to viewpoints whether they are true or false, benign or repugnant. Proposition 4 indicates that because of the importance of human flourishing, states at the very least should not hinder the pursuit of flourishing. There is a compatibility restraint on state action provided the individual pursuits of flourishing do not directly hindering the flourishing of others. However, because the JOA assumes that there are objective components of flourishing that are also partly constitutively necessary, as 3.1 explained, there is a problem of compatibility for states that seek to promote, protect, or affect flourishing by their actions. ${ }^{92}$

The incompatibility of constitutively necessary components of flourishing presents a particular difficulty. If these constituents are incompossible, it will be necessary for the state to decide which constituents it will protect or promote in order to promote flourishing. However, since each constituent is necessary, the state's actions could hinder other constituents in important ways. This compossibility objection can be summarized in the following way:

The Compossibility Objection:

\footnotetext{
92 For a discussion about the apparent conflict between constituents of flourishing for a single individual (e.g.
} conflict between intellectual and moral flourishing) see 3.2. 
Some constituents of intellectual self-development are likely to be incompossible among citizens. The intellectual self-development of some will conflict with the flourishing of others. If the state promotes flourishing, it will be forced to trade the flourishing of some for the flourishing of others and this is at odds with the notion of flourishing.

This presents a dilemma: either the JOA must admit trade-offs of the constituents of flourishing and weaken the concept of flourishing or the JOA must give up the idea of promoting flourishing. This conflict can be sharpened in two different ways:

1) Individual flourishing can conflict between the same constituent of flourishing (e.g. between the intellectual flourishing of A and the intellectual flourishing of B)

2) Individual flourishing can conflict between different constituents of flourishing (e.g. conflict between the intellectual flourishing A and other constituents of B's flourishing.

I will take each of these in turn and argue that neither formulation is a reason to reject the JOA and its promotion of flourishing.

Let us start with a straightforward example of 1). Suppose in order for Arnold to reach his full intellectual potential he should have a teaching job at a university. Jobs being a scarce resource, ensuring that Arnold reaches his full potential might mean Bing will end up without a teaching job at a university which might also help his intellectual flourishing but not as much as Arnold.

A more interesting case is one where the constituents of flourishing for each person, Arnold or Bing, may conflict. Recall that while intellectual virtue is an objective constituent of flourishing — it is a fact that everyone needs intellectual virtue to flourish - 3.1 also said that the amount of practice that is needed to develop intellectual virtue differs between individuals.

It is an objective fact that wrestlers need protein to be good wrestlers, but the amount of protein will differ for different wrestlers. Likewise, it is an objective fact that all 
individuals need intellectual virtue to flourish, but the practice needed to develop this virtue will differ for different persons. This opens the possibility that the practices and justified opinions Arnold needs to develop intellectually may drastically differ from that needed for Bing.

There are two different ways the state could promote flourishing-one strong and one weak. ${ }^{93}$ Assume the state in question acts out of the assumptions of some form of human flourishing. The strong way that the state could take an active role is to see its role as one of creating as many eudemons as possible. Thus every citizen should be provided with whatever is necessary to make each citizen capable of pursuing endaimonia. This is often referred to as the capability approach. ${ }^{94}$

However, the state does not necessarily have to embrace this strong conception of its role. Instead, it is consistent with the individualized nature of endaimonia to instead promote and maintain the background conditions of eudaimonia. On this conception, the role of the state is to ensure flourishing is possible within the state and that none of its legislation hinders access to the constituents of flourishing included intellectual development. The state could even go further and subsidize certain aspects of intellectual development (public libraries, incentives for the arts, etc.). Nothing in the perfectionist role precludes such provisions but at the same time, nothing in the Justified Opinion Argument requires this kind of intervention. Indeed, there may be many reasons why proponents of the JOA could recommend a policy against subsidizing flourishing activities.

\footnotetext{
93 See Daniel C. Russel, “Two Conceptions of Eudaimonistic Politics” forthcoming in Social Philosophy and Policy.

94 See Martha Nussbaum, "Human Rights and Human Capabilities," Harvard Human Rights Journal 20 (2007), 21.
} 
We can sum up the choice for state action as a choice between what Fred Dycus Miller calls "mutual advantage" and an "overall advantage.","

Mutual advantage: The state should strive to help each individual flourish.

Overall advantage: The state should strive to help as many members as possible flourish.

As Miller argues, the overall advantage choice permits trade-offs between the flourishing of Arnold and Bing. The mutual advantage choice, however, requires that the state protect the means for both Arnold and Bing to flourish even if this means that the foreseeable effect will be that Bing will not flourish as much as Arnold.

Is there any reason to prefer mutual advantage as opposed to overall advantage? There is if we consider the nature of state action. The state generally executes the will of the political organization through law. There is a tension between the relative permanence of law and the individualized nature of flourishing. Whatever the state does will affect the flourishing of some more than others. This means that legislation will never be able to adapt perfectly to the individualized nature of flourishing. How then can the state promote flourishing without engaging in trade-offs between different types of individuals? Put another way, why privilege intellectual development over other goods?

Before answering this, we must also consider 2) above. What if the apparent tradeoff is between the intellectual development of some and the overall flourishing of others? This is a far more serious case. It seems intuitive that if the choice is between intellectual development and several other constitutively necessary components, then why privilege the intellectual as the JOA seems to do?

\footnotetext{
${ }^{95}$ Fred Dycus Miller, "Virtue, Rights, and Justice in Aristotle's Best Regime," in Virtues and Values: Aristotelianism in Contemporary Ethics, ed. Timothy Chappel (Oxford: Clarendon Press, 2006), 82.
} 
Consider the case of Alan, Barbara, and George. Alan is a racist. He thinks minorities are inferior to whites intellectually and morally. Alan blogs about "mud people" and laments the dilution of the white race. Like Oliver, the NAMBLA supporter in the last chapter, Alan's opinions are egregious and Alan is blameworthy for holding them. We could plausibly say that Alan does not flourish because of his vicious irrational hatred. From Propositions 13, we concluded that if Alan's opinion were systematically censored, Barbara's opinion about people like Alan would be personally unjustified and perhaps if enough opinions similar to Alan's were censored, Barbara's practices of justification (and by extension her intellectual development) could be compromised.

If the state allows "a thousand opinions to bloom" in order to enable anyone, including Barbara, to pursue intellectual development—as the mutual advantage strategy would do-other people will have to tolerate Alan's vicious opinions. What the compossibility objection highlights is the idea that a third party, George, will have to suffer Alan's pernicious views for the sake of Barbara's intellectual virtue. George also needs to be justified in his opinions as well and, prima facie, should decry any state censorship.

But now suppose there is something about Alan's racist ramblings that does not just disgust George but genuinely causes him psychic trauma. This might be because George (or a close family member) is a minority or because George has been the victim of a racially motivated crime. Alan's racist vitriol causes George to relive those horrible events. In fact, if George knew that Alan was somewhere in his home town, George could experience a great deal of fear. The point is that George's own flourishing could be undermined by encountering racist messages like Alan's during the course of his life. 
Susan Brison refers to the undermining of the flourishing of minorities due to state tolerance of hate speech. ${ }^{96}$ Being exposed to speech that does not just offend but causes emotional distress, or degradation could undermine flourishing if such speech were encountered throughout one's life. ${ }^{97}$

If the state allows "a thousand opinions to bloom" this will likely mean that people like Allan will get their messages to the public and such messages may be the means to the intellectual development of someone like Barbara at the expense of the flourishing of someone like George. If the state adopts the overall advantage strategy where the state tries to ensure the flourishing of the greatest number of people, it looks like it would be far better to trade Barbara's intellectual development for George's overall flourishing because the intellectual development of Barbara through justified opinion forming is likely incompossible with George's sense of safety. However, if the state adopts the mutual advantage strategy, where it tries to ensure the conditions for each individual to flourish, the state should not trade Barbara's pursuit of justified opinions in order to prevent George's fear even if this has the regrettable side effect of deterring George's flourishing overall.

There are two questions involved in this dilemma. The first is whether or not George's flourishing is threatened? Second, what if anything could and should the state do to prevent the threat?

For George, it is the confrontation with ideas that seem threatening and harmful to his flourishing. ${ }^{98}$ According to the Neo-Aristotelian Individual Perfectionist model, there are

\footnotetext{
96 Brison, Autonomy Defense of Free Speech, 366-8.

${ }^{97}$ In other words one would have to be exposed more than once to undermine flourishing. To paraphrase Aristotle, one brief moment of degradation does not undermine flourishing anymore than one moment of happiness makes for a happy life.

98 There is yet another possibility where the conflict is not with different components of flourishing but with the threshold of opinions necessary for intellectual development which will vary across agents. Compare the flourishing Alice, a budding professional philosopher, and Eddie, a professional mechanic. Both need to develop their intellect, yet Alice's requirements will be quite different from Eddie's. What happens if the state
} 
many different components of flourishing, including the intellectual and moral. A perennial

\author{
debate in virtue theory is how much fortuitous circumstance and external goods (goods
}

external to the agent) are necessary for flourishing. The incompossibility objection above

\begin{abstract}
"lets a thousand opinions bloom" as Proposition Four indicates and this enhances Alice but the din of a thousand opinions actually discourages Eddie or frustrates him from pursuing his intellectual development? Eddie does not need all that intellectual stimulation to meet his intellectual needs. A little will do. Does this force the perfectionist state to trade Alice's flourishing for Eddie's? For Eddie, a world full of opinions becomes a din. If the state lets a thousand opinions bloom to protect intellectual development, nonintellectuals like Eddie may give up and ignore their intellectual development all together, but to attempt to privilege non-intellectuals like Eddie and promote overall flourishing, the state would have to find some threshold of public expression that would satisfy non-intellectuals. Besides the aforementioned knowledge problem response, there are three other rejoinders to this version of the compossibility objection.

First, what this objection may reveal is that the AIP model of individual perfection as I have described is unavoidably intellectualist. The objection may force the proponent of the argument to admit that Eddie's intellectual capacity is not as fixed as the example gives. In other words, it may be that viewpoint neutrality only creates a din for Eddie if he gives up on the objective good of justifying his beliefs. If the state sacrifices some of Alice's justification by restricting the level of discourse, relying on Alice to find alternatives; Eddie may be spared the din, but this surrenders the intellectualist bent of the AIP. Allowing a thousand opinions to bloom may force Eddie to devise ways to cope with the din. For instance he may rely on proxies (experts) the reliability for which he has independent justification. Whatever his mechanism, the state may force Eddie to do this because the state believes that anyone can accommodate the mutual advantage of viewpoint neutrality because no one has a fixed threshold. Unfortunately an argument for this would be beyond the scope of this dissertation.
\end{abstract}

Second, this objection is not so much a specific flaw in the JOA but rather a more general difficulty for political perfectionism. To see why, replace "justified believing" as the conflicting part of the good life with "autonomy." Using a "maxmin" strategy for autonomy reveals the same problem. If the state adopts a form of political perfectionism that says autonomy is constitutive of the good life along with other goods, then there will be cases where the mutual advantage strategy which seeks to promote the good life by protecting the conditions of autonomy will conflict with the good life for all. For some too much autonomy will undermine their flourishing. Others will require a great deal of governmental restraint to exercise their autonomy. This response does not parry the objection, but it does blunt its force. To the extent that my argument entails political perfectionism, it is infected with this more general problem. If it turns out there is no good solution to this perfectionist problem, then the JOA suffers. However, it is beyond the scope of this dissertation to address the difficulty for political perfectionism as a whole.

Third, this objection reveals a tension between the definition of "constitutive," as I have rendered it, and promotion of flourishing. Trading off components of flourishing between necessary, insufficient and noninstrumental parts of a whole seems to deny the special nature of these components as constituents of flourishing. Promoting flourishing by maximizing one constituent will almost inevitably require trade-offs. In other words, there is a tension between constituent value indicative of a neo-Aristotelian approach and the promotion of neo-Aristotelian flourishing. It very well may not be possible to reconcile these two aspects of state action in principle. One solution is to abandon the AIP account in favor of some other account of flourishing that does not involve this reliance on a definition of "constitutive" where some components of flourishing can be traded for others. However, such a view will not likely produce a less slippery slope than the one above. Any restriction on state action based on flourishing will have difficulty drawing a line between content that enhances or undermines flourishing. Thus, there is always the worry that such tampering will do more harm than good to the promotion of flourishing. Another solution is to take this incompossibilty as a sign that any virtue justification for flourishing is hopelessly flawed. However, if this is true, the alternatives seem to be the previous four justifications presented in Chapter two which will not generate an adequate special justification for viewpoint neutrality. Given all of this, it is reasonable to trade the overall for the mutual advantage strategy and set up an $e x$ ante principle that will in the long run mitigate the slippery slope even if the foreseeable consequence is the sacrifice of the flourishing of some for the flourishing of others. 
implies that something important is lost for those unfortunate enough to be minorities in a world that allows racist speech.

What is at stake is George's ability to shield his psyche from racist messages that harm him in the public square. If George is constantly exposed to racist speech throughout his life, a considerable amount of his time, energy, and thought will be channeled into coming to terms with racism. If this struggle is significant enough or if George fears for his life as a result of his trauma, his plight might be analogous to Joseph Raz's example of the hounded woman:

A person finds herself on a small desert island. She shares the island with a fierce carnivorous animal which perpetually hunts her. Her mental stamina, her intellectual ingenuity, her willpower and her physical resources are taxed to their limits by her struggle to remain alive (Raz, 374).

Comparing George, the victim of racism, with the hounded woman may seem hyperbolic

but there is good reason to think that if the state allows racist speech, it will produce circumstances where individuals are afraid, degraded etc.

This could plausibly have the effect of frustrating the goods of flourishing. Consider

Joel Feinberg's list of interests that if violated seriously undermine the pursuit of a good life:

The interests in continuance for a foreseeable interval of one's life, and the interests in one's own physical health and vigor, the integrity and normal functioning of one's body, the absence of absorbing pain and suffering or grotesque disfigurement, minimal intellectual acuity, emotional stability, the absence of groundless anxieties and resentments, the capacity to engage normally in social intercourse and to enjoy and maintain friendships, at least minimal income and financial security, a tolerable social and physical environment, and a certain amount of freedom from interference and coercion. ${ }^{99}$

Susan Brison points to the likely effects of minorities like George being confronted by either face-to-face racial degradation or a hostile environment of racial hatred. Victims of these conditions experience a violation of some of the interests mentioned by Feinberg

${ }^{99}$ Joel Feinberg, The Moral Limits of the Criminal Law, Vol. vol. 1, "Harm to Others" (New York: Oxford University Press, 1984), 37. 
including emotional stability and the capacity to engage in social intercourse (Brison, 338).

Mari Matsuda gives anecdotal evidence that allowing hate speech could lead to greater disruptions:

The constitutional commitment to equality and the promise to abolish the badges and incidents of slavery are emptied of meaning when target-group members must alter their behavior, change their choice of neighborhood, leave their jobs, and warn their children off the streets because of hate group activity. ${ }^{100}$

By Matsuda's lights, if George is forced to cope with racist speech like Alan's, he may very well resemble Raz's hounded woman and, as such, may not flourish.

The bite of Matsuda's objection concerns the foreseeable consequences of the mutual advantage strategy. If the state restricts its action to those things that will be mutually advantageous it will do so with the foreseeable consequence that some individuals may not flourish as well as others. If this is the case, then the mutual advantage strategy does seem to trade the flourishing of some for the flourishing of others even if that is not its aim. What is the difference between trading the flourishing of some for others by way of maximizing the number of flourishing people and trading the flourishing of some for others by setting in place a viewpoint neutral policy that is almost certain to result in making it more difficult for some to flourish more than others?

If the state adopts the over-all advantage strategy, it will be necessary to pick and choose which opinions are detrimental to maximizing flourishing. Beyond the knowledge problem where the state must determine which opinions will maximize flourishing across agents, there is a worry about a slippery slope. If racist speech is outlawed to protect people like George who have been traumatized, assuming the state can draw a fairly bright line between racist opinions that traumatize and those that are merely offensive; there is the

\footnotetext{
100 Mari J. Matsuda, Words that Wound: Critical Race Theory, Assaultive Speech, and the First Amendment (Boulder,
} Colorado: Westview Press, 1993), 48. 
further worry about the justification for restricting censorship to just racist content. Why not sexist content, proselytizing, and satire?

Proponents of hate-speech regulation, like Matsuda, may object that my response is only a version of the traditional slippery slope argument against censorship. However, the standard slippery slope argument against censorship is recognized even by their most vehement objectors to viewpoint neutrality. Matsuda recognizes the force of the standard slippery slope:

If we outlaw the $\mathrm{Ku}$ Klux Klan as an organization repugnant to democratic values, then we can outlaw the Communist party for the same reasons. Admitting one exception will lead to another, and yet another, until those in power are free to stifle opposition in the name of protecting democratic ideals (33).

But to see how the choice between mutual advantage and overall advantage presents a different and perhaps more treacherous slope, let me differentiate the standard slippery slope argument from the slippery slope that emerges when one accepts the inference from intellectual virtue to flourishing argued for in Propositions 1-3 in the JOA. The Standard Slippery Slope Argument against Censorship has the following form:

Censorship should never be a policy of the state because it is very difficult to set up criteria for censorship that excludes hard cases. Allowing the state to pick and choose what is objectionable or harmful will result in arbitrary distinctions that could stifle important opinions and sentiments.

Matsuda recognizes the force of this objection because she attempts to describe racist opinions as a sui generis category that would not easily bleed into other kinds of speech. Furthermore, she says a law that prohibits racist speech actually would maximize more liberty for the most number of people. ${ }^{101}$ Obviously such a law would run afoul of the viewpoint neutrality principle which would disqualify any such law that silenced any sentiment or opinion.

\footnotetext{
101 Matsuda, 38. “. . . Explicit content-based rejection of narrowly defined racist speech is more protective of civil liberties than the competing -interest tests or the likely-to-incite violence tests that can spill over to censor forms of political speech."
} 
Matsuda's challenge to the JOA seems to be the following: If the concern is about causing less harm in the long run, why tie the hands of the government with a law prohibiting viewpoint specific censorship? Why not instead adopt a policy of sorting out those opinions that certainly harm a large number of people and censor piecemeal?

However, if the state adopts the overall advantage strategy to promote flourishing, then the concern over a slippery slope is an even greater threat. If the goal is promoting flourishing, then the slippery slope from racist to obscene to repugnant is actually "slipperier" than the standard slippery slope worry over separating innocuous but offensive from pernicious content. If Matsuda recognizes the force of the slippery slope argument, as she does by arguing for a sui generis account of racist speech, then a fortiori the slippery slope argument in my response should engender greater concern. If the incompossibility objection assumes the importance of flourishing, it will be very difficult or impossible to argue that racist speech is a sui generis category that does not entail censorship of other expression that undermine flourishing such as sexist, homophobic, religiously offensive speech.

On the one hand, if the state instantiates the mutual advantage strategy in order to protect the background conditions of flourishing, the foreseeable consequence is that some people will fare better than others. On the other hand, if the state attempts to isolate certain kinds of speech on the grounds that it undermines the flourishing of individuals, then there is a real possibility that the state could end up censoring a great deal of speech and seriously compromise the flourishing of many in its efforts to promote the most flourishing.

If the state adopts the mutual advantage strategy, an ex ante rule that prohibits any viewpoint specific censorship will, in the long run, enable as many people as possible to flourish rather than if the state were to attempt to identify certain exemptions to its speech policy as they occur and risk a slippery slope. 
Furthermore, if the state does adopt the over-all strategy and censors Allan's racist speech to keep George from being hounded, there is a serious cost to people like George. Because George does not hear Allan's racist arguments, George may not be personally justified in condemning Allan's deplorable character. George may not develop the right reaction to such useless tripe. George's children could be even less justified than George himself.

One of the most striking implications of the JOA is that censorship undermines the practices of virtue and by extension the flourishing of both the perpetrators and the victims of pernicious messages. This provides a reason for setting the base line for speech regulation as "letting a thousand opinions bloom" in the first place. While censorship undermines a necessary element of flourishing both for speakers and victims of bad speech, by contrast, allowing the bad speech hinders the flourishing of its victims only. It does not make it impossible for them to flourish. For this reason, we should set the baseline at laissez-faire and judge mutual advantage with respect to it. The consequences of the bad speech for the victims then could be addressed in the other ways previously mentioned in 4.1 that do not require censorship.

Given all of this, how does Proposition 4 fare? The potential for a very slippery slope and the difficulty with aggregating and legislating to maximize the number of eudemons, as the overall advantage strategy would do, are both good reasons to accept Proposition 4 and its commitment to the mutual advantage strategy. It does seem better than the alternatives. One strategy for the dilemma would be to modify the definition of the term "constitutive" from 3.1. However, this definition was adopted in order to capture the Aristotelian conceptions of intellectual and moral virtue and their relation to eudaimonia. Changing one of these 
constituents would mean abandoning the Neo-Aristotelian character of JOA's virtue argument for viewpoint neutrality.

Alternately one could abandon the promotion of flourishing as a suitable justification of a viewpoint neutral principle. In essence this alternative would throw out the best specific kind of virtue argument and leave us with Alexander's concerns about vague appeals to virtue and tolerance which are both under inclusive and over inclusive at the same time.

In the end, Proposition 4 may be the most difficult proposition to accept because it would require many people to tolerate harmful speech in their pursuit of the good life. It would require the state to tie its own hands to protect the victims of hate speech in order to prevent harms to the flourishing of victims and perpetrators.

This is no small concession. However, adopting Proposition 4 does not tie the hands of the state in the ways that the robust forms of Neutralism mentioned in 4.2 would do. Legislative neutrality allows the state to combat hate speech robustly precisely because it does not have to remain neutral in its evaluation of the perpetrators of hate speech. The state is free to be polemical in its moral assessment of perpetrators and discourage their speech in many ways. The state could nullify the appeal of hate expression by public education or by encouraging that moral blame to be heaped on those who engage in it. The state could also lessen the occasions under which people like George are confronted with hate speech by regulating time, place, and manner. The point is that adopting the neutrality of state action as conceived in Proposition 4 creates new options that can remedy the impact of hate speech without undermining intellectual virtue.

\subsection{Proposition 5}

Proposition 5 states, "The state should prevent legislation that systematically censors any

opinions or sentiments." Like Proposition 3, Proposition 5 is the result of an inference from 3-4. 
In order to promote the practices of justification as a way of protecting human flourishing, the state is obligated to set up a requirement of all legislation that could interfere with access to opinions and sentiments. In effect Proposition 5 sets up a meta-law-a law about lawsor a disqualifying principle for state legislation regarding expression.

It is important to explain what Proposition 5 does not disqualify. Proposition 5 does not require the state to refrain from regulating freedom of expression. Proposition 5 would allow so-called second-tier regulation of time, place and manner. Proposition 5 also does not require the state to prevent de facto censorship where a society finds some opinion so awful as to effectively tune out the message by avoidance, ridicule, or shunning those who express pernicious messages. This is an important point because arguably Mill was as concerned if not more concerned about the "tyranny of the majority" as he was with the tyranny of legislation. Proposition 5 requires only that no one may prevent the expression of any opinion or sentiment. In essence the speaker has the liberty to express his opinion but has no right to a particular audience. Individuals are free to ignore, avoid, respond in kind, or listen.

\subsection{Proposition 6}

Proposition 6 states: "Developed States have the institutions to prevent systematic censorship of opinions." A reasonable and accepted principle of morality is that "Ought implies can." The weight of a moral ought in some important way rests on the ability to carry out the obligation. The inclusion of Proposition 6 limits the JOA to developed states capable of instituting and protecting viewpoint neutrality.

If one accepts Propositions 1-5, they require a particular kind of legislation. The state would have to put a restriction on any of its laws in order to promote the conditions of flourishing to the mutual advantage of all citizens. In the previous section it was argued that 
this promotion would require the state to adopt an ex ante principle of viewpoint neutrality to avoid the slippery slope, among other things. If this move is plausible, then it will help us limit permutations of the state that would be able to consistently enforce the viewpoint neutral principle. In what follows we will see that the JOA applies only to states that meet two criteria: 1) The state must recognize the viewpoint neutral principle as a limit on its authority. This is a minimal version of the rule of law. 2) The state must have a system of checks and balances to guard against both executive abuse and popular pressure which threaten a viewpoint neutral principle.

The JOA concerns developed states. There may be other reasons that non-developed states have to prevent censorship, but the argument presented here does not apply to them. Once conditions 1) and 2) are met however, the viewpoint neutral principle becomes a matter of political morality. This implies that states that lack these conditions are less developed than states that do have these conditions.

Notice the distinction is not about government. Even pre-modern societies might carry out their will through a governing body that pronounces laws. The definition given at 4.1 implies that even primitive societies could be characterized as a state. However, what separates developed states from those less developed is the presence of certain institutions that make it possible to implement and maintain a stable political principle like viewpoint neutrality.

Tribal societies, loose knit confederations, and states in temporary upheaval may have overriding reasons to postpone adopting (or maintaining) a principle of viewpoint neutrality. However, the conditions mentioned above are not merely customs. This is the reason the JOA is couched in terms of political morality. Developed states that have the means to implement these conditions should do so. States capable of recognizing a rule of 
law and checks and balances that do not adopt viewpoint neutrality undermine the

flourishing of individuals and communities. To this extent such states are blameworthy.

Once again we find the impetus for these conditions in Mill. In "On Civilization"

Mill draws a sharp line between primitive societies and what he deems "civilization." Mill

does not think that those outside of civilization have either the same obligations or the same expectations as civilized societies. Setting aside the baggage that comes with Euro centrism and terms like "civilization," we should examine the dividing line between developed states that have the institutions to implement the viewpoint neutral principle and those that do not.

Despotism is a legitimate mode of government in dealing with barbarians, provided the end be their improvement, and the means justified by actually effecting that end. Liberty, as a principle, has no application to any state of things anterior to the time when mankind have become capable of being improved by free and equal discussion. Until then, there is nothing for them but implicit obedience to an Akbar or a Charlemagne, if they are so fortunate as to find one $(I, 10)$.

What separates primitive societies from developed societies is the ability to engage in and respect free and equal discussion. Developed states value and engage in political discourse as a feature of their social interaction. Mill goes on to say that developed states use political discourse as the primary way to solve conflicts.

We accordingly call a people civilized, where the arrangements of society, for protecting the persons and property of its members, are sufficiently perfect to maintain peace among them; i.e. to induce the bulk of the community to rely for their security mainly upon social arrangements, and renounce for the most part, and in ordinary circumstances, the vindication of their interests (whether in the way of aggression or of defence) by their individual strength or courage.

Mill divides developed and non-developed states around their "arrangements of society." It seems reasonable to substitute political institutions for Mill's "arrangements of society." As Douglass North says, "Institutions are the rules of the game in a society or, more formally, 
are the humanly devised constraints that shape human interaction." 102 According to Mill, the end of these institutions is peace, which is described in terms of the attitudes and practices of its citizens. First the citizens rely on social arrangements to keep the peace. Second, they renounce the right to vindicate their interests by their own power.

The key is that these arrangements of society are deeply respected by the citizens and government, and they are relatively stable over time. As we have seen in previous chapters, the viewpoint neutral principle is both counterintuitive and costly to society. Therefore, the arrangement of society wherein individuals settle differences by free and equal discussion is one that requires a viewpoint neutral principle.

The arrangement of society that marks off regimes that rely on discussion rather than force to improve social circumstances includes the rule of law. Put simply, rule of law means that the law serves as a restriction on governmental power, and this is recognized by those in government. It might be objected that introducing the institution of the rule of law, limits the scope of the JOA to liberal states because the rule of law is seen as a means to protect the individual from the state. It is true that Liberalism has relied on the rule of law as a driving principle. However, there is no reason to think the addition of this institution as I have described it requires a liberal state:

...There is nothing inherently individualist or liberal about this form of the rule of law. It will protect the integrity of the community from government interference or oppression, if that is the prevailing orientation, just as it will protect the individual from the same, if that is the prevailing orientation, and it will protect both in situations of pluralism. ${ }^{103}$

\footnotetext{
102 Douglass Cecil North, Institutions, Institutional Change, and Economic Performance (Cambridge ; New York: Cambridge University Press, 1990), 3.

103 Brian Z. Tamanaha, “The Rule of Law for Everyone," St. John's Legal Studies Research Paper, 27. [Available at SSRN: http://ssrn.com/abstract=312622 or DOI: 10.2139/ssrn.312622. ] Tamanaha differentiates a pre-liberal and a liberal justification for rule of law but denies that the actual institution is wedded to liberalism.
} 
The rule of law need not be a liberal institution. This is because the rule of law, as an arrangement of society, is both negative and formal. It restrains government action relative to law and has no specific ideology behind it. As Raz puts it, "[the rule of law] says nothing about how the law is to be made: by tyrants, democratic majorities, or any other way. It says nothing about fundamental rights, about equality, or justice.”104

Essentially the rule of law as an institution is an arrangement of society whereby individuals and groups are subject to stable rules which they can rely on in order to plan their lives, projects, and pursuits. The rule of law negates the uncertainty that accompanies arbitrary use of state power. It is the recognition by citizens that the laws derived from some codified principles circumscribe government action. Mill's arrangements of society should cause people to rely on them for security and as a substitute for their own private enforcement of their interests.

The other institution necessary to promote viewpoint neutrality is a system of checks and balances between the executive, legislative, and judicial branches of the state. There are two reasons for this institution of checks and balances. First, the legislature should be prevented from violating the principle under popular pressure. This is important to meet Mill's criteria for the arrangements of society to ensure that individuals do not vindicate their own interests in silencing pernicious speech.

Second, there must also be an institution that checks the executive body from silencing speech on the basis of its content especially when that content is critical of the executive body itself. This is the familiar concept in liberal traditions that free speech is necessary to prevent executive impunity.

\footnotetext{
${ }^{104}$ Joseph Raz, "The Rule of Law and Its Virtue," in Joseph Raz, The Authority of Law : Essays on Law and Morality (Oxford; New York: Clarendon Press; Oxford University Press, 1979), 214.
} 
It will be helpful to elucidate the role of these institutions with an example. Suppose we can isolate a society that, by Mill's lights, is undeveloped. Veltopia as it is called operates in a loose confederation of tribes. They have established primary rules against theft, unprovoked violence etc. There is a confederation council which assigns punishment and retribution for crimes. A separate council handles intertribal conflict.

Veltopia is a non-developed, pre-legal state. As such, there is no issue of political morality that requires Veltopia to protect viewpoints within the society through a viewpoint neutral restraint on state action. This does not mean that Veltopia does not have obligations to the flourishing of its citizens. It is not politically obligated to make viewpoint neutrality viable because it lacks the necessary institutions. If "Ought implies can", Veltopia, at present, cannot. Veltopia has greater reason to convince its confederation to establish infrastructure, a national identity, and peace between tribes. Until Veltopia reaches the point where the improvement of Veltopian society can be accomplished by free and equal discussion, then Veltopia is not obligated to promote intellectual virtue among its citizens.

However, once Veltopia is relatively stable as an entity and its society is capable of being improved by free and equal discussion, it has the duty to restrain itself with social arrangements that will promote flourishing among its members. This means instituting a viewpoint neutral principle to ensure the conditions of intellectual virtue are available to all regardless of their class or economic circumstances. In order to make this arrangement one that individuals and groups can rely on to plan their pursuits, viewpoint neutrality will have to be supported by a state that recognizes both the rule of law and checks on its own power. In this way, the viewpoint neutral principle would serve as one of the boundaries of government action. The government must act within the restraint of its laws including the provision against viewpoint specific censorship. 


\subsection{Proposition 7}

Proposition 7 states: "Adopting the viewpoint neutral principle is the best way for developed states to prevent legislation that would systematically censor some opinions or sentiments by law." Proposition 7 is inference from 4-6. Proposition 6 establishes which institutions are necessary to prevent systematic censorship. Proposition 7 concretizes viewpoint neutrality into a principle that can be enshrined in the institutions of developed states.

The viewpoint neutrality in Proposition 4 is obligatory for developed states according to the JOA. The wording of viewpoint neutral principle is a rendering of an ex ante principle that incorporates legislative neutrality explained in 4.1. By best way, is simply meant the best of all alternative ways of preventing systematic censorship of opinions and sentiments. In what follows I will lay out the viewpoint neutral principle and then argue that given Propositions 1-6, the viewpoint neutral principle is the best instantiation of viewpoint neutrality.

Assuming the class of states is restricted to developed states, the viewpoint neutral principle is stated as the following:

In order to foster and maintain buman flourishing, as a matter of public morality, any public institution is disqualified from intentionally aiming to binder the expression of any viewpoint by suppression except for purposes of temporary censorship to prevent clear and present danger.

As with all the controversial premises in the JOA, several terms need to be clarified.

\subsection{1. "Public morality...public institutions"}

4.1 discussed what is meant by political morality. Raz defines political morality as the morality that governs political action" (Raz, 3). There is a debate about whether or not political morality can be derived from individual morality or whether political morality is 
made up of an independent class of moral principles that apply primarily to government. ${ }^{105}$ We side step this debate by using the term "public morality." Whatever the relationship between political and individual morality, this much seems clear: there are moral principles relevant to public situations that do not govern private situations between individuals. The viewpoint neutral principle is concerned with the public square where everyone has a prima facie right to access and no one has a prima facie right to exclude others (See 1.2).

As a matter of public morality, the viewpoint neutral principle would not govern private interactions within one's own home nor does it apply to corporate interaction within the work place. It certainly will be the case that access to opinions and sentiments can be severely curtailed within corporate communities. However the viewpoint neutral principle would be concerned with government action and not the action of individuals, civil associations, or private corporations per se except in so far as any of these would infringe on access to opinions within the public square. As explained in 4.1, "public institutions" refers to government institutions as well as public libraries, community centers, and public areas where anyone has the prima facie right of access.

\subsection{2. "Intentionally aiming to binder..."}

The viewpoint neutral principle is concerned with the intentional aims of the government. If any legislative body has the goal of suppressing opinions rather than persuading citizens to abandon some opinions, this violates the political morality that seeks to promote flourishing. The viewpoint neutral principle would rule out attempts to hinder any viewpoint by means of suppression or censorship. As I explained in 4.1 this does not restrict the state from hindering opinions it considers repugnant, vicious, etc by means other

105 See Raz 4ff. for discussion of this debate. 
than censorship. These means could include counter-speech, public service announcements, etc.

\subsection{3. "Temporary censorship"}

The viewpoint neutral principle has an exception clause. There may be cases where temporary censorship is needed in times of war or to prevent societal collapse. In other words, the JOA does not advocate viewpoint neutrality though the heavens fall. However, any censorship directly undermines intellectual virtue and as such is prima facie bad. Once the clear, present, and immediate danger has passed, the state should re-instate the viewpoint neutral principle. The familiar "clear and present danger" language of first amendment jurisprudence is invoked only as a rough-and-ready criterion for catastrophic situations where viewpoints may be temporarily suspended. Catastrophe of the societal upheaval variety is a necessary condition for temporarily suspending the viewpoint neutral principle but it may not be sufficient. There may be good reason to remain neutral between viewpoints because of intellectual virtue, and instead censor subject matter in public. For instance, instead of fining or imprisoning dissenters in time of war, it may be better to outlaw all public demonstrations. It may be less harmful to relegate these practices temporarily to the private sphere than to undermine viewpoint neutrality because the practices of justification are necessary for flourishing.

Now that the terms of the viewpoint neutral principle have been clarified, Proposition 7 indicates that this principle is the best way to instantiate viewpoint neutrality. It is the best of all the alternatives.

Recall the science fiction analogy from 1.2. If everyone had personal force-fields that could screen out offensive and harmful opinions once they were exposed, this would seriously mitigate the costs of Mill's public square and its unregulated thought and 
discussion. 1.2 asserted that the goal of speech regulation is to approximate the ideal in the science-fiction example. Some of the other alternative regulation we have discussed do hypothetically approximate the personal force field. Suggestions that harmful speech can be confined to libraries or private conversation serve a kind of filter for those who require this kind of intellectual justification, as does the suggestion that racist speech is a sui generis category that would not chill other speech. Even the fanciful philosopher-kings objection in 3.2 approximates a kind of force field. The infallible judges provide just enough access to counter-opinions to allow in justified believing without exposing unprotected individuals to a hostile public square.

These alternatives, however fail in two ways. First, if we were able to screen off offensive expression with a personal force field, this would not be a good thing. What would suffer is a particular virtue necessary for flourishing - justified believing. If we block out speech that offends and yes, even harms our sensibilities too much, we compromise the justification for moral condemnation of those opinions and more importantly the people who express them.

Second, such approximations of the force field are unattractive because they harm more than they protect. If one accepts that flourishing is legitimate grounds for state concern, any sort of force field approximation that seeks to protect the public from harm invokes a very real slippery slope where any opinions that could potentially compromise flourishing must be censored. The result could be too much censoring. The bottom line is that only a principle like the viewpoint neutral principle will provide access to opinions necessary for the virtue of justified believing and protect individuals or groups from opinions that will harm them. 


\subsection{Proposition Eight}

The JOA argument begins with a point about intellectual virtue and concludes with a specific policy recommendation for developed states. Proposition Eight is the recommendation. States have an obligation to adopt a viewpoint neutral principle as an $e x$ ante principle enshrined in law. Developed states have the means to adopt and maintain a viewpoint neutral principle. Proposition 7 asserts there are no attractive alternatives to viewpoint neutrality. Proposition Eight is merely an inference from 6-7. Developed states, as defined in Proposition 6, should adopt or maintain a viewpoint neutral principle like the one mentioned previously.

\section{Conclusion}

The explication of the JOA is now complete. We are ready to see how the JOA resolves the problems of free expression first described in 1.1. Recall that there are two philosophical problems with freedom of expression-one conceptual and one involving justification for state restriction.

The conceptual problem asks: "What is the scope of the freedom to express? What things are we free to express? What is the difference, if any, between expressions that lead to action, expressive acts, and acts that might also be expression?" The justification problem asks: "How do we justify including hateful, offensive, and useless speech in that class of expression that is immune to censorship?"

It should hopefully be evident how the JOA answers the justification question. The justification question elicits a call for some reason why hateful, offensive, and degrading opinions should be protected when other harms are not. The answer is that the practices of justification require access to different opinions including the hateful, offensive and useless in order for individuals to acquire and express justified opinions on a variety of ethical, 
religious, and political topics. This access is necessary for justified believing and intellectual virtue.

The Justified Opinion Argument answers the conceptual question by narrowing down expression to opinions and sentiments rather than all expression. Because opinions are necessary for justified believing, the JOA can reasonably privilege opinions and sentiments to protect rather than any mode of expressive act. The proponent of the JOA can agree with Mill that opinions are context specific. The opinion that "Homosexuality is a sin and provokes the wrath of God" printed in an op-ed column is different from the same opinion spoken to a mob already gathered outside of a gay bar.

The JOA does not support the expression of any opinion irrespective of context. Rather all the JOA requires is that the anti-gay opinion must not be censored in the public square. There must be somewhere opinions of this variety can be spoken or those who would condemn homophobic opinions and their perpetrators are not justified. This does not mean that "opinions" will be easily distinguished from expression. However, it does provide some degree of distinction that is useful. Furthermore, by protecting opinions, the JOA does not involve itself in protecting the other things we do with words such as publishing state secrets, libel, slander, threats, and pornography. ${ }^{106}$

Chapter 4 concludes the JOA argument. The final chapter applies the propositions of the JOA to draw attention to the costs of abridging pernicious speech as exhibited in recent amendments to the UN Declaration of Human Rights.

\footnotetext{
106 The debate about pornography and free speech is extensive. My statement denies that pornography is a form of opinion not that it is a form of expression to which people may or may not be entitled. Pornography does not come under the purview of the JOA because it is not opinion. For more on this see my article, "Bumper Stickers and Boobs (or Why the Free Speech Argument for Porn Fails)" forthcoming in Pornography and Philosophy, Dave Monroe ed., (Wiley-Blackwell publishers).
} 


\section{CHAPTER 5 THE PRACTICES OF JUSTIFICATION AND THE COSTS OF CENSORING PERNICIOUS SPEECH}

The purpose of this chapter is to apply the JOA argument from Chapters 3 and 4 to a specific debate about international free speech policies and the conflict with racial and religious defamation. UN amendments to the Universal Declaration of Human Rights and abridging racial and religious defamation are considered. The conclusion is that racial and religious defamation cannot be censored by law without undermining the practices of justification necessary for intellectual virtue.

\subsection{Free Speech and Pernicious Speech}

No serious advocate of "freedom of speech" has used that term to refer to an absolute right to say anything at any time. Arguably, the staunchest free speech champion, J.S. Mill, advocated freedom of thought and opinion while excluding certain speech acts such as incitement. This seems reasonable. Strictly speaking it would be nearly impossible to allow anyone to say anything. Such a stance would protect shouting in a hospital or monastery, protests in the middle of lectures or religious services, and criminal solicitation. It is better to conceive of free speech--as Mill does_-as a protected class of speech acts that excludes shouting for no reason, threats and other things we do with words. Free speech advocates like Mill do not seek to protect "speech" in whatever form but rather a certain class that is labeled "free speech." In fact the only people to ever suggest that freedom of speech or "expression" must not exclude anything are those who attack the very concept of free speech. ${ }^{107}$

The problem of free speech is determining what class of speaking to exclude and what kinds to protect and to what degree in a way that is not question-begging. The United States, which arguably has the most lenient speech laws, makes a distinction between laws abridging the time,

\footnotetext{
107 See Stanley Fish, “There's No Such Thing as Free Speech, and it's a Good Thing Too.” (New York: Oxford
} University Press, 1994), 102ff. 
place, and manner of some expression and the censorship of some expression on the basis of its content. This does not mean that the U.S. does not censor on the basis of content. Incitement to riot, publishing of formulas and state secrets, and the willful attempt to publish false scientific data are examples of speech that is excluded even on the basis of its content.

In the Millian defense of free speech, there remains one class of protected speech that is to be completely protected (I, 12). That core class is opinion and sentiment regardless of how pernicious or offensive or useless. In terms of the state, this means that any law that abridges the expressions of opinions is illegitimate. We can call this state restriction on abridging opinions, viewpoint neutrality. The state must remain neutral about the value of the viewpoint (opinion, sentiment) within the public square and refrain from censoring a viewpoint outright.

The spirit of viewpoint neutrality is not unique to Mill. It is expressed in the UN Declaration of Human Rights (hereafter the Declaration). Section 17 says the following: "Everyone has the right to freedom of opinion and expression; this right includes freedom to hold opinions without interference and to seek, receive and impart information and ideas through any media and regardless of frontiers." 108 This is an expansive provision for the broadest dissemination of ideas whatever their content. However, just as with the general principle of free speech, no free speech advocate seriously thinks this provision does not admit exclusions. After all, a literal reading of this tenet would require UN signatories to protect incitement to riot and tolerate the publishing of the formula for making a dirty bomb.

A more charitable reading would interpret the UN commitment, in Millian fashion, to require that any law excluding some speech-act from the class of protected speech should be neutral between viewpoints. This would mean that time, place, and manner restrictions may regulate when and where an opinion may be expressed but these abridgments do not conflict with the freedom to

108 http://www.un.org/en/documents/udhr/ [available June 2009] 
hold opinions without interference and regardless of frontiers. It is true that these traditional abridgments can end up censoring some opinions more than others. For instance a ban on political parades in residential areas could not only prevent Nazi marches but also could favor the regime in power by robbing dissenters of easy access to their intended audience.

But why should we think all viewpoints on a par? After all, some viewpoints seem beyond the pale. Why not think that incitement to hatred of some group on the basis of their race or religion should not be included in the exclusions to free speech along with incitement to violence, or threats, or criminal solicitation? After all, the objection might go, they both harm, and the latter kind of indirect influence is often more pervasive, incendiary, and devastating than an isolated incident of racial or religious violence. The indirect harm of fomenting hatred could fill out Mill's allusion to “pernicious speech.” Pernicious speech would refer to any message that is dangerous, harmful, or corrupting.

Concern about pernicious speech is included in the International Covenant on Civil and Political Rights (ICCPR), a treaty binding UN signatories to uphold specific articles based on the Declaration. ${ }^{109}$ The ICCPR treaty includes an expansion of the free speech article in the Declaration. Article 20 of the ICCPR prohibits "Any propaganda for war shall be prohibited by law. Any advocacy of national, racial or religious hatred that constitutes incitement to discrimination, hostility or violence shall be prohibited by law."

Some members from Islamic countries, as part of the Organization of Islamic Congresses (OIC) have interpreted this portion of the ICCPR to indicate some speech goes beyond the pale because it represents not expression but defamation of some religious or ethnic group which leads to hostility, violence, and discrimination. This viewpoint is expressed in a recent resolution passed by the UN Human Rights Council. Resolution 7/19 urges states to "prohibit the dissemination,

109 The full text of the ICCPR can be found at http://www2.ohchr.org/english/law/ccpr.htm [available September 2009] 
including through political institutions and organizations, of racist, xenophobic ideas and material aimed at any religion or its followers that constitute incitement to racial and religious hatred, hostility or violence." 110

Resolution $7 / 19$ represents a critique of the broad veneration of the core value of viewpoint neutrality, represented by the ICCPR and raises an important philosophical question. How does one justify including hateful and defamatory speech in that class of expression that is immune to censorship given that such expression can cause a great deal of emotional distress, social discord, and unrest while at the same time admitting that actions of these kind are normally good reasons to restrict the action? If no satisfactory justification exists, and hateful and defamatory speech can be clearly identified, then ostensibly there is no principled reason to allow hateful and defamatory speech. In $1.1 \mathrm{I}$ referred to this as the justification question of free speech. ${ }^{111}$ The challenge to traditional viewpoint neutrality is most clearly put forth in the ICCPR as treaty binding on signatories. It is worth quoting articles 19 and 20 of the ICCPR in their entirety: Article 19

1) Everyone shall have the right to hold opinions without interference.

2) Everyone shall have the right to freedom of expression; this right shall include freedom to seek, receive and impart information and ideas of all kinds, regardless of frontiers, either orally, in writing or in print, in the form of art, or through any other media of his choice.

3) The exercise of the rights provided for in paragraph 2 of this article carries with it special duties and responsibilities. It may therefore be subject to certain restrictions, but these shall only be such as are provided by law and are necessary:

a. For respect of the rights or reputations of others;

110 The entire text of Resolution $7 / 19$ can be found at

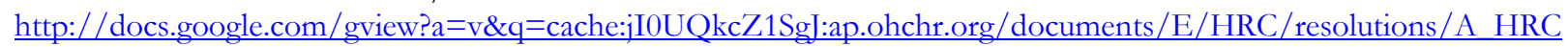
RES 7 19.pdf+Resolution+7/19\&hl=en\&gl=us\&sig=AFQjCNEaC5-6dNNoSk5XLAO2jzM9GdMuVw accessed September 28, 2009]

${ }^{111}$ See section 1.1 for more on the justification problem. See "A Theory of Freedom of Expression" in T.M. Scanlon, Difficulty of Tolerance: Essays in Political Philosophy, (Cambridge: CUP, 2003), 6ff. 
b. For the protection of national security or of public order (ordre public), or of public health or morals.

\section{Article 20}

1) Any propaganda for war shall be prohibited by law.

2) Any advocacy of national, racial or religious hatred that constitutes incitement to discrimination, hostility or violence shall be prohibited by law,

Both article $19.3 \mathrm{a}-\mathrm{b}$, with abridgments for public morals, and 20.2, abridgments to incitement to discrimination and hostility, represent an expansion of the traditional exclusions against incitement to include opinions and sentiments concerning race, ethnicity, or religion.

What follows is an examination of the compatibility of the subsections of Article 19 and 20 of the ICCPR with the Declaration's commitment to freedom of expression without frontiers and implied viewpoint neutrality. The conclusion will be that the ICCPR is not compatible with viewpoint neutrality as Resolution 7/19 shows. The inclusion of articles 19 and 20 undermines the Declaration in ways that traditional exclusions like those permitted by free speech advocates like Mill such as incitement and criminal solicitation do not.

The argument proceeds in two steps. Section 5.2 argues that the ICCPR's exclusions for hostile or discriminatory speech fail to distinguish between three crucial elements in Mill's defense of free speech in On Liberty. Without these distinctions, the ICCPR's exclusions are incompatible with viewpoint neutrality. Section 5.3 argues that such neutrality is a necessary component of a free society and for individual human flourishing. Without the crucial distinctions discussed in 5.2, the ICCPR threatens access to arguments true and false, pernicious and benign, which are part of the practices of justification first articulated in Chapter 3. These practices were shown to be integral to human flourishing as a form of intellectual development for individuals. Traditional exclusions however do not threaten this access. This serves as an answer to the justification question 
mentioned earlier which asks for a reason to allow for traditional exclusions without expanding those exclusions to include pernicious speech.

\subsection{Mill's Crucial Distinctions}

Like nearly all free speech advocates, Mill does not believe that all speaking should be protected. He makes several key exclusions to his argument for unregulated freedom of thought and opinion. Mill distinguishes between expression and expressive acts, viewpoints and the context in which they are uttered, and mental states and actions motivated by mental states. However, the ICCPR's amendments do not make these distinctions.

\subsubsection{Expression and Expressive Acts}

Mill says that the opinion that "corn-dealers are starvers of the poor" or "private property is robbery" expressed in a newspaper article is pure opinion and must be immune from censorship (III, 1). However the same opinion uttered to a group assembled outside a corn dealer's house is not opinion but an expressive act and thus not as free as an opinion. It will be helpful to look at Mill's exact words: "An opinion that corn-dealers are starvers of the poor, or that private property is robbery, ought to be unmolested when simply circulated through the press, but may justly incur punishment when delivered orally to an excited mob assembled before the house of the corn-dealer, or when handed out among the same mob in the form of a placard" (III, 1).

It is curious that Mill, a utilitarian, does not directly appeal to the consequences to decide whether or not some expression loses immunity from censorship or prosecution. Mill says that if the newspaper article (or pamphlet) leads to the same violent outcome as a speech before a gathered crowd, it is nonetheless pure opinion and should not be censored.

We can take Mill's example and update it to cover recent concerns about racial or religious pernicious speech. A recent controversy has arisen about the enforcement of libel laws in the U.K. 
with respect to expose books concerning the funding of terrorism. ${ }^{112}$ If the opinion "Middle-Eastern philanthropist $X$ is an Islamo-fascist" is published in a book that causes others to hate $X$ and harm him, then according to Mill, the opinion should be protected. However, if the same opinion were uttered to a mob outside of said philanthropist's house, the speech could be subject to prior restraint or if violence occurred, the speaker could be punished.

Why is it that only the latter context can be censored given that both have the same content? The answer seems to be that the speech to the mob is not expression (as the publication of an article would be) but rather an expressive act. Mill makes a clear distinction between opinions and acts just before he presents the corn-dealer example. It will be important to quote Mill at length to follow the progression of his thought:

Let us now examine whether ... men should be free to act upon their opinions-to carry these out in their lives, without hindrance, either physical or moral, from their fellow man, so long as it is at their own risk and peril. This last proviso is of course indispensable. No one pretends that actions should be as free as opinions. On the contrary, even opinions lose their immunity, when the circumstances in which they are expressed are such as to constitute instigation to some mischievous act (III, 1).

Mill makes a crucial distinction between expressive actions and expressions of opinion and says no one expects the former to be as free as the latter. Then he says that opinions may lose their immunity to censorship when they become instigation to some harmful act. This means that opinions can become something more than opinion and lose their immunity under Mill's principle of liberty for thought and discussion. I suggest that the most charitable way to read this is that there are three categories. There are two poles, at one end is opinion and at the other end are actions that may express. Mill says that expression of opinion can wander from the pole of opinion under certain conditions which we will examine in detail below. This is the most charitable reading of Mill since he does not immediately place incitement into the camp of pure action but acknowledges that opinions can lose their status as being immune from legal sanction which is a status already assumed for pure

112 See Stanley Kurtz, "Not without a Fight," New Criterion, no. 2008 Supplement (2008), 5-15. 
actions. In other words there is a presumption that actions are not as free as opinions, but expression enjoys immunity from that assumption until it becomes incitement.

We need not delve into the complexities of speech-act theory for the purposes of this argument. We can simply stipulate that there is a distinction between opinions and use of words to perform some act. Austin and Searle have differentiated speech acts which are utterances of content from the other things we do with words such as promise, bestow titles, and threaten. ${ }^{113}$ If this is accurate, incitement is not just a speech act but a performative act using utterances.

The concept that an opinion can lose its immunity when it becomes a performative act like incitement is consistent with the Declaration's provision for freedom of speech without frontiers. This is because the opinion itself is always free. The use of the opinion for a performative act is not. The ICCPR, however, does not make this distinction. Any speech that incites hostility, discrimination or violence can be censored by law. The Human Rights Council in Resolution 7/19 calls for the prohibition of the dissemination of any xenophobic ideas in any context. This means that the viewpoint itself must not be uttered. Ostensibly, there is no distinction between expression disseminated before a mob and expression disseminated through a blog.

Without this distinction, expression is ruled in or out of permissibility according to the results it produces. If it is shown that pernicious opinions affect the public order in the same way that incitement to riot does, then the ICCPR can be interpreted to condemn both. All that matters are the consequences. It is logically consistent to say such consequences may not even have to actually occur. But this raises a thorny question. What determines when the expression of an opinion becomes a performative act subject to censorship or legal sanction if it is not the consequences? For Mill the distinction is the context in which the speech is uttered.

\footnotetext{
113 See J. L. Austin, How to do Things with Words (New York: Oxford University Press, 1965, c1962), 166. and John R.
} Searle, Speech Acts: An Essay in the Philosophy of Language (Oxford: Cambridge University Press, 1970), 203. 


\subsubsection{Viewpoints and Contexts}

The aforementioned example of the corn-dealer from Mill highlights this second crucial distinction between the viewpoint itself and context. For Mill, what determines immunity from censorship is the context in which the viewpoint is uttered and the content. Content can be immune from censorship based on where or when it is expressed. Likewise, context is not sufficient to turn speech into incitement. Shouting baseball scores before a mob is not incitement for the purposes of state action. As I have shown in Chapter 4, this neutrality need not imply that the state is neutral in its assessment of the value of viewpoints, only in its regulation of them (see 4.1).

To see how this distinction would apply to the current concerns about incitement and hostility, consider the so-called Mohammed Cartoon controversy. On September 30, 2005 the Danish newspaper, Jyllands-Posten published twelve political cartoons lampooning Islam and the prophet Mohammed. This sparked protests throughout Denmark and several other Muslim countries. During the protests that led up to the torching of several foreign embassies. Two imams, Akkari and Abu Laban, constructed a dossier entitled "Dossier about championing the prophet Muhammad peace be upon him." (hereafter the AL dossier). In the dossier, Akkari and Abu Laban expressed the opinion that Denmark was overcome by secularism and that the Danish people who supported the cartoons are infidels. ${ }^{114}$ The inclusion of the term "infidels" sparked a particularly violent response from Islamic militants who interpreted jihad to include violence against infidels. Violence did indeed occur. On February 4, 2006, the Danish embassies in Syria were burned.

A Millian response to the AL dossier and the subsequent violence would not exclude the expression on the basis of its viewpoint. The opinion did not call for violence which would be an expressive act. The imams stated an opinion about the moral state of Denmark. The imams' 
viewpoints were, therefore, expressions of opinion and not performative speech-acts. However, if the same dossier were read to a mob assembled in front of the Danish embassy, the context would transform the viewpoint from pure expression to incitement. In order to be excluded from the protected class of speech-acts, the content would have to have a reasonable expectation of causing incitement to violence and the context (time and place) must be specific. The ICCPR's defamation amendments however do not make this distinction.

\subsubsection{Mental States and Actions}

The last crucial distinction that the ICCPR fails to make is the distinction between mental states and actions that can be motivated by mental states. This omission is evident in section 20.2 when pernicious speech that incites discrimination, hostility or violence is prohibited. The language of the ICCPR conflates actions (discrimination and violence) with mental states like hostility.

Is there a difference between incitement to violence and incitement to hostility? The terms are not conceptually tied together. One could be hostile without discriminating. One could discriminate without hostility. One could act violently without hatred. One could discriminate without violence etc. Likewise, violence need not be motivated by hostility. It can also be motivated by other attitudes. Football games are said to be violent. The same can be said of some movies. If we define violence as only those acts of harm that stem from some negative attitude, this only proves the point. The definition would prove that the act of violence can be separated from the mental state that sparked it. ${ }^{115}$

When we isolate "hostility toward a race or religion" the divide becomes even more apparent. It is relatively easy to imagine someone being hostile toward a religious group and

\footnotetext{
115 Violence need not stem from a negative attitude toward the victim. Some serial killers are motivated to violence without any particular negative attitude toward the victim. Violent offenders do violence out of many attitudes which are not blameworthy as an attitude but only blameworthy when wrongfully applied or as instigation for some violent act. Pride, anger, lust, and pleasure may all motivate violence but so does honor, fear, courage. These are also attitudes that can be the impetus for violence.
} 
manifesting that hostility in ways other than violence or discrimination. For example atheists can often be said to be hostile towards any religion, yet it is reasonable for an atheist to be hostile toward a religion or even religious people but not engage in violence or discrimination.

When it comes to freedom to express opinions, distinctions between mental states like hostility and actions like violence and discrimination are very important. Mill certainly thought so. Thought and belief are in the same sphere of liberty as speech. This is important since an argument could be raised that hostility, discrimination, and violence all harm; therefore, they violate the Millian harm principle. Proponents of this argument could appeal to the harm caused by hostility as a reason to exclude it from the protected class Mill says is immune from censorship.

Mill never uses the term "harm principle" however. Instead Mill says that exclusion from the sphere of liberty occurs only when a clear and assignable duty has been violated (IV, 10). Not all harms violate clear and assignable duties to others. Thus, if some action does not violate a clear duty, it may still harm without losing its status as part of the protected class of speech acts. Surely when the imams uttered their opinion that Danes are infidels, these utterances were a cause of the harm that resulted; however, the opinions themselves did not violate any clear duty to those harmed. ${ }^{116}$ Hostility should be clearly distinguished from violence because the latter represents a violation of clear and assignable duty. Without due process and just authority, violence is always a violation of the clear right not to be physically assaulted. No one, however, has a duty not to have hostility toward another. Likewise, violence should be distinguished from discrimination for the same reason. While violence violates a duty not to assault, discrimination toward another may or may not violate a clear duty depending on the grounds for the discrimination and what is discriminated. We do not have a duty to refrain from the mental state of discriminating. We make discriminating decisions all

\footnotetext{
116 As Jacobson (Jacobson 2000) points out, it is more accurate to say that Mill has an anti-paternalism principle than a
} harm principle given that he admits some self-regarding acts will harm yet be immune to state intervention. 
the time. Rather it could be said that we have a duty not to act on unjust discriminatory groundsrace, sex, religion etc.- - to deny someone their due.

Given that hostility is a mental state, can it be argued that incitement to hostility is the same as incitement to violence or discrimination in such a way as to say they harm in the same way? There are two reasons that the answer should be negative. First, since hostility is a state of mind, it can be separated from the action that was motivated by the hostility. Legal punishment makes this distinction as a matter of course. If Alan hits Betty out of hostility for Betty's religion, Alan can be punished for hitting Betty. In Mill's terms, he has violated a clear duty to leave Betty alone. It is controversial whether or not the state of mind Alan had means that his assault should be punished more harshly, but what is not controversial is that his punishment is for hitting Betty, not for being in a hostile state of mind. Evidence of this is that most people would not think that Alan should be arrested if he confessed to being hostile to Betty's religion but did nothing to her. We might call him blameworthy or cruel, but not punish him. Alan may harm Betty by his hostile state of mind if he expresses it. Just knowing that Alan is hostile may harm Betty, but Betty has no clear right to Alan's mental state as long as Alan fulfills his duties not to assault Betty.

If all of this is true, does it even make sense to speak of incitement to hostility rather than hostile actions? Another way to put the question is to ask: Can person make someone else feel hostile without persuading him to feel hostile towards a third person? Setting aside drugs and brainwashing, incitement to hostile states of mind seems to be, in reality, persuasion. If so, what is required is a distinction between good persuasion and bad persuasion. If that distinction is made, however, then it seems the only difference between good and bad persuasion is the opinion itselfnot the hostile state of mind. One can be persuaded to feel hostile towards evil or injustice as easily as hostile towards religion or race. 
The UN defamation amendments do not make Mill's three crucial distinctions between opinions and performative acts, between viewpoints and the context of their utterance, and the utterance of opinions and the mental states that they spring from. But these examples and worries only prove that there are crucial interpretive distinctions not spelled out in the ICCPR. No covenant can be completely clear. Someone might object that splitting hairs may be the pastime of philosophers, but it is a luxury that international policy makers do not have. All policy is vague, and there is no compelling reason why the ICCPR should be held to the standard of philosophical analysis. What is needed is some compelling reason why it is crucial to draw a sharp line between the class of speech acts that represent the expression of opinions which are to be protected and performative acts that are excluded from the protection.

This is especially important because some protected opinions lead to the same kind of harm as the performative acts. That the ICCPR is at best vague and at worst negligent does not answer this objection. Those in favor of the original Declaration without the amendments will have to explain why the ICCPR exclusions threaten free speech when traditional exclusions for incitement to violence do not. Section 5.3 addresses the reason why the ICCPR's amendments as they stand threaten the very heart of the Declaration's free speech policy and its implied commitment to viewpoint neutrality as expression without interference or frontiers.

\subsection{Defamation and the Practices of Justification}

In order to make the case that traditional exclusions permitted by even the staunchest free speech proponent do not threaten the Declaration itself, but the ICCPR does, we need to draw upon the practices of justification argument in Chapter 3. For convenience, let me briefly summarize the relevant features of the Millian argument in Chapter 3. In On Liberty, Mill gives a reason for governments not to interfere with the exchange of ideas no matter how pernicious. Mill claims that a man is not deserving of his confidence in his opinion unless: 
He has kept his mind open to criticism of his opinions and conduct. Because it has been his practice to listen to all that could be said against him; to profit by as much of it as was just, and expound to himself, and upon occasion to others, the fallacy of what is fallacious (II, 32).

We can put this in terms of the Declaration itself. Freedom to hold opinions without interference and regardless of frontiers is important because a state where viewpoint neutrality is the norm is one where individuals can exercise the practices of justification. Recall that the practices of justification expounded in 3.1 are critical attention ("listen to all that could be said against him"), critical adjustment ("profit by as much of it as was just") and critical exposition ("expound to himself, and upon occasion to others the fallacy of what is fallacious").

Recall also that any viewpoint specific censorship undermines these practices and can even undermine one's justification in holding a particular opinion. The cost of abridging viewpoints is not being entitled to consider one's opinion justified. If pernicious speech directed toward some religious group is abridged completely, it is not just the speakers who suffer from the censorship. The intended targets of the pernicious speech also lose something very important. They lose the confidence they have in their own opinions about the pernicious speakers and their message. To have confidence that one's opinion is justified requires that one pay critical attention to the opinions of detractors, adjust one's own position where the detractors' opinions have merit, and, finally to expound to oneself and others those opinions that are fallacious and blameworthy. Only then can anyone say that he is justified in his judgment of the detractors.

Censorship of pernicious opinions robs the targets and bystanders of the confidence to say those same opinions are false, blameworthy, or fallacious. To return to the cartoon controversy, if as many imams would require, the Danish state were to fine, imprison or otherwise punish those who would defame the prophet Mohammed in image or message, the Muslim community would not be deserving of confidence in its own claim that these anti-Muslim opinions are blameworthy, misleading etc. One example: a sentiment very much implied in the cartoons was that Islam is a 
violent religion. A cartoon depicted the prophet Mohammed with a bomb for a turban. If this sentiment were censored by law, the price would be that Muslims who condemn the stereotype of the violent Muslim would not deserve to consider their criticisms of anti-muslims, that they are blameworthy for their prejudice and bigotry, as justified. Furthermore, there is a good chance that the next generation of Muslims would not deserve to call their opinions of anti-Muslim justified at all. They would only know those who disparage Islam are bad.

It should be clear why traditional exclusions to free speech do not threaten the practices of attention, adjustment, and exposition. Exclusions for time, place, and manner do not ultimately censor the opinions themselves. It is true that traditional restrictions on time, place, and manner can combine to produce a draconian effect that raises the costs of accessing opinions in ways that could affect the practices as much as outright censorship. However, such measures would quickly show that they betray the Declaration itself - especially the principle that everyone should have the ability to hold opinions without interference.

Other traditional exclusions do not bar access to the practices of justification. If the government restricts certain content-

such as the publishing of state secrets, false advertising or false scientific data-the censorship does not bar access to opinions necessary for the practices of justification. None of these exclusions, including those for incitement, bar access to the opinions themselves to the extent that citizens cannot engage in their own justification of their viewpoints.

The same cannot be said for exclusion of pernicious opinions. While there are many ways to accommodate the practices of justification and even encourage them, it seems unlikely that such practices will flourish in a regime that declares some opinions to be anathema. Slippery slopes aside, when some opinions are deemed unworthy of critical attention because they are censored out of the 
public square, it undermines the whole enterprise of justifying one's personal beliefs on the basis of individual judgment.

However, there is another objection to consider. Is it not better to sacrifice justified opinions in order to quell hostility, discrimination and potential violence? Even if the practices of justification are part and parcel of intellectual development of individuals, is not public order and peace too high a price to pay for unfettered intellectual satisfaction?

In response to this challenge it is important to point out that intellectual development is not merely an optional form of the good life (i.e. one among many interchangeable ways of life)—at least not according to Mill. Recall another quote from On Liberty: "Liberty, as a principle, has no application to any state of things anterior to the time when mankind have become capable of being improved by free and equal discussion. Until then, there is nothing for them but implicit obedience to an Akbar or a Charlemagne, if they are so fortunate as to find one [emphasis mine]" (I, 10). For Mill, what separates free societies from despotic ones is the ability of the citizenry to develop intellectually through free and equal discussion. By implication, this means that regimes where the citizenry do not engage in the practices of justification because of viewpoint specific regulation should not claim to be free regimes.

There is one last price for abridging hostile and discriminatory opinions. If one takes the value of intellectual virtue in the Aristotelian sense (as argued for in 3.2) intellectual development is necessary for overall flourishing. Individuals who do not develop intellectual virtue cannot be said to fully flourish. The inference from practices of justification to human flourishing can be summed up by reiterating the first inference of the JOA from Chapter 3:

1) The ability to justify one's opinions and sentiments is partly constitutive of human flourishing because it is constitutive of intellectual virtue.

2) If some opinions or sentiments are systematically censored by law a) the practices to justify one's opinions and sentiments are compromised and b) the justification of specific opinions is undermined. 
3) If some opinions or sentiments are systematically censored by law, a constituent of flourishing will be compromised.

What this inference indicates is that the cost for abridging pernicious speech is the undermining of human flourishing itself. This is far more than the sacrifice of intellectual satisfaction for the quelling of one of many sources of hostility, discrimination and violence.

We are now ready to answer the justification question mentioned at the beginning of this section. The challenge to the UN Declaration's speech without interference and regardless of frontiers is to explain why traditional exclusions barring incitement, publishing state secrets, false advertising and other viewpoint neutral exclusions should not expand to include exclusions for pernicious speech given that all of these harm others. As was noted, this is a form of the justification question referred to in 1.1. The Millian arguments above are an attempt to answer the justification question. Freedom of Speech may indeed harm because it may lead to hostility, discrimination or violence towards others. Abridgment of free speech, however, undermines human flourishing and the foundation of a free society—improvement through free and equal discussion that leads to justified opinions about the good life, including opinions about race, religion, etc. Traditional exclusions do not do this.

\section{Conclusion}

This chapter has argued for a distinction between traditional exclusions of a viewpoint neutral free speech policy and exclusions for pernicious speech that causes hostility or discrimination. The position embodied in the ICCPR's amendments 19 and 20 is not compatible with the UN Declaration's right to free speech. The ICCPR amendments call for exclusions that are incompatible with viewpoint neutrality implicit in the Declaration. The ICCPR fails to make explicit three key distinctions between opinions and performative acts, between the content and the context of an opinion when it is uttered, and between the expression of opinions and the mental states that they spring from. All of these distinctions are necessary to uphold the viewpoint neutrality implied 
by the Declaration's freedom to hold opinions. More importantly these distinctions are crucial to preserving and promoting the practices of justification necessary for free societies and individual human flourishing.

Regimes that would abridge pernicious speech rob their citizens of justified opinions about their detractors and their own judgments of pernicious expression. These regimes also stunt the intellectual developments of their citizens in a way that robs them of the practices of liberty and free and equal discussion. 


\section{CONCLUDING REMARKS}

A platitude often invoked when speaking of free speech is that if free speech is anything it is freedom for the thought we hate. While there are certainly practical problems with regulating the time, place, and manner of free speech, it is certainly this idea of tolerance for the thought we hate that epitomizes the philosophical problems of free speech. As Chapter 1 indicated, it is conceptually difficult to set the parameters of free speech while at the same time excluding some actions that use words. It is also difficult to justify protecting ideas while excluding actions when both may cause similar harms. As we have seen, some argue that free speech is too costly if it allows pernicious ideas to harm others. It is argued that censoring pernicious ideas may stifle the expression of speakers but this is a small price to pay for preventing harms to the public at large.

If the Justified Opinion Argument is plausible however, the costs of censorship are not born merely by the speakers who have their ideas stifled. The JOA establishes that the costs of censorship are born by everyone in the public square-perhaps more by the audience than the speakers. To quote Mill, "The peculiar evil of silencing the expression of an opinion is that it is robbing the human race; posterity as well as the existing generation; those who dissent from the opinion, still more than those who hold it" (II, 1). The JOA establishes Mill's point. The peculiar evil of censorship is that it robs everyone who would dissent from a pernicious opinion of the entitlement to consider their dissent justified. This seems particularly damaging to those who would denounce pernicious ideas as immoral. Without access to the best arguments on all sides of an issue, dissenters lose the moral high ground from which to rightfully rebuke pernicious speakers for the character of their ideas.

The JOA also establishes that his lack of justification is not the only price paid for censorship. The practice of justifying one's own opinions is a constituent of intellectual virtue which 
is, in turn, a constituent of human flourishing. If we agree the perfectionist intuition held by a large portion of the human race, there are objective components of a good life. Lives can go better or worse because of the presence or absence of these components. The JOA argues that one of these constituent components is intellectual virtue. Developing the virtues of listening, challenging, and profiting from the opinions of others is not just a skill but part and parcel of living a flourishing life. The curious thing about these virtues, however, is that they cannot be successfully promoted by censorship, only by liberty of thought and discussion.

This brings us to the last contribution of the JOA as a defense of free speech. It is often claimed that freedom for the thought we hate means that when it comes to the state, there is no such thing as a false idea. This allusion to neutrality is often interpreted to mean that government must develop epistemic abstinence about the conceptions of the good life, rather than just tolerance, in order to provide freedom for the thought we hate. On the contrary, the JOA establishes that it is precisely because the state has a reason to promote flourishing that it must refrain from censoring any viewpoint in the public square. This legislative neutrality implicit in the JOA does not require the state to treat all ideas as if they were on a par. In fact, because the practices of justification require access to the best arguments on issues, the state might be negligent if it did not weigh in on the merits (deficiencies) of opinions that undermine the flourishing of its citizens.

The Justified Opinion Argument establishes a Neo-Millian argument from a Eudaemonist conception of intellectual virtue. The JOA should therefore be considered a self-development argument for free speech. Unlike the standard self-development arguments, however, the JOA does not diffuse free speech into a more general right to liberty or render it merely instrumental to some greater good. Instead the JOA establishes the value of free speech as a constituent good of a flourishing life because censorship undermines intellectual virtue. This is the reason states have a duty to establish freedom for the thought we hate. 


\section{BIBLIOGRAPHY}

Alexander, Larry. Is there a Right of Freedom of Expression?. Cambridge Studies in Philosophy and Law. New York: Cambridge University Press, 2005.

Anderson Poul. Shield Berkley, 1982.

Austin, J. L. How to do Things with Words. A Galaxy Book ; GB-132. New York: Oxford University Press, 1965, c1962.

Barendt, Eric. Freedom of Speech. Oxford: Oxford University Press, 2005.

Bork Robert. "Neutral Principles and some First Amendment Problems." Indiana Law Journal 47, no. 1 (1971): 591-645.

Brison, Susan J. "The Autonomy Defense of Free Speech." Ethics 108, no. 2 (Jan., 1998a): 312-39.

Carter, Ian. "The Independent Value of Freedom." Ethics 105, no. 4 (07, 1995): 819.

Engel, Mylan. "Personal and Doxastic Justification in Epistemology." Philosophical Studies 67, no. 2 (1992): 133-50.

Feinberg, Joel. The Moral Limits of the Criminal Law. Vol. vol. 1 Harm to Others. New York: Oxford University Press, 1984a.

- The Moral Limits of the Criminal Law. Vol. vol. 3 Offense to Others. New York: Oxford University Press, 1984b.

Fish, Stanley Eugene. There is No Such Thing as Free Speech and it's a Good Thing, Too!" New York: Oxford University Press, 1994.

Fiss, Owen. The Irony of Free Speech. Cambridge Massachusetts: Harvard University Press, 1996.

George, Robert P. Making Men Moral. Oxford: Clarendon Press, 1993.

Greenawalt, Ken. “Free Speech Justifications.” Columbia Law Review. vol. 89, No. 1 (January, 1989): 119-155

Hurka, Thomas. Perfectionism. Oxford Ethics Series. 1st Oxford University Press pbk. ed. New York ; Oxford: Oxford University Press, 1996, c1993.

Jacobson, Daniel. "Mill on Liberty, Speech, and the Free Society." Philosophy and Public Affairs 29, no. 3 (Summer, 2000): 276-309. 
. "Free Speech Includes Hate Speech" in New Waves in Applied Ethics. Jesper Ryberg, et. al, eds. Blasingstoke: Palgrave-MacMillan, 2007.

Klosko, George and Steven Wall. Perfectionism and Neutrality : Essays in Liberal Theory. Lanham, Md.: Rowman \& Littlefield Publishers, 2003.

Kurtz, Stanley. "Not without a Fight." New Criterion, no. 2008 Supplement (2008): 5-15.

Kruschwitz, Robert B. and Robert Campbell Roberts. The Virtues : Contemporary Essays on Moral Character. Belmont, Calif.: Wadsworth Pub. Co., 1987.

Larmore, Charles. The Morals of Modernity. Cambridge: Cambridge University Press, 1996.

Lockhart, William B. The American Constitution : Cases, Comments, Questions. American Casebook Series. 8th ed. St. Paul, Minn.: West Pub. Co., 1996.

MacKinnon, Catharine A. Only Words. Cambridge, Mass.: Harvard University Press, 1993.

Matsuda, Mari J. Words that Wound: Critical Race Theory, Assaultive Speech, and the First Amendment. New Perspectives on Law, Culture, and Society. Boulder, Colo: Westview Press, 1993.

Miekeljohn, Alexander. Political Freedom. New York: Random House, 1960.

Miller, Fred Dycus. "Virtue, Rights, and Justice in Aristotle's Best Regime." In Virtues and Values Aristotelianism in Contemporary Ethics, edited by Timothy Chappel. Oxford: Clarendon Press, 2006.

Milton, John. Areopagitica and other Tracts. London: Dent Publishing, 1900.

Narveson, Jan. "Freedom of Speech and Expression: A Libertarian View." Free Expression: Essays in Law and Philosophy. ed. W.J. Waluchow. Oxford: Clarendon Press, 1994.

. "Contracting for Liberty." Liberty in the $21^{\text {st }}$ Century. ed. Tibor R. Machan and Douglas B. Rasmussen. Lanham Maryland: Rowan and Littlefield, 1995.

North, Douglass Cecil. Institutions, Institutional Change, and Economic Performance. The Political Economy of Institutions and Decisions. Cambridge ; New York: Cambridge University Press, 1990.

Nozick, Robert. Anarchy, State, and Utopia. New York: Basic Books, 1974.

Nussbaum, Martha. "Human Rights and Human Capabilities." Harvard Human Rights Journal 20 (2007): 21-4.

Rand, Ayn. "The Rights of Man." Capitalism the Unknown Ideal. New York: Signet Publishing, 1966. 
Rasmussen, Douglas B. and Douglas J. Den Uyl. Norms of Liberty : A Perfectionist Basis for NonPerfectionist Politics. University Park, Pa.: Pennsylvania State University Press, 2005.

Rawls, John and Erin Kelly. Justice as Fairness : A Restatement. Cambridge, Mass.: Harvard University Press, 2001.

Raz, Joseph. The Morality of Freedom. Oxford Oxfordshire; New York: Clarendon Press; Oxford University Press, 1986.

- The Authority of Law : Essays on Law and Morality. Oxford; New York: Clarendon Press; Oxford University Press, 1979.

Redish, Martin H. "The Value of Free Speech." University of Pennsylvania Law Review 130, no. 3 (Jan., 1982): 591-645.

Rocke, A.J. "Hypothesis and Experiment in the Early Development of Kekule's Benzene Theory." Annals of Science. vol. 42, no. 4, (1985):355-381.

Rothbard, Murray. The Ethics of Liberty. New York: NYU Press, 2003.

Russell, Daniel C. “Two Conceptions of Eudaimonistic Politics.” [forthcoming in Social Philosophy and Policy].

Scanlon, Thomas. The Difficulty of Tolerance : Essays in Political Philosophy. Cambridge ; New York: Cambridge University Press, 2003a.

- The Difficulty of Tolerance : Essays in Political Philosophy. Cambridge: Cambridge University Press, 2003b.

Schauer, Frederick. Free Speech: A Philosophical Inquiry. Cambridge: Cambridge University Press, 1982.

Searle, John R. Speech Acts: An Essay in the Philosophy of Language. Oxford: Cambridge University Press, 1970.

Sher, George. Beyond Neutrality : Perfectionism and Politics. Cambridge: Cambridge University Press, 1997.

Shklar, Judith N. and Bernard Yack. Liberalism without Illusions : Essays on Liberal Theory and the Political Vision of Judith N. Shklar. Chicago: University of Chicago Press, 1996.

Smith, Steven D. “Barnette’s Big Blunder.” 78 Chicago-Kent L. Review 625 (2003).

Strum, Phillipa. When the Nazis Came to Skokie. Lawrence, Kansas: University of Kansas Press, 1999.

Tamanaha, Brian Z. “The Rule of Law for Everyone.” St. John's Legal Studies Research Paper, 27. Available at SSRN: http://ssrn.com/abstract=312622 or DOI: $10.2139 /$ ssrn.312622. [accessed September 1, 2009] 
Waldron, Jeremy. "Mill and the Value of Moral Distress." Political Studies, vol. 35, (1987): 410-423.

Wall, Steven. Liberalism, Perfectionism and Restraint. Cambridge, England ; New York: Cambridge University Press, 1998.

Wall, Steven and George and Klosko, eds. Perfectionism and Neutrality. Lanham: Rowan and Littlefield, 2003.

Zagzebski, Linda Trinkaus. Virtues of the Mind: An Inquiry into the Nature of Virtue and the Ethical Foundations of Knowledge. Cambridge; New York, NY, USA: Cambridge University Press, 1996.

Bibliography

Kruschwitz, Robert B. and Robert Campbell Roberts. The Virtues : Contemporary Essays on Moral Character. Belmont, Calif.: Wadsworth Pub. Co., 1987. 